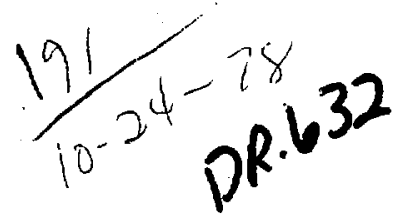

\title{
MASTER
}

\section{AUTOMATION OF THE JARRELL-ASH MODEL 70-314 EMISSION SPECTROMETER}

\author{
W. F. Morris \\ E. R. Fisher \\ L. Taber
}

April 17, 1978

Work performed under the auspices of the U.S. Department of

Energy by the UCLLL under contract number W-7405-ENG-48.

\section{니 \\ LAMRENCE \\ LNE:PMOAE LABORATORY}

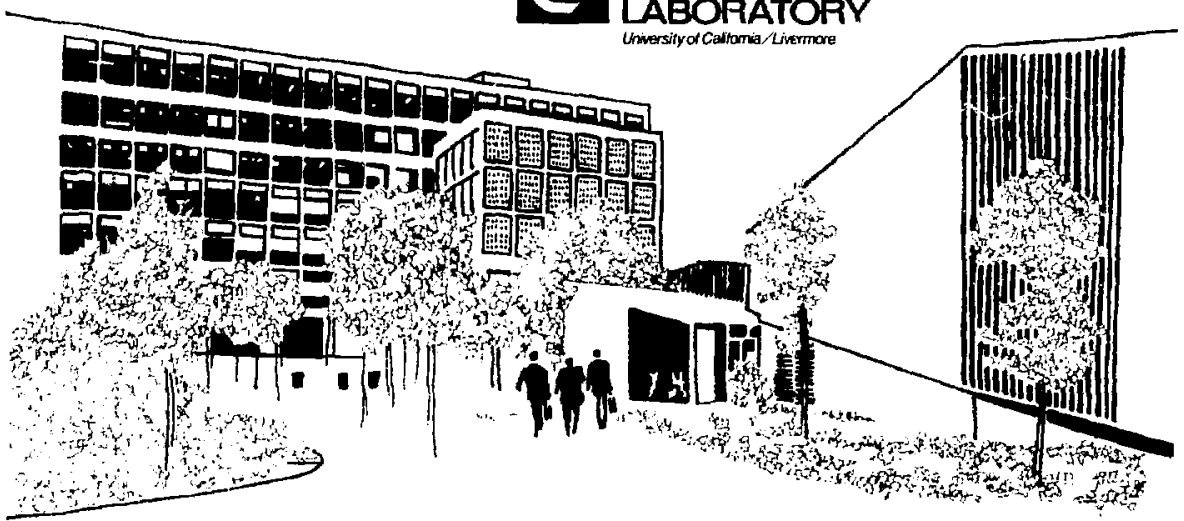




\title{
近 \\ LAWRENCE I_IVERMORE I_ABORATORY
}

University of Calfornia Livermore.Calitornia 94550

\section{UCRL.52474 \\ AUTOMATION OF THE JARRELL-ASH MODEL 70-314 EMISSION SPECTROMETER}

\author{
W. F. Morris \\ E. R. Fisher \\ L. Taber
}

MS. date: April 17, 1978

HSOSE

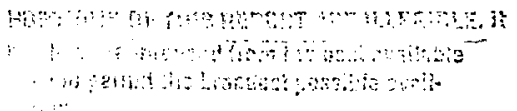




\section{CONTENTS}

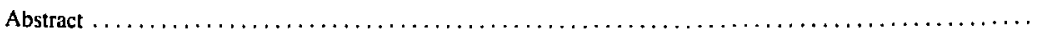

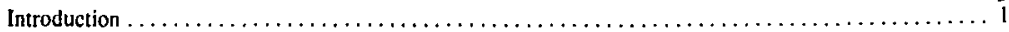

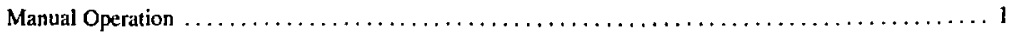

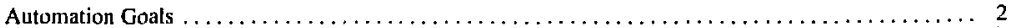

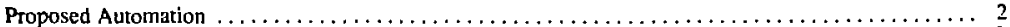

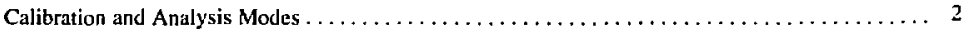

Background Corrections and Calculation of Detection Limits $\ldots \ldots \ldots \ldots \ldots \ldots \ldots \ldots \ldots, 3$

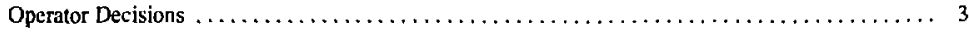

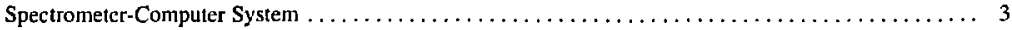

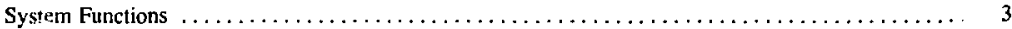

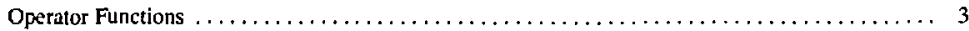

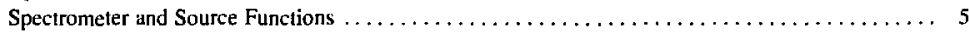

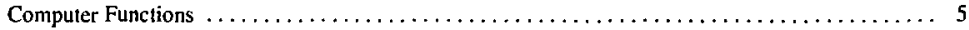

Spectrometer-Computer Interfacing $\ldots \ldots \ldots \ldots \ldots \ldots \ldots \ldots \ldots \ldots \ldots \ldots \ldots \ldots \ldots \ldots \ldots \ldots$

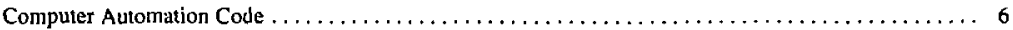

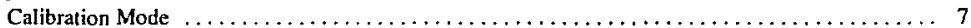

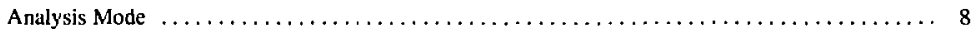

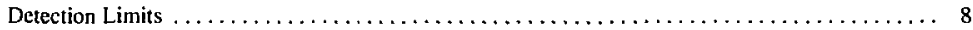

Assenbly Language Calls $\ldots \ldots \ldots \ldots \ldots \ldots \ldots \ldots \ldots \ldots \ldots \ldots \ldots \ldots \ldots \ldots \ldots \ldots$

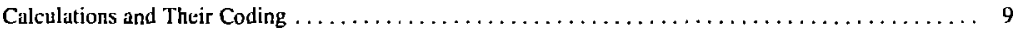

Standard Calibration Calculations by Least Squares $\ldots \ldots \ldots \ldots \ldots \ldots \ldots \ldots \ldots \ldots \ldots$

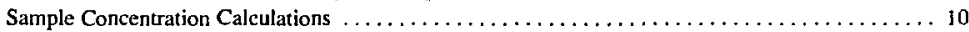

Dynamic Background and Detection Limit Calculations $\ldots \ldots \ldots \ldots \ldots \ldots \ldots \ldots \ldots \ldots \ldots, \ldots$

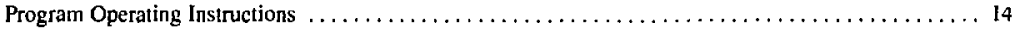

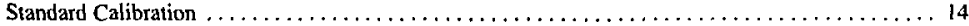

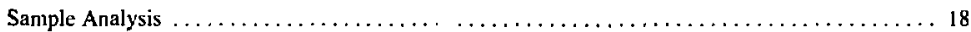

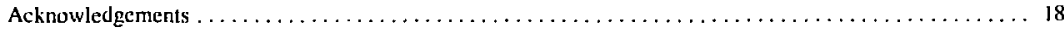

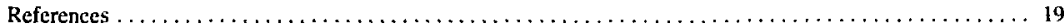

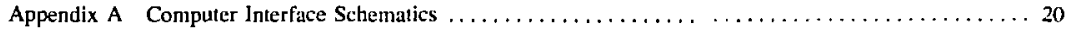

Appendix B Flowcharts of the Basic Language Programs for the Enission Spectroneter . . . . . . . . 24

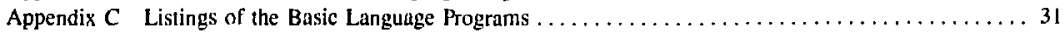

Appendix D Emission Spectrometer Programs: Descriptions of Variables, Arrays, and Files . . . . . . . 53

Appendix E Enission Spectrometer Sample Data Repors ....................... 58

Appendix F Flowchans of the Assembly Language Calls and Descriptions of Miscellancous Subroutines and

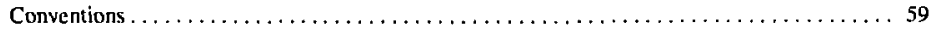

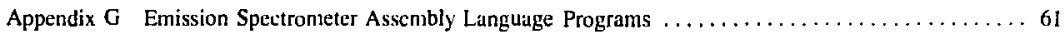

Appendix H Line Printer Report of Least Squares Data-Emission Spectremeter Program . . . . . . . . . . 64 


\section{Automation of the Jarrell-Ash Model 70-314 Emission Spectrometer}

\section{ABSTRACT}

We describe automation of the Jarrell-Ash 3.4-Meter Ebert direct-reading emission spectrometer with digital scaler readout. The readout is interfaced to a Data General NOVA 840 ninicomputer. The automation code consists of BASIC language programis for interactive routines, data processing, and report generation. Call statements within the BASIC programs invoke assembly language routines for real-time data acquisition and control. In addition, we present the automation objectives as well as the spectrometer-computer system functions, coding, and operating instructions.

\section{INTRODUCTION}

The Jarrell-Ash direct-reader emission spectrometer consists of an excitation light source, a 3.4-Meter Eber optical grating specirometer moded 70-314, and a 22-channel photomultiplier detector-readout model $66-110$. It is used to determine 20 elements in water samples. Table 1 shows two alternative element lists of which the element channels "In" and " $Y$ " are for background monitoring and internal standardization, respectively; the remaining element channels monitor the 20 elements determined in the spectrometric analysis. A high-voltage ac spark source excites the sumple that is introduced into the spark gap by a rotating disk electrode. Prior to excitation, most samples ure concentrated by evaporating enough of the sample to yield a dissolved solids content of $100 \mathrm{mg}$ per $5 \mathrm{ml}$.
The method applies to a wide range of water samples. ${ }^{1.2}$

Table 1. Elements determined by the Jarrel-Ash emission spectrometer.

\begin{tabular}{|c|c|c|c|c|c|}
\hline \multicolumn{3}{|c|}{ Glement list 1} & \multicolumn{3}{|c|}{ Element list 2} \\
\hline 1. In & 9. $\mathrm{Ag}$ & 16. Mlo & I. In & 9. $\mathrm{Ag}$ & 16. Mu \\
\hline 2. Y & 10. $\mathrm{Yi}$ & 17. B & 2. $Y$ & 11. $\mathrm{Ni}$ & 17. $S b$ \\
\hline 3. Fe & 11. Co & 18. Li & 3. $\mathrm{Fe}$ & II. Co & 18. $\mathrm{sin}$ \\
\hline 4. $\mathrm{Zn}$ & 12. $\mathrm{Pb}$ & 19. Be & 4. $\mathrm{Zn}$ & 12. $\mathrm{Pb}$ & 19. BC \\
\hline 5. Cd & 13. Cr & 201. $\mathbf{T i}$ & 5. Cd & 13. Cr & 201. $\mathrm{Ti}$ \\
\hline 6. As & 14. $v$ & 21. Al & 6. As & 14. V & 2t. Al \\
\hline 7. $11 \mathrm{n}$ & 15. T1 & 23. Bil & 7. $\mathrm{In}$ & 15. $\mathrm{TI}$ & 22. $\mathrm{Ba}$ \\
\hline $8 . \mathrm{Cu}$ & & & 8. Cu & & \\
\hline
\end{tabular}

\section{MANUAL OPERATION}

After preparing the water sample, the operator places a small volume of sample into a porcelain boal, sets the pre-exposure and exposure timers, and visually checks the $\mathrm{Hg}$ monitor for spectrum alignment. He then positions a motor-mounted graphite disk in the solution, moves the eounter electrode to within $3 \mathrm{~mm}$ of the lop of the disk, and depresses the excitation START button. The disk rotates in the solution and feeds sample into the high-voltage spark gap between the disk and the counter electrode where elements in the sample are excited.

During the excitation, each of the detectorcapacitor channels detects and stores light from each of the 22 element fines. When excitation is completed, a Nixic tube display generates a test count signal and the operator determines if the value is within a predetermined level (to check electronic stability). The operattor then depiesses a sequencer buttons : read each of the 22 element channels. He reads and records the value from the Nixic tube display for each of the 22 sleps of the sequencer.

The spectrometer is operated in either the calibration or analysis mode. In the calibration mode, the analyst rans a range of standards containing the slements of interest. He then reads and records cortesponding count values, averages these values, and perfonns a least squares fit of the duta, thus producing a valibration curve that relates known concentration with counts. In the analysis mode, the analyst checks the avcraged count values of an unknown simple against the calibration curve to deternine the concentrations of the clements of interest. In addition. he makes background corrections on all channels in both the calibration and analysis modes by running a "blank" at the beginning 
of a series of calibrations or analyses, or at intervals during the series of runs, at his discretion. A "blank" is a water matrix typical of the waters being run und frec of the tratce elements of interest. The operator re- cords the yalues of the blank for each channel and then subtrats them from the standards or samples ufter they have been run.

\section{AUTOMA'TION GOALS}

The printipal objectives in automating the emission spectronteter, staled in Ref. 3, are to increase throughput and decrease errors, and at the sime time preserve interaction between the operutor, the instrument, and the datu being generated. The following specific operations have been designaled for automation: (1) sequential readout of the element channels: (2) dala logging for standards and samples; (3) culculations of stindards datil and fitting of the standard reference curves; (4) storage and retrieval of standärds data: (5) calculation of sample dala and results; (6) generation of detailed data sheets of standards and samples; and (7) generation of analysis repors.

\section{PROPOSED AUTOMATION}

Aulomation of the emission spectrometer is provided by interfacing the spectrometer readout to a Data General NOVA 840 computer system. The operitor communicates with the atomation computer by means of a video terminal with a teletype keyboard.

The automation designed for the emission spectrometer provides the operator with several options. including direct-coum atiu count-ratio methods for lineintensity measuremeni. static and dynanic backgrourd correction, and two procedures for the calculation of detection linits. The system may be operated in esther calibration or analysis mosdes and a variety of prompts allow the operator to interact with the progrum.

\section{Calibration and Analysis Modes}

In both the calibration and analysis modes, the system automatically rads the outpuls of a test channel and the 22 element channels. The readings are displayed automatically on a terminal immediately after the sumple or standard is run. The operator views the results, determines their acceptability, and elects to continue replieate (four or less) excitations. When the replicate excitations are completed, the operator examines the results and designates the two mast acceptahle runs. A sequence of dynamic retrieval. cialeulation, and display operations are then performed ats follows: the data for the two acceptable runs are retrieved and displayed sequentially as they are retrieved: the values are averaged, corrected for background. ratioed to the internal standard (if that option is heing used), and displayed.

At this point, if standards are being run (eilibration mode), the mean counts or count ratios for all replieates of each standard run are calculated. displayed. and stored. If samples are being run (analysis mode). the concentrations in the processed and original samples are calculated and displayed. When all we dati for ill 22 elements have been retrieved. calculated. and displayed, the operator essentially views the delailed summary data for the exirent sample or standard being run. By a keybourd command. he can obtain a printout of the detailed summary dati sheet followed. in the case of samples, by a more concise report containing only the sample identification and the concentration values,

The ealibration mode of operation is used to itcquire data from known standards to estublish standard working curves. Data for each crneenlration of each element in a number of standards will he acquired over itn extended period of lime, e.g . one run of each standard per day over several days. S:andards and stmples are run in the salne way. The interactive instrumentoperator sequence is the sance for the calculation of the background errected count or count ratio values. For standlards, running mean values of the counts or count ratios for each element are calculated using values from the current stundard and running mean values based on all slandard runs up to the current run. All the data are dynimieally displayed at the spectrometer terninal. A summary data shect can be requested after each run of calch standard. In practice, five runs of each standard are mide-one run per standard per day. The tinal mean values. culculated from the accumulated data of the five runs, are used in the culibration fit that relates either background-comected counts or coun ratios to known contentrations. The operator may choose a linear or polynomical fit of the data in a normal or logarithnic form of the equation.

The analysis mode of operation is used to acquire and process sumple dala. Concentrations of the 20 elements in a sample are determined using the average bickiground-eorrected counts or count ratios of the eltments from two ateeplable runs of the sample. The concentrations are calculated using an equation with the coefieients of the currently stored standard calibration. 


\section{Background Corrections and Calculation of Detection Limits}

The automation program provides static and dynamic methods for background correction and two methods for calculating detection limits. In the static method the buckground values for each element channel are derived from a separate run (average of two excilations) of a blank standard or sample. The background values are stored for subsequent retrieval and subtracted from standards and samples when they are run. When the stutic meihod of baekground correction is used, the detection? linits are calculated to be those concentrations equivalent to count values $10 \%$ above the background level.

The second method of background correction is termed "the dynamic background correction." In this method. background correction is made possible by assigning one channel of the array of 22 photomultiplier chamnels to monitor a losation on the focal curve that is responsive to differing levels of background from one excitation 6 another. Of the 22 channels currently installed, the Indium channel (45: 1.3 A) has been found to be the most appropriate background monitor. The actual backgrourd correction on each element channel is performed by the computer using the reading from the background channel and previously stored fuctors relating each element channel to the baskground channel. The latter factors are established in the initial standardization (calibration mode) procedure using data from 10 replicate expesures of a standard solution blank free of the 20 elements of analytical interest. When the standard solution blank is run, the mean number of counts for euch of the 22 channels is detcrmined and the background factors are calculated by dividing the mean counts for each element channel by the mean counts for the batkground channel. Onte established, the factors are stored in files for later retrieval.

When dynamic background correction is being used, the detection limits are deternined while the auIomation program is run in the analysis mode. The limits for the 20 analysis elements are established by making nuliple runs of a sample blank ( 10 are reconmended). The mean count values and standurd deviations for the 20 analys is elements are calculated and the detection limits are established as the concentration equivilent to the blank plus 2 times the standard deviation of the nlean of the blank.

\section{Operator Decisions}

Certain operator decisions, e.g.. selection of the most acceptable runs, are relained in the overall systen operation. These are necessury because of the diversity of the water samples and the nature of the sample electrode and high-vollage spark discharge. In nost instances. precision is $\pm 10 \%$. The operator determines whether replicate excitations fall within the speeified precision and makes allowances where matrix effect is an overtiding factor.

\section{SPECTROMETER-COMPUTER SYSTEM}

Figure $!$ is a schematic of the Jarrell-Ash spectrometer -NOVA 840 computer system. The system includes a Data General NOVA 840 miniconiputer with disk storage and iine printer, as well as Data General's real-time disk operating system (RDOS) and multiuser BASIC software. The latter software has been modified to provide CALLS to invoke assembly linguage subroutines for real-time data acụuisition and other funcsions.

One of the key items in the system is the video displuy. fi allows the operator to view the results almost immediately after they are returned from the computer. He cun compare data from sucessive excitations and choose those data suitable for further processing. He can also compare current and stored data during a calibration run as well as the parameters of the least squares fit.

The computer monitors the pre-exposure and exposure timer relays of the spectrometer souree and controls the channel sequencer. It automatically "homes" the sequencer prior to an exposure and causes it to step through 22 channels immediately alter an exposure has been completed. On each step through the 22 channels, the capacitor-stored photonultiplier output is read. stored, and displiyed under control of the computer. For each excitation, a single column of 22 values is displayed. Up to four columns of data representing four excitations can be displayed side by side for comparison.

\section{SYSTEM FUNCTIONS}

The term "system" includes the spectrometer. excitation light souree, computer, operator, and interactive processes that produce reports.

\section{Operator Functions}

The operator is responsibie for the tollowing functions: 


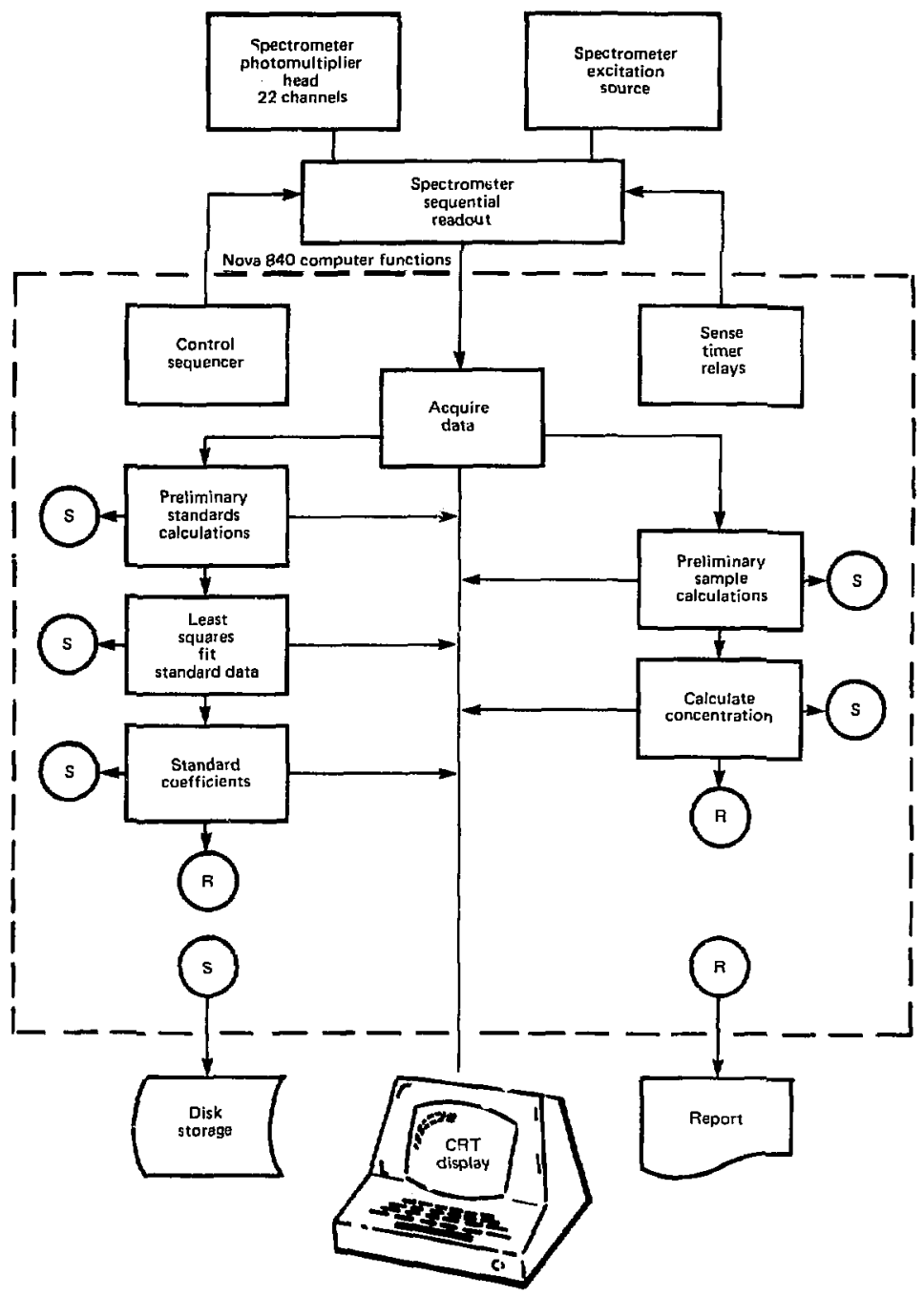

Flg. 1. Confgurstion of the spectrometer - compuler systent. 
- Prepares samples and standards.

- Chooses the program mode.

- Selects the type of background correction (static or dynamic).

- inputs identifications, descriptions of samples and standards, and number of replicates.

- Sets excitation suurce parameters.

- Sets pre-exposure and exposure tiners.

- Checks the $\mathrm{Hg}$ monitor and adjusts the refractor plate as necessary to ensure alignment.

- Prepares the electrode system and initiates the excitation.

- Examines the data after each excitation and judges its quality.

- Determines the number of replicate excitations required to obtain two acceptable excitations.

- Selects the two acceptable cxcitations.

- Determines the number of replicate runs of each standard when cartying out a calibration.

- Chonses the order of the least squares calibration fit and if it is to be a normal or log equation.

- Chooses appropriate data and types of analysis reports.

\section{Spectrometer and Source Functions}

The high-voltage ac spark source excites the elements of interest in the sample. The spectrometer disperses the light from the source and detects the spectrun. The duration of exposure and integration of the 22 spectrum line signals are determined by the settings on the source timers. Each element channel signal is stored on an electronic capacitor; capacitor-stored signals are converted to pulsed signals by a circuit in the spectromeser readout.

\section{Computer Functions}

The computer issues prompts relative to each requined input, e.g. operation mode and sample number. It also issues prompts relative to the next step in the procedure, e.g., select excitation runs. It senses the start of the excitation as well as the start and completion of the integration interval. It cycles the channel scquencer to the test position, reads the value, and evaluates whether it is within rolerance; it then cyeles the channel sequencer to each of 22 channels, reads the integrated counts on cach channel, displays the value on the video screen, and stores the value in a disk file. The channel sequencer is then cycled back to the initial readout position (HOME) after all 22 channel values have been read, displayed and stored. The above sequence of functions is repeated for cach excitation. When the 22 values for each succeeding excitation are displayed, the preceding excitation values are also displayed to a maximum of four excitations. Thus a maximurn of four columns of data each contairuing 22 values can be displayed. The computer processes the data from two of a maximum of four excitations. The two columns of data to be processed are chosen by the operator and the choices entered via the keyboard. The data are processed in any of several ways depending on whether an analysis or calibration is being carried out, whether direct counts or count ratios vs concentration are being used, or whether static or dynamic background corrections are being applied.

In the data processing procedure, values for the 22 elements in each of the two selected excitation runs are retrieved, one element at a time. The two values for each elcment are avcraged and corrected for background by means of the static or dynarnic method. If internal standardization is used. the intensity ratios of the analysis clements to the internal standard are calculated. Subsequent steps will depend on whether calibrations or analyses ure being performed.

If a calibration is being carried out, the background-corrected counts or count ratios are stored in $\mathbf{3}$ disk file. As replicates of each standard are run (usually five replicates of each standird), the computer calculates and stores a running mean value of the counts or count ratios for each element in each standard.

When the operator has established that enough standards and replicates have been run, he requests a least squares fit of the data. The computer then requests the degree of fit and the selection of a log or nornal form of the cquation. The computer performs the least squares fit and outputs both the coefficients of the fit as well as the cocfficient of determination for each clcment. It also outputs a line printer reporl of the least squares data.

In the analysis mode, after the background corrected counts or count ratios are calculated, the computer caleulates the concentration of each element in the samplc by an itcrative procedure using the coefficients of the least squares fit.

When data processing is completed, the computer outputs appropriate printed reports in response to operalor input. The reports contain header information such as date, sampic number, standard number, description, ctc. Reports can be obtained for individual standard runs, least squares fit parameters, laboratory data records, and customer sample analysis report.

\section{SPECTROMETER-COMPUTER INTERFACING}

The emission spectrometer interfacing links the Jarrell-Ash model 66-110 scaler readout to the compu. ter system. The interfacing nonitors completion of the test signal counting and provides control signals to $\mathrm{se}-$ 
quentially step the element channel selector to read the accumulated counts as well as to step the channel selector switch back to the starting test position (HOME). The control signals actuate solid-state relays in the scaler readour.

Some modifications of the scaler readout were required to implenent the interfacing. We modified the 12 AU7 analog-to-digital converter circuit by adding solid-state FETRONS for better reliability. These were mounted under the 12AU7 circuit box and were connected to the interfacing by a iwisted-puir cable. The data signal was routed from the box to the intertace mounted in the sealer chassis and in turn through a plug and cable to the digital interface at the computer. Figure 2 shows a simplified schematic of the interfacing. More detailed schematics are included in Appendix $A^{*}$

*The autumation software and hardware will be described in more deteil in a later section of the fext. Note that the description periains to the original atumation software developed by LLL for the EPA. Subsequent changes in hoth hardware and soltwane have been mads by EMSL to accommodate nodifications to the Jarrell-Ash scaler readout system. Reyuests for infomation regarding any changes should he directed to EMSL in Cincinnati, Ohis.

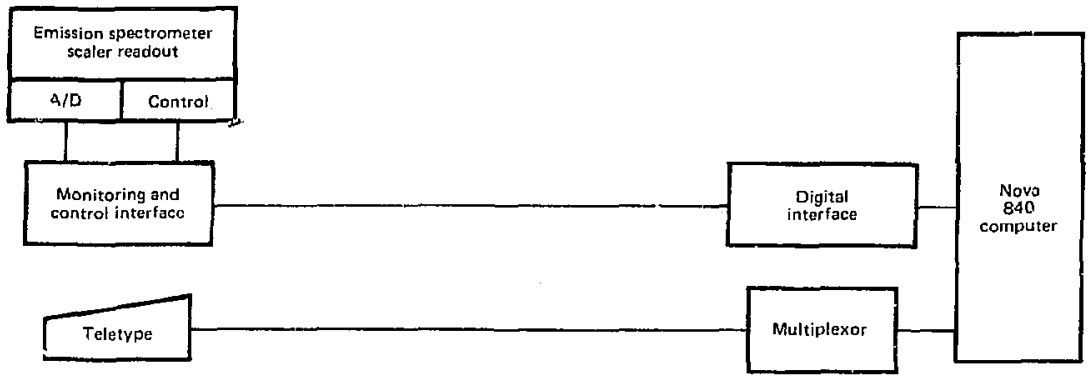

Fig. 2. Sinplified schematic of system interfacing.

\section{COMPUTER AUTOMATION CODES}

The autonation code for operating the emission spectrometer is composed of BASIC and Assembly language programs. Four programs ES1, ES2, ES3, and ES4, written in high-level BASIC (Dalı General extended BASIC language), are linked to one another by a chaining technique described on pages 5 through 16 of Ref. 4. The ESI program makes BASIC language CALLS invoking assembly language programs that read the spectrometer element channel signats, control the channel sequencer, and sense the time- relays. The calls are summarized in Table 2 and are described later.

Table 2. Summary of assembly language calls.

\begin{aligned} & \hline Cail \multicolumn{1}{c}{ Function } \\ & \hline 12 Resets channel eycle-sunse switch and data counter \\ & 2 Resets chunnel cycle switch to home position \\ & 3 Reads data counts \\ & \hline\end{aligned}

Flow charts of the BASIC program functions and operator intersctions are shown in Appendix B. Functions controlled by the computer are designated by a " $C$ " in the flow charl symbols. Listings of the BASIC language programs are given in Appendix C; tables and descriptions of the variables, arrays, and files used in the programs are shown in Appendix D.
The division of the BASIC coding into four programs is for the most part according to inputs, calculations, and ouputs.

ES ! contains the statements and routines 10 :

- Issue prompts either requesting input information or indicating the next step to be carried out.

- Acquire initial excilation data from the specIrometer.

- Store instrument dati or descriptive information keyed in by the operator.

ES 2 contains the statements and routines to:

- Retricve initial data fron two designated acseptable excitutions.

7 Calculate the average counts for each of 22 elements.

- Culculate hackground factors for use in dynamic background correction.

- Calculate static background corrections.

- Calculate atensity ratios.

- Calculate deteclion limits.

- Cajculate concenirations in the processed sumple and original samples.

- Store the calculated data in appropriate files for further processing or reporl gencrations.

ES3 contuins the statements and roulines to:

- Retrieve standard data from the files. 
data.

- Conduct the least squares fit of the standard

- Store the least squares fit coefficients.

- Print the reports of the standard concentrations, the corresponding counts or count ratios, the least squares fit cocfficients, and the coefficients of delermination.

ES4 contains the stutements and foutines to: files.

- Relricve standard and sample data from the

- Print reports of the initial standard data, working data relative to samples, and customer reports of simple analysis.

Note that ES4 does most of the hard-copy oulput report generatiori. The latter part of ES3 does the hardcopy output report of the least squares fit coefficients. The anamic outputs to the visual display (ADM-1) are generated throughout all four programs as evidenced in the program listings by the numerous PRINT statemints that display the data as it is being acquired, retrieved, or calculuted.

\section{Calibration Mode}

Initial excitation data are acquired in ESI by means of the assembly call, CALL $3, X$. The data are piaced in the array $C(1,5)$ for printing on the ADM-I display as well as into the array $\mathrm{E}(\mathrm{I})$ for transfer into the initial dala file INDAT. Data from 22 channels for a maxinum of four excilations are stored both in the array $C(I, J)$ and in the INDAT file and are displayed on the ADM-1.

When the progratn askis the opurator "GIVE RUN SIELECTIONS" anci he responds with two numbers that reposent his two selected excitations (e.g., 2,3), certain variables will be stored in the SPECVAR file (e.t.. operation mate, sample number, etc.). The ESI program will be cleared from core and ES2 will be loaded from the disk by means of the statement CHAIN ES2. The variables saved in the SPECVAR file allow contiguous operation with the newly loaded program.

ES2 conducts the calculations needed to convert the raw dala from the lwo selected runs into averaged, background-eorrected valies for the siandards. As stated sarlier. the program provides for both static and dynamic background correetions. In the static method the background values are derived from the blank standard. The averige count values of the element channels for the two designated axcitations of the blank are stored in files BCOUNTSAB or BCOUNTSCD for programis $A, B, C$, or $D$. The backeround values are retriaved from these files when the background correctimss are made. When dynamic background corrections are used, background fictors for each channel must first be establisiled from mulliple runs of a standird blank, sach run consisting of iwo to four excitations of the blank stanclard. Whes data from swo selected excitations of the blank standard are retrieved, the ratio of the count level for each element chinnel to that of the background channel is calculated and the rusultant factors are stored in file BFAB or BFCD, depending on whether program A,B.C, or D is being run. As slleceeding runs of the blank standards are miade, a running mean-background factor is calculated for each element using the stored background factors and the current factors. As many as ten runs are made to establish the mean background factors to be used in subsequent calibration (and analysis) runs. When standards containing known levels of the elements of interest are run, the ES2 program calculates the background corrections by multiplying the stored background factors for watch element channil tinres the background channel reading of the current excitalion and then dyramically subtracting the background correclions fron each channel reading. The baekground-comected values are stored in the files SCNTSA or SCNTSC for programs $A$ or $C$. If the count ratio method is used. the ratio of the background-corrected counts for each element relative to the internal standard is culculated and stored in the files STARB or STARD for programs $B$ or $D$. The successive retrieved and calculated values are stored in the array $L(J, J)$ as follows:

- L(I.I): lirst selected value for element channel 1.

- L(1,2): second selected value tor element channel !.

- L(I,4): average valua for 1 and 2 for element chaunel I.

- L(1.7): average value minus background for 1.

- L(I,8); cotinl ratio, i.c. ratio of average value for elemen! I. relative to the averdge vilue for the internal standard.

When the operator determines that enough standards and replicates have been run for a calibration, ES3 performs a least squarss fit of the standard data. The least squatris fit program is involed by the statement "CHAIN ES3," and will handle up to seven standatis each with one internal standard and 20 analysis elements in the concentration scheme shown in Table?.

Tla options available in tic program are: firstthrough third-corder least squares tit of the stimilird data using a normal or loy form of the lincar- through thirdorder polynomiall equations. Prior to conducting the least squares fit. the operttor mays examine the standard datit in the SCN'TS or STAR liles. When the fit is being carried out. pertinent information is displayed on ADM-1. Eximples are shown in a laler section. A hard-copy repent ot the least syuares fil may be whtained with a "Y" re:ponse to a computer prompt indicating its availabidity. The report lists the degres of fit, the pertinent actuations. the concentuation and corres- 
ponding mean counts ir count ratios of the standards for each element, the coefficients of the fit, and the coefficients of determination. The least squares coetficients, the degree of fit, and an indication that a log or normal equation was used are stored in the files SLINTA, SLINTB, SLINTC, or SLINTD, depending. on the spectrographic program bcing run.

After completing the least squares tit, appropriate prompts will indicate the next options available to the operator. Operation can either be terminated or the program will chain back to ESI where the operator can choose to conduct analyses or run new standards.

\section{Analysis Mode}

When the operatcr chooses to carry out a sample analysis, the operation of the computer program is virtually the same as in the calibration mode including initial data acquisition, storage, selection of excitation data, and calculations of the backgroutrd corrections. At this point, the background-corrected counts or count ratios are used to calculate consentration. The computer program calculates concentration in the processed sample by an iterative procedure with the number of $i$. erations being a function of the degree of fit of the current calibration.

Just as in calibration mode, background corrections are made on the average counts of all samples that are run. If the static background correction is used, the background is derived from a BLANK sample that is usuaily run at the beginning of a series of sample runs or at the operators discretion. The average counts derived from two designated exeitations of the BLANK are stored in files BCOUNTSAB and BCOUNTSCD and are retrieved when the background correction is made. If dynamic background correction is used, the background is caleulated as described earlier for the calibration mode.

In the analysis mode, as in calibration, the sucesssive retrieved and calculated values are placed in array $\mathrm{L}(\mathrm{I}, \mathrm{J})$. In turn, the values are storcd in files SAMFILE and SAMREP and are later retrievec when line printer reports are generated. SAMFlLE contains all of the values required for the laboritory data r'por, while SAMREP contains only the concentration values reported to the customer. Examples of both of these reports are shown in Appendix $\mathrm{E}$.

\section{Detection Limits}

The sample blank is used to determine detection limits. However, they are calculated differently depending on whether static or dynamic background correction is used. With the static method the detection limit is defined as the concentration that corresponds to an average count value that is $10 \%$ above background. Every time a blank sample is run, the detection limits for the 20 analysis elements are calculated by the iterative concentration calculation prisedure referred to earlier. They are stored in files DLIMITA or DLIMITB for the elements in lists 1 and 2 respectively (see Tablc 1).

When the dynamic background correction method is used, the detection limit is defined as the concentration equivalent to the mean value of the sample blank plus two times the standard deviation of the mean of the blank. Ten replicate runs of the sample blank are recommended to estabiish the nean value. The equivalent concentration is calculatcd in the program by the iterative procedure described in a later section. The detection timit concentrations are stored in files DLA, DLB, DLC, and DLD for programs A.B.C. and D respectively.

Table 3. Makeup of standards.

\begin{tabular}{|c|c|c|c|c|c|c|c|}
\hline & 1 & 2 & 3 & 4 & 5 & 6 & 7 \\
\hline In & ВKG & HKG & BKG & BKG & BKG & HKG & BKG \\
\hline$y$ & IS & IS & IS & IS & IS & Is & IS \\
\hline $\mathrm{Fe}$ & 1 & 2 & 4 & 10 & 20 & 40 & I00) \\
\hline Zn & 1 & 2 & 4 & 10 & 211 & th & 109 \\
\hline Cd & I & 2 & 4 & III & 20) & 40 & 100 \\
\hline As & I & 2 & 4 & 10 & 20 & 48 & 1013 \\
\hline $\mathrm{N} n$ & 1 & 2 & 4 & 19 & 20 & 41) & I(N) \\
\hline Cu & 1 & 2 & 4 & 10 & 211 & 40) & I100 \\
\hline Ag & 0.01 & 0.02 & 10.04 & 0.1 & 0.2 & (1.4 & 1 \\
\hline $\mathrm{Ni}$ & 1 & 2 & 4 & 10 & 21) & 4) & 100 \\
\hline co & I & 2 & 4 & 111 & 20 & 41 & 100 \\
\hline P', & I & 2 & 4 & 11) & 20 & 40 & 100 \\
\hline $\mathrm{Cr}$ & 1 & 2 & 4 & 111 & 20 & 40 & $I(H)$ \\
\hline v & 1 & 2 & 4 & 10 & 20 & 49 & $I(H)$ \\
\hline $\mathbf{T I}$ & I & 2 & 4 & 10 & 211 & 40 & I 160 \\
\hline S10 & 1 & 2 & 4 & 10 & 20 & 411 & $11 \times 0$ \\
\hline B & 1 & 2 & 4 & 111 & 20) & 411 & 100 \\
\hline $\mathbf{L i}$ & 1 & 2 & 4 & I0 & 20) & 40 & 100 \\
\hline Be & 0.0014 & $\mathbf{0 . 0 1 8}$ & 0.016 & 0.04 & $\mathbf{0 . 0 8}$ & 0.16 & 0.411 \\
\hline $7 \mathbf{i}$ & I & 2 & 4 & 10 & 20 & 411 & I(N) \\
\hline A] & 1 & 2 & 4 & 10 & 20 & 40 & 110 \\
\hline Ba & 0.1 & 0.2 & 0.4 & 1.0 & 2.0 & 4.0 & 10 \\
\hline
\end{tabular}

BKG = Background (f... Jynunic background cerrecti;n). 15 = Internal standird,

Numbers $=\mu \mathrm{p} / \mathrm{jit}$.

\section{Assembly Language Calls}

The Assembly language subroutines for acquiring data and controlling the emission spectrometer are called into operation by the BASIC language prozrams through the BASIC statements CALL2. CALL3, and CALL12. The assembly language subroutine assigns a special user table, transfers control to an interrupt service routine, and then performs the requested function. When the function is completed the inierrupt service routine passes control back to the assembly lan- 
guage subroutine which transfers the data and control to the BASIC program. The following are trief descriptions of the three calls:

- CALL2-Sets to the "home" position the stepper relay that selects the photomultiplier cnaprel of the emission spectrometer. This call does not have argumnents and executes in approximately two seconds."

- CALL3-Acquires data sequentially from cach photomultiplier. The call checks a sense flag to confirm compietion of stepping to each pholomultiplier pusition. When the flag is set (at each photomaltiplier position), readings are taken unitil stability is achieved (a mininum of six identical readings). The teading is passed back to the BASIC program and the stepper relay is activated to step to the next photomultiplicr posilion. This call lyas one argument, the data reading. and executes in a minimuni time of approxima ly three seconds.

- CALL12-Delays dala acquisition until the sample excitation has been inmplated Completion is determined by checking a hard-wired ort-off condition in the spectrometer source. There are no arguments associaled with CALL12.

Tivwcharts of the assersbly language calls and de scriptions of other subroutines and conventions used by the assembly language programs are given in Appendix F. Listings of the assembly language program' arc included in Appendix $\mathrm{G}$.

\section{CALCULATIONS AND THEIR CODING}

The various calculations described in the preceding sections are represented by algebraic equations. In this section we present some of the principal equations. their corresponding representations in BASIC language code. and the statement numbers where the equations appear in the automation code.

\section{Standard Calibration Calculations by Least Squares}

The least squares method is used to calibrate the spectrometric analysis using known standards. The method provides a logical procedure for fitting a line through a set of data points that possess the coordinates $x$ and $y$. This method minimizes the sun of the squares of the point deviations from the "best fitting" line. The least squares fit of data assumes that errors in the measurensent of the independent variable are insignificant compared with those of the dependent variable.

In standardizing a spectrometric malysis, it would seem logical to assign the independent variable $(\mathrm{X})$ to the concentration be otuse it is accurately known. in a physical sense. the rilagnitude of the measured signal depends on the criscentration. Also, the systematic and random errors in measurenient of the signal are greater than the uncertainty in the concentrations of the standards. Therefore, it follows that the dependent variable (Y) should be assigned to the measured signal.

It has been found that a polynominal equation produces the best fit to analytical ealibration data. The normal or logarithmic form of the polynominal may be used. The equations are:

$$
Y=a_{1}+a_{2} X+a_{3} X^{2}+\ldots+a_{x_{1}} S^{\left(X_{1}-3\right)}
$$

and

$$
\begin{aligned}
& \log Y=a_{1} \cdot a_{2} \log X+a_{1} \log X^{\prime \prime} \\
& +\ldots+a_{x 1} \log X^{(n 1-1)},
\end{aligned}
$$

where $\mathrm{Y}$ is the ciemsent line intensity or intensity ratio measured in counts or count ratio, and $X$ is the concentration.

A polynomina! of $X 1$ tcrms (degree $X(-1)$ may be fitted to an array of $X 2$ data points by solving the sollowing matrix equations:

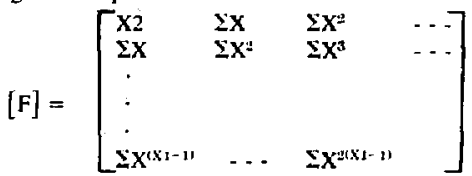

and

$$
\begin{aligned}
& {[M]=\left[\begin{array}{l}
\Sigma Y \\
\Sigma X \cdot Y \\
\Sigma X^{u} \cdot Y \\
\cdot \\
\cdot \\
Z X^{X+1} \cdot Y
\end{array}\right] \text { ind }[A]=\left[\begin{array}{c}
a_{1} \\
a_{2} \\
i_{1} \\
\cdot \\
\cdot \\
a^{X 1}
\end{array}\right]} \\
& \text { Then }[\mathrm{F}] \times[\mathrm{A}]=[\mathrm{M}] \\
& {[G]=[F]^{-1} \text {. }} \\
& \text { and }[A]=[G] \times[M] \text {. }
\end{aligned}
$$

The coefficients of the desired polynominal are calculated by inputting the degriat of fit desired and generating the $[F]$ and $\left[M_{j}^{7}\right.$ matrices from the concentration and counts or count ratios of the calibration set. $X()$ and $Y()$.

The coefficient of determination. $A(0)$ is refined as:

$$
\begin{aligned}
& A(0)=\text { (Regression sum of squares)/(total sum } \\
& \text { of syuares) }
\end{aligned}
$$

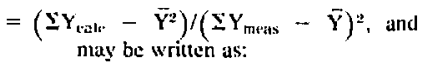




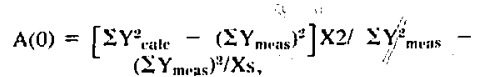

or in matrix notation

$$
\begin{aligned}
A(0)= & {\left[A^{\prime} F A \quad-i \quad[M(1)]^{2} / X 2\right] } \\
& t\left[Y^{t} Y-[M(1)]^{2 / X}\right] .
\end{aligned}
$$

The BASIC language statements corresponding to the above matrix algebraic functions are found in program ES3 between statements 210 and 1300 .

\section{Sample Concentration Calculations}

Concentrations in unknown samples are cakulated by' substituting the experimentally measured intensity counts or count ratios of the samples into the polynominal equation along with the coefficients derived from the standard calibration fjt. Concentrations are calculated by an iterative approximation procedure, the number of iterations being a function of the degree of fit of the current calibration. For example. if the current calibration is a third-order polynominal that relates concentration $(X)$ to counts or count, ratios ( $Y$ ). then the concentration in the sample will be calculated in three steps. The first approximation of concentration is:

$$
X^{\prime}-\frac{Y-a_{1}}{a_{2}}
$$

the second approximation is

$$
X^{\prime \prime}=\frac{\left(Y-a_{1}\right)-a_{3}\left(X^{\prime}\right)^{2}}{a_{2}} \quad ;
$$

and the final concentration is

$$
X=\frac{\left(Y-a_{1}\right)-a_{3}\left(X^{\prime \prime}\right)^{2}-a_{4}\left(X^{\prime \prime}\right)^{3}}{a_{2}} .
$$

The BASIC language statements corresponding to the above equations are found in program ES2, statements 1730,1810 anj 1870 for the normal versions of the equations, and statements 1710,1790 and 1890 for the logarithnic versions.

The first approximation (statement 1730) is

$$
\text { LET } L(I, 9)=[L(1,8)-Y(k, 1)] / y(k, 2) \text {; }
$$

the second approximation (statement 1810 ) is

$$
\text { LET } L(I, 9)=[L(t, 8)-Y(k .1)-(k .3) * D \mid \uparrow 2]
$$

$$
/(\mathbf{k}, 2) \text {; }
$$

and the final concentration (statentent 1870) is

$$
\begin{aligned}
\text { LET } & L(1,9)=\left[L(1,8)-Y(k, 1)-(k, 3)^{*} D 2 \uparrow 2\right. \\
& -Y(k, 4) * D 2 \uparrow 3] / Y(k, 2) .
\end{aligned}
$$

D1 and D2 are variables assigned to the first and second approximations of concentration. $Y(k, 1)$. $Y(k, 2), Y(k, 3)$, and $Y(k, 4)$ art: the calibration coefficients. $L(J .8)$ is the eleinent of array $L$ containing the background-corrected count or cotist ratio, and $L(1.9)$ is the element of array $L$ where the concentration value of the processed sample (Cp) is placed. The program then calculates the concentration in the original simple (Co) by mulliplying $\mathrm{Cp}$ by the concentration factor. The value Co is placed in the element $L(I, 10)$ of array L.

\section{Dynamic Background and Detection Linit Calculations}

The equations included in this section are used in the dynamic background correction method to calculate background corrected counts, count ratios, and detection limits. For each calculation, the algebraic expression is presented followed by the corresponding BASIC language coded staterient.

\section{Calculation of Background Factor - Algebraic} Equation

$$
B F_{r}=\frac{A C_{1}}{A B} .
$$

where

$$
\begin{aligned}
& \mathrm{BF}_{\mathrm{e}}= \text { bachground factor, current channel, } \\
& \text { current run, } \\
& \mathrm{AC}_{\mathrm{r}}= \text { average counts, current channel. } \\
& \mathrm{AB}=\text { averuge counts, background channel. }
\end{aligned}
$$

\section{Calculation of Background Factor - BASIC Coded} Statement

Statement 7350, ES2:

LET $B(1,1)=L(I .4) / L(I, 3)$,

where

$$
\begin{aligned}
& \mathrm{B}(\mathrm{I}, 1)=\mathrm{BF}_{\mathrm{C}}, \\
& \mathrm{L}(\mathrm{I}, 4)=\mathrm{AC}_{\mathrm{l}} . \\
& \mathrm{L}(\mathrm{I}, 3)=\mathrm{AB} .
\end{aligned}
$$

Calculation of Running Mean Background Factor

- Algebraic Equation

$$
\mathrm{MBF}=\frac{\mathrm{MBF}_{\mathrm{p}}(\mathrm{n}-1)}{\mathrm{n}}+\frac{\mathrm{BF} \mathrm{c}}{\mathrm{n}},
$$


wher:

$\mathrm{MBF}=$ running mean background factor,

$M B F_{\mathrm{p}}=$ running mean background factor, previous.

n $=$ run number,

$B F_{e}$ = background factor, current channel, current run.

\section{Calculation of Running Mean Background Factor}

- BASIC Coded Statement

Stutement 7470. ES2:

LET $B(I, 1)=\left\langle\mathrm{B}(1,3)^{*}(\mathrm{~W}(3)-\{)) / W(3)+\mathrm{Y}\right| / W(3)$,

where

$$
\begin{aligned}
& B(I . I)=M B F \\
& B(I, 3)=M B F_{0} . \\
& W(3)=n . \\
& Y 1=B F_{i} .
\end{aligned}
$$

Calculation of Running Mean Standard Deviation of the Background Factor - Algebraic Equation

$$
\operatorname{MSDBF}=\left[\left(\mathrm{MSDBF}_{\mathrm{b}}\right)^{2}+\frac{\mathrm{n}\left(\mathrm{MBF}-\mathrm{BF} \mathrm{F}_{\mathrm{c}}\right)^{2}}{(\mathrm{n}-1)^{?}}\right]^{1 / 2} .
$$

where

$$
\begin{array}{ll}
\text { MSDBF } & =\begin{array}{l}
\text { running mean standard deviation of } \\
\text { background factor, }
\end{array} \\
\text { MSDBF }_{\mathrm{p}}= & \begin{array}{l}
\text { previous nunning mean standard } \\
\text { deviation of background faetor, }
\end{array} \\
\mathrm{MBF} & =\text { running mean background factor, } \\
\mathrm{BF}_{\mathrm{t}} & =\text { background factor, current chan- } \\
& \text { nel, cument run, } \\
\mathrm{n} & =\text { run number. }
\end{array}
$$

Calculation of Running Mean Standard Deviation of the Background Factor - BASlC Coded Statement

Statement 7480, ES2:

L.ET $B(I, 2)=((B(I, 4)) \Lambda 2$

$+\left(\left(W(3)^{*}(B(I, 1)-Y() \Lambda 2 / W(3)-1) \wedge 2\right)\right) \Lambda .5$.

where

$$
\begin{aligned}
& \mathrm{B}(1,2)=\text { MSDBF, } \\
& \mathrm{B}(\mathrm{I}, 4)=\mathrm{MSDBF}, \\
& \mathrm{B}(\mathrm{I}, 1)=\mathrm{MBF}, \\
& \mathrm{Y} 1=\mathrm{BF}_{\mathrm{l}}, \\
& W(3)=\mathrm{n}, \\
& \mathrm{B}_{4}=\mathrm{BF}_{\mathrm{c}} \text { (AB). }
\end{aligned}
$$

Calculation of Bockground for Current Channel, Current Run - Algebraic Equation

$\mathrm{B}_{\mathrm{c}}=\mathrm{BF}_{\mathrm{c}}(\mathrm{AB})$,

where

$B_{\mathbf{c}}=$ background, current channel, current run, $\mathrm{BF}_{\mathrm{c}}=$ background factor, current channel,

$A B=$ average counts, background channel, current run.

Calculation of Background for Current Channel, Current Run - BASIC Coded Statement

Statement 6000, ES2:

LET $L(I, 6)=L(I .5) * L(1.3)$,

where

$$
\begin{aligned}
& \mathrm{L}(\mathrm{I}, 6)=\mathrm{B}_{\mathrm{l},} \\
& \mathrm{L}(\mathrm{I} .5)=\mathrm{BF}_{4 .} \\
& \mathrm{L}(\mathrm{I}, 3)=\mathrm{AB} .
\end{aligned}
$$

Calculation of Background-Corrected Counts, Current Channel, Current Run - Algebraic Equation

$$
\mathrm{ACBC}_{\mathrm{c}}=\mathrm{AC}_{\mathrm{r}}-\mathrm{B}_{\mathrm{c}} \text {. }
$$

where

$$
\begin{aligned}
\mathrm{ACBC}_{\mathrm{c}}= & \text { average counts, background-cor- } \\
& \text { rected, cument channel, current run, } \\
\mathrm{AC}_{\mathrm{c}}= & \text { average counts, current channel, } \\
& \text { cunrent run, } \\
\mathrm{B}_{\mathrm{c}}= & \text { background, current channel, current } \\
& \text { run. }
\end{aligned}
$$

Calculation of Background-Corrected Counts, Current Channel, Current Run - BASIC Coded Statement

Statcment 6010, ES2:

LET $L(I .7)=L(I .4)-L(I, 6)$,

where

$$
\begin{aligned}
& L(I, 7)=A C B C_{i^{\prime}} \\
& L(I, 4)=A C_{l^{\prime \cdot}} \\
& L(I, 6)=B_{c^{\prime}} .
\end{aligned}
$$


Calculation of Running Mleun BackgroundCorrected Counts - Algebraic Equation

$$
M C=\frac{M C_{v}(n-1)}{n}+\frac{A C B C_{E}}{n} .
$$

where

$$
\begin{aligned}
\mathrm{MC} & =\begin{array}{r}
\text { running mean counts, background- } \\
\text { corrected. }
\end{array} \\
\mathrm{MC}_{\mathrm{p}} & =\begin{array}{l}
\text { previous running mean counts, } \\
\text { background-corrected. }
\end{array} \\
\mathrm{ACBC}_{\mathrm{c}}= & \text { average counts, background-cor- } \\
& \text { rected, current channel, current run, } \\
\mathrm{n} & =\text { run number. }
\end{aligned}
$$

Calculation of Running Mean Background Corrected Counts - BASIC Coded Statement

Statement 6180, ES2:

LET $D(I, I)=\left(Q^{*}(B 9-1) / B 9\right)+L(I, 7) / B 9$

where

$$
\begin{array}{ll}
\mathrm{D}(\mathrm{I}, \mathrm{L}) & =\mathrm{MC}, \\
\mathrm{Q} & =\mathrm{MC}_{\mathrm{p}}, \\
\mathbf{L}(\mathrm{I}, 7) & =\mathrm{ACBC}, \\
\mathrm{B} 9 & =\mathbf{n} .
\end{array}
$$

Calculation of Running Mean Standard Deviation of the Background-Corrected Counts - Algebraic Equation

$$
M S D C=\left[\left(M_{S D C}\right)^{2}+\frac{n\left(M C-A C B C_{c}\right)^{2}}{(n-1)^{2}}\right]^{1 / 2},
$$

where

$$
\begin{aligned}
& \text { MSDC = running mean standard deviation of } \\
& \text { the background-corrected counts, } \\
& \mathrm{MSDC}_{\mathrm{p}}=\text { previous running mean standard de- } \\
& \text { viation of the background-corrected } \\
& \text { counts, } \\
& \text { MC = running mean counts, background- } \\
& \text { corrected, } \\
& \mathrm{ACBC}_{\mathrm{c}}=\text { average counts, background-cor- } \\
& \text { rected, current channel, current run, } \\
& n \quad=\text { nun number. }
\end{aligned}
$$

Calculation of Runuing Mtean Standard Ikeviation of the Background-Correted Counts - BASIC

Coded Statement

Stalement 6J90, ES2;

LET $D(I, 3)=R \Lambda 2+((B) *(D(1.1)-L(1.7) \Lambda 2) /(B 9$ -()$\wedge 2)) \Lambda .5$.

where

$$
\begin{aligned}
& D(1,3)=\text { MSDC, } \\
& \mathbf{R}=M S D C_{D} . \\
& D(1,1)=M C, \\
& L(1,7)=A C B C_{1} . \\
& B 9=n .
\end{aligned}
$$

Calculation of the Detection Limit in Count Units Algebraic Equation

$$
\text { D.L. }=2 \text { (MSDC). }
$$

Calculation of the Detection Limit in Count Units BASIC Coded Statement

Statement 6200, ES2:

LET $D(I, 2)=2 * D(I, 3)$,

where

$$
\begin{aligned}
& D(1,2)=\text { D.L.. } \\
& D(\mathbf{I}, 3)=\text { MSDC. }
\end{aligned}
$$

Calculation of the Detection Limit in Concentration Units - BASIC Coded Statements

Refer to the ES2 program statements 1640, 1700 , and the BASIC language statements for calculating concentrations referred to earlier in section entitled Analysis Mode.

Calculation of Background-Corrected Count Ratio, Current Channel, Current Run - Algebraic Equation

$$
\mathrm{CR}_{\mathrm{c}}=\frac{\mathrm{ACBC}_{\mathrm{c}}}{\mathrm{ACBC}_{\mathrm{ls}}} .
$$

where

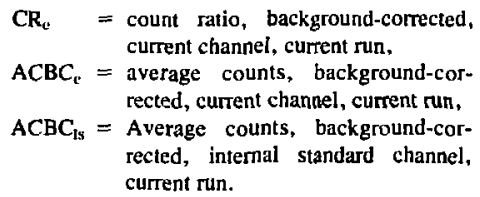


Cakulation of Background-Corrected Count Ratio, Current Channel Current Run - BASIC Coded

\section{Statement}

Statement 6610, ES2:

LET $L(I, 8)=L(I, 7) / X 3$,

where

$$
\begin{aligned}
& \mathbf{L}(\mathrm{I}, 8)=\mathrm{CR}_{\mathrm{c}}, \\
& \mathrm{L}(\mathrm{I}, 7)=\mathrm{ACBC}_{\mathrm{c}}, \\
& \mathrm{X3}=\mathrm{ACBC}_{\mathrm{Is}} .
\end{aligned}
$$

Note that $X 3$ is calculated by a series of statements including 6010,6060 , and 7020 .

Calculation of Running Mean

Background-Corrected Count Ratio - Algebraic Equation

$$
M C R=\frac{M_{C R}(n-1)}{n}+\frac{C_{c}}{n},
$$

where

$$
\begin{aligned}
M C R & =\text { running mean count ratio, } \\
M_{\mathbf{C}}= & \text { previous running mean count ratio, } \\
\mathrm{CR}_{\mathbf{c}}= & \text { count ratio, background-comected, } \\
& \text { current channel, current run, } \\
\mathrm{n} & =\text { run number. }
\end{aligned}
$$

\section{Calculation of Running Mean}

Background-Corrected Count Ratio - BASIC Coded Statement

Statement 6380, ES2:

LET $D(I, 1)=\left(Q^{*}(B 9-1) / B 9\right)+L(I, 8) / B 9$,

where

$$
\begin{aligned}
& \mathrm{D}(1,1)=\mathrm{MCR}, \\
& \mathrm{Q}=\mathrm{MCR}, \\
& \mathrm{L}(\mathrm{I}, 8)=\mathrm{CR}_{\mathrm{p}}, \\
& \mathrm{B} 9=\mathrm{n} .
\end{aligned}
$$

Calculation of Running Mean Standard Deviation of the Background-Corrected Count Ratio Algebrak Equation

$$
\operatorname{MSDCR}=\left[\left(\operatorname{MSDCR}_{\mathrm{p}}\right)^{2}+\frac{\mathrm{n}\left(\mathrm{MCR}-\mathrm{CR}_{\mathrm{c}}\right)^{2}}{(\mathrm{n}-1)^{2}}\right]^{1 / 2},
$$

where

$$
\begin{aligned}
& \text { MSDCR = running mean standard deviation of } \\
& \text { background-corrected count ratio, } \\
& \text { MSDCR }_{\mathrm{p}}=\text { previous running mean standard } \\
& \text { deviation of background-corrected } \\
& \text { count ratio, } \\
& \text { MCR = running mean count ratio, back- } \\
& \text { ground-corrected, } \\
& \mathrm{CR}_{\mathrm{c}} \quad \text { = count ratio, background-corrected, } \\
& \text { current channel, current run, } \\
& \text { n } \quad=\text { run number. }
\end{aligned}
$$

Calculation of Running Mean Standard Deviation of the Background-Corrected Count Ratio - BASIC Coded Statement

Statement 6390, ES2:

LET $D(I, 3)=(R \Lambda 2+((B 9 *(D(I, 1)-L(1,8)) \Lambda 2))$ (B9-1) 2)) A.5,

where

$$
\begin{aligned}
& \mathrm{D}(1,3)=\text { MSDCR, } \\
& \mathrm{R}=\mathrm{MSDCR}_{\mathrm{p}}, \\
& \mathrm{D}(\mathrm{I}, 1)=\mathrm{MCR}, \\
& \mathrm{L}(\mathrm{I}, 8)=\mathrm{CR}_{\mathrm{c}}, \\
& \mathrm{B} 9=\mathrm{n} .
\end{aligned}
$$

Calculation of the Detection Limit in Count Ratio Units - Algebraic Equation

$$
\text { D.L. = 2(MSDCR). }
$$

Calculation of the Betection Limit in Count Ratio Units - BASIC Coded Statement

Statement 6200 (via statement 6400), ES2:

LET $D(I, 2)=2 * D(I, 3)$

where

$$
\begin{aligned}
& D(I, 2)=\text { D.L. } \\
& D(1,3)=\text { MSDCR. }
\end{aligned}
$$

Calculation of the Detection Limit in Concentration Units - Algebraic Equations

Refer to the equations in section entitled Sample Cancentration Calculations.

Calculation of the Detection Limit in Concentration Units - BASIC Coded Statements

Refer to the ES2 program statements 1640,1700 , and the BASIC language statements for calculating concentrations referred to earlier in section entitled Sample Concentration Calculations. 


\section{PROGRAM OPERATING INSTRUCTIONS}

The emission spectrometer progran will acquire and process data from one test chammel and 22 element detector channels positioned we detecl either of the two lists of elements shown in Table 1 . li will process the datal based on direct sounts from cach channel or on count ratios of each of 20 analysis channels compured to the Ytrium intemal standard thannel. Background corrections are made on all channels by either the static or dynamic background-comection methods destribed carlier.

The program is replete with prompts that are displayed on the CRT display terminal to which the operator responds via the terninal keyboard. Instructions for operating the program are facilitated in the following tex 1 by using examples of actual input/output copy. In the examples, the underlined information is the input entered by the operator via the keyboard. Each input must be followed by a carriage return indicated by a $>$.

Prior to running the program, the operator logs into the system, loads the ES1 program, and types RUN, or more simply "Run ESI" as shown in the following exumple. After the RUN command, the systen will begin displaying prompts requesting inpul or reminding the operator of the next step to be carried out. Questions requiring $Y$ (Yes) or $\underline{N}$ (No) answers will be displayed. These are usually points in the program where optional modes of operation or output are chosen by the operator.

If the operator mistypes a response to a prompt and the error occurs before a carriage return. he simply strikes the RUB-OUT key for each erroneous character and types the correct response followed by a carriage return. If the error has been followed by a carriage retum, the program in all likelihood will have proceeded to a wrong branch of the program. To correct this problen, the operator tan either start over by typing RUN. "ES1." or he can go back to the place in the program (statement number) where the last prompt occurred. The statement number of the prompt can 're found quite easily in the program listing. After the number has been found, the operator lypes RUN followed by the statement number. The prompt where the input error occurred will again be displayed and the operator can now respond with the correct entry.

To illustrate the operation of the program, we present exanples of a standard calibration followed by a sample analysis. We also illustrate the dynamic background correction along with the determination of detection limits.

\section{Standard Calibration}

The first of a series of inputs and responses (dialog) is shown in Fig. 3. The prompts are self explanatory and in virtually all cases single-character entries use all that ure needed. Of the series of standards to be run in calibration mode, the first is a blank followed by succeding replicates of the blank for establishing the background factors. The program autonatically idenlifies the blank standard as stundard zero. It also keeps track of the blank run number to properly calculate the mean background factors derived from replicate runs of the standard blanks. Operator response to the prompt, "GIVE PROGRAM A.B,C.D". direets the program to either the direct counts or count ratio method and element lists 1 or 2 (Tuble 1). The promp' also reninds the operator to check the seting of the ABCD progran switch on the spectromeler read-out chassis. The

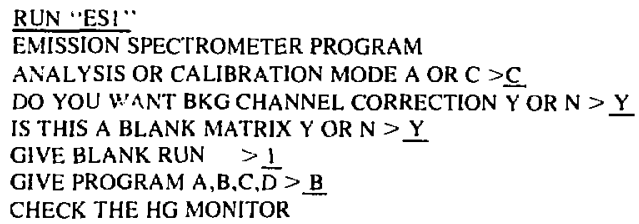

Fip. 3. Initial interuttive diulog. 
prompt "CHECK THE HG MONITOR" reminds the operitor to visually check the HG monitor on the spectrometer and take whatever action is necessary to ensure alignment.

Following the ubove $1 / O$, the program prompts "LOAD ELECTRODES - EXCITE" immediately followed by "HIT S'TART". These are illustrated in Fig. 4. In response, the operator loads the electrode into the excitation stand and initiates the start button on the sequential readout chassis. This starts the excitation, signal integration, and readout sequence. The excitation number is displayed on the terminal, and when the excitation ecases, the test count followed by the counts trom each of the 22 element channels is displayed. For reasons of space, only 9 elentent channcls are shown in these examples. Following the first excitation colly, the prompt "IS DATA OK"' will be dis' played. This is a reminder for the operator to view the dati front the first excitation conditioning run to determine if the data are correct to continue additional excitations. In the above example he has responded $Y$.

Alternatively, if he were to respond $\mathrm{N}$, the progran would pronipt "PREP NEW SAMPLECHANGE ELECTRODES", "LOAD ELECTRODES-EXCI'TE". The $Y$ response allows the operator to proceed to the next excitation. The display then shows two colunins of data, namely the first and secind exeitution, so that the operator can compare the dala. He usually proceeds to a third and somerimes a fourth excitation, depending on the quality of the data. If the response to the prompt "MORE EXCITATIONS" is $N$, the program displays the message "YOU HAVE COMPLETED EXCITATIONS" and requests that the operator designate two of the four (or less runs) as aceeptable dala via the prompt "GIVE RUN SELECTIONS". In the example the response is 1,2 for excitations 1 and 2 .

Response to the prompt "GIVE RUN SELECTIONS" immediately initiates a series of storage, retrieval, data processing, and output operations. The complexity of these operations is a function of whether a blank, standard or sample is being run. In $1 / 0$ example, (Fig. 5) certuin identifying information is displayed in the lieader followed by the element symbols, two columns of selected data, their averaged values, calculated background factors, and the standard deviztions of the factors. Each lime a run is completed the program asks the operator if he wants a line-printer copy of the displayed data and if he wishes to continue to a next run. If he chooses to continue additional runs, the proecss is repeated for each run. In the next $1 / O$ example (Fig. 6) the data for a seventh (und final) standard of a series of slandards are illustraled. Having run enough standards, the operator indicales that he is ready to fit the slandard data. The computer then re-

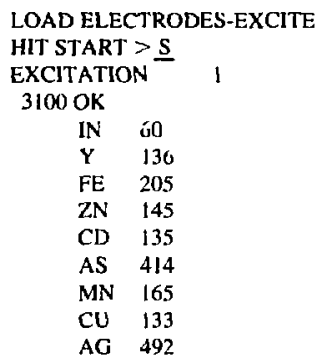

IS DATA OK $>\underline{Y}$

LOAD ELECTRODES-EXCITE

HIT START $>\underline{S}$

EXCITATION 2

3100 OK

IN $60 \quad 63$

Y $136 \quad 141$

FE $205 \quad 211$

ZN $145 \quad 148$

$\begin{array}{lll}\text { CD } & 135 \quad 138\end{array}$

AS $\quad 414 \quad 417$

MN $\quad 165 \quad 167$

CU $133 \quad 132$

AG $492 \quad 490$

MORE EXCITATIONS - Y OR N $>\underline{\mathrm{N}}$

\section{YOU HAVE COMPLETED EXCITATIONS GIVE RUN SELECTIONS $>\underline{1.2}$}

Fīu. 4. Initial duta output.

quests the form of the equation, the degree of fit, and the number of standards to be used in the fit. Afler the operator responds to the input requests, the program performs the fit and displays the known concentrations of the standards, the running mean counts (or count ratios), certain summations (e.g., $\mathbf{S X}, \mathbf{S} \mathrm{X}^{2}, \mathbf{S} \mathrm{X}^{3}, \mathrm{SY}$, $\Sigma Y^{2}$, etc.) pertinent to the calculation. and the coefficient of determination (refer $k$ the section entitled Method of Least Squaress). If the operator had inslicated the $\log$ form of the polynominal, the log equivalent values of concentration and counts (or count ratios) would have been displayed. The above example shows the least squares calibration data for only the first of 20 analysis clements that are actually displayed.

A line-printer report of the catibration coefficients for all 20 elements from the least squares fit can be obtained with a $Y$ response to the appropriate nommpt displayed when the program has completed all of the calculations. If a third-order fit has been pertormed, the line-printer report will include the coefficients for the 


\begin{tabular}{|c|c|c|c|c|c|}
\hline \multirow[b]{2}{*}{ IN } & \multicolumn{2}{|c|}{$\begin{array}{l}\text { DATE 3/12/1976 } \\
\text { PROGRAM-B }\end{array}$} & \multirow[b]{2}{*}{$\begin{array}{l}A C \\
60.0\end{array}$} & \multirow[b]{2}{*}{ BF } & \multirow{2}{*}{$\begin{array}{l}\text { STANDARD } \\
\text { RUN } 2 \\
\text { STDEY }\end{array}$} \\
\hline & $\begin{array}{l}\mathrm{Cl} \\
60 .\end{array}$ & $\begin{array}{l}\mathrm{C} 2 \\
60 .\end{array}$ & & & \\
\hline $\mathbf{Y}$ & 136. & 136. & 136.0 & 2.26 & 0.0103 \\
\hline $\mathrm{FE}$ & 205. & 205. & 205.0 & 3.40 & 0.0244 \\
\hline ZN & 145. & 146. & 145.5 & 2.40 & 0.0303 \\
\hline $\mathrm{CD}$ & 135. & 135 & 135.0 & 2.23 & 0.0215 \\
\hline AS & 414. & 424. & 419.0 & 6.87 & 0.1607 \\
\hline MN & 165. & 165. & 165.0 & 2.72 & 0.0359 \\
\hline $\mathrm{CU}$ & 133. & 133. & 133.0 & 2.19 & 0.0440 \\
\hline AG & 492. & 492. & 492.0 & 8.09 & 0.1529 \\
\hline DO Y & I WAN & A REP & RT ON & E SLPT & \\
\hline
\end{tabular}

Fig. 5. Data from selected excitations.

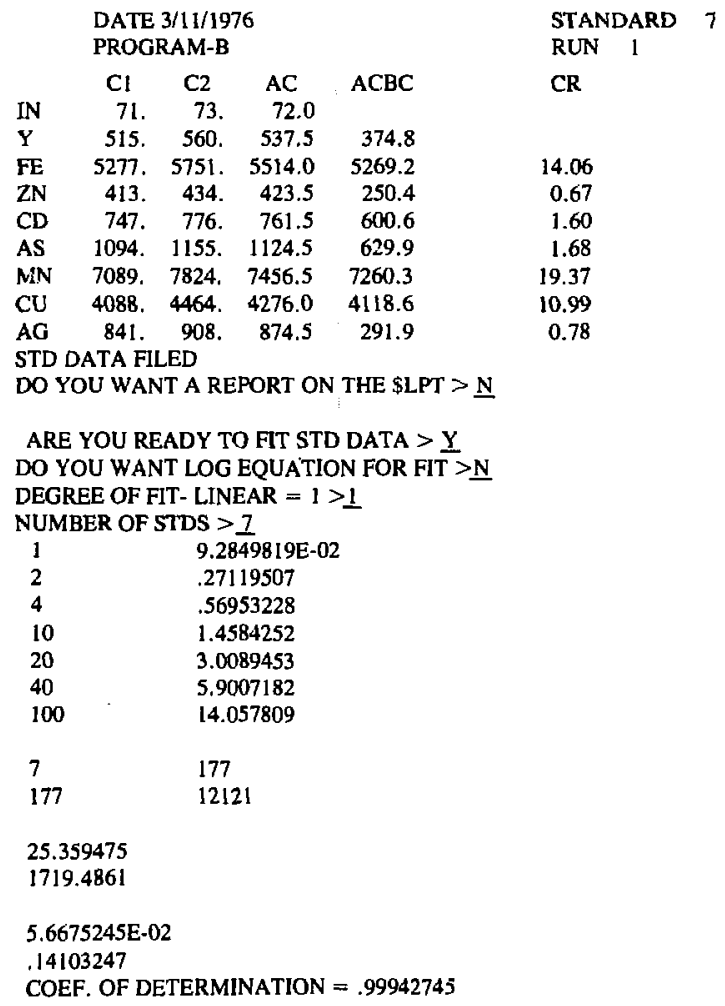

Fig. 6. Data output from fingl standard and least squares fit. 
DO YOU WANT A REPORT ON THE SLPT $>Y$

DO YOU WANT TO CONTINUE $>Y$ OR $N>Y$

ANALYSIS OR CALIBRATION MODE A OR C $>$ A

DO YOU WANT BKG CHANNEL CORRECTION $\bar{Y}$ OR N $>\underline{Y}$

SAMPLE NUMBER > BLANK

GIVE SAMPLE TYPE $>$ DL

GIVE $\triangle$ IMPLE SOURCE $>2$

GIVE VLL. (ML) OF ORIG SAMPLE ALIQUOT $>1$

GIVE VOL. (ML) OF PROCESSED SAMPLE $>1$

DO YOU WANT TO ESTABLISH NEW DETECTION LIMITSY

RECOMMENDED OF BLANKS TO ESTABLISH D.L. IS 10

GIVE PROGRAM A.B.C.D $>$ B

CHECK THE HG MONITOR

LOAD ELECTRODES-EXCITE

HIT START $>\underline{\mathbf{S}}$

EXCITATION 1

3100 OK

IN 61

$Y \quad 151$

FE 215

ZN 158

CD 156

AS 457

MN 164

CU 149

AG $\quad 571$

15 DATA OK $>\underline{Y}$

LOAD ELECTRODES-EXCITE

HIT START $>S$

EXCITATION 2

$3100 \mathrm{OK}$

IN $\quad 61 \quad 59$

$\begin{array}{lll}Y & 15 ! \quad 150\end{array}$

FE $215 \quad 217$

ZN $\quad 158 \quad 16 !$

CD $\quad 156 \quad 150$

AS $\quad 457 \quad 457$

MN $167 \quad 169$

$\begin{array}{lll}\text { CU } & 149 & 15 !\end{array}$

AG $571 \quad 576$

MORE EXCITATIONS - Y OR N $>\underline{N}$

YOU HAVE COMPLETED EXCTTATIONS

GIVE RUN SELECTIONS > $\underline{1.2}$

\section{DATE 3/12/1976}

TYPE DL.

$\begin{array}{lcccc} & 01 & 02 & \text { AC } & \text { ACBC } \\ \text { IN } & 61 . & 59 . & 601.0 & \\ \text { Y } & 151 . & 150 . & 150.5 & 14.9 \\ \text { IE } & 215 . & -17 . & 216.0 & 12.0 \\ \text { ZN } & 158 . & 151 . & 159.5 & 15.3 \\ \text { CD } & 156 . & 150 . & 153.0 & 18.9 \\ \text { AS } & 457 . & 457 . & 457.0 & 44.8 \\ \text { MN } & 164 . & 169 . & 166.5 & 3.0 \\ \text { CU } & 149 . & 151 . & 150.0 & 18.9 \\ \text { AG } & 571 . & 576 . & 573.5 & 88.0\end{array}$

DO YOU WANT A REPORT ON THE \$LPT $>\underline{Y}$

DO YOU WANT TO CONTINUE $Y O R N>Y$

ANALYSIS OR CALIBRATION MOIDE A OR C $>A$
SAMPLE BLANK

SOURCE 2

$\begin{array}{ccr}\text { CR (RM) } & \text { SD } & \text { DLIM } \\ & & \\ & & \\ 0.85 & 0.0604 & 6.4714 \\ 1.03 & 0.0049 & 15.4903 \\ 1.26 & 0.0157 & 7.4033 \\ 3.06 & 0.0913 & 19.5493 \\ 0.25 & 0.0642 & 1.5989 \\ 1.25 & 0.0177 & 9.2962 \\ 5.88 & 0.0142 & 7.5512\end{array}$

Fig. 7. Interaclive Jialog and data output for defection limits. 
20 elements for the three orders of the fit. An example of a report of the least squares data is shown in Appendix H. Again, for the sake of brevity, only a limited number of channels are shown in the example.

\section{Sample Analysis}

After having completed the standard calibration and printing the least squares data, the program issues a series of prompts to provide the operator with the option to discontinue or continue operations and to input additional information. Figure 7 illustrates some V/O for the sample analysis mode of operation and specifically for the determination of detection limits by means of samplt blanks described earlier. Operator-program interactions are virtually identical to those described for the running of calibration standards except for the ob- vious prompts that apply to the analysis mode and detection limit calculations. In the example given here, after the operator selects the two most acceptable excitations, the program prints the columis of data containing the counts for the two excitations, their averages, the background-corrected averages, the count ratios, the running mean-standard deviations of the count ratios, the running mean standard deviations of the count ratios up to the current run, and the corresponding detection limits.

Figure 8 shows the output generated for a typical sample after the operator has selected the two most acceptable excitation runs. When a sample analysis has been completed, the operator can choose a line printer report of the detailed analytical data. In addition, the program provides a separate, more concise report of the sample identity, the elements sought, the concentrations found and the detection limits of the elements not deteeted. Examples are given in Appendix E.

\begin{tabular}{lrrrr}
\multicolumn{5}{c}{ DATE 3/12/1976 } \\
TYPE WATER \\
IN & Cl & C2 & AC & ACBC \\
Y & 62. & 66. & 64.0 & \\
FE & 573. & 598. & 585.5 & 440.9 \\
ZN & 912. & 944. & 928.0 & 710.4 \\
CD & 247. & 257. & 252.0 & 98.2 \\
AS & 322. & 329. & 325.5 & 182.5 \\
MN & 539. & 566. & 552.5 & 112.8 \\
CU & 744. & 877. & 856.0 & 681.6 \\
AG & 592. & 591. & 760.5 & 620.6 \\
& & & & 73.6 \\
DO YOU WANT A REPORT ON THE $\$$ SLPT >
\end{tabular}

\begin{tabular}{|c|c|c|c|c|}
\hline \multicolumn{5}{|c|}{$\begin{array}{l}\text { SAMPLE } 1200 \\
\text { SOURCE RIVER }\end{array}$} \\
\hline $\mathrm{CR}$ & & $\mathrm{CP}$ & & $\mathrm{CO}$ \\
\hline 1.61 & & 11.023 & & 11023.4 \\
\hline 0.22 & ND- & 15.490 & ND- & 15490.3 \\
\hline 0.41 & ND. & 7.403 & NR. & 7403.3 \\
\hline 0.26 & ND- & 19.549 & $\mathbf{N}_{i}:$ & 19549.3 \\
\hline 1.55 & & 7.627 & & 7627.2 \\
\hline 1.41 & ND- & 10.405 & & 10405.3 \\
\hline 0.17 & ND- & 7.551 & ND- & 7551.2 \\
\hline
\end{tabular}

Fig. 8. Data output from sample unalysis.

\section{ACKNOWLEDGEMENTS}

This study has been a cooperative effort of muny people. We especially wish to acknowledge the helpful advice of G. W. Barton, Jr, and A. M. Kray of Law- rence Livermore Laboratory, and T. Martin of the Environmental Monitoring and Support Laboratory of EPA. 


\section{REFERENCES}

1) J. F. Kopp and R. C. Kroner, Appl. Spectros. 19, 155 (1965).

2) Methods for Emission Spectrochemical Analysis, 6th Ed. (American Society for Testing asd Materials, Philadelphia, Pennsylvania (971), pg. 1010.

3) J.W. Frazer, Lawrence Livermore Laboratory, Internal Document JWF: 73-2222 (1974). Readers outside the Laboratory who desire further information on LLL internal documents should address their inquiries to the Technical Information Department, Lawrence Livermore Laboratory, Livermon, California 94550.

4) Extended Basic Users Munual, Data General Corporation 093-000065-05, (1974). 


\section{APPENDIX A \\ COMPUTER INTERFACE SCHEMATICS}

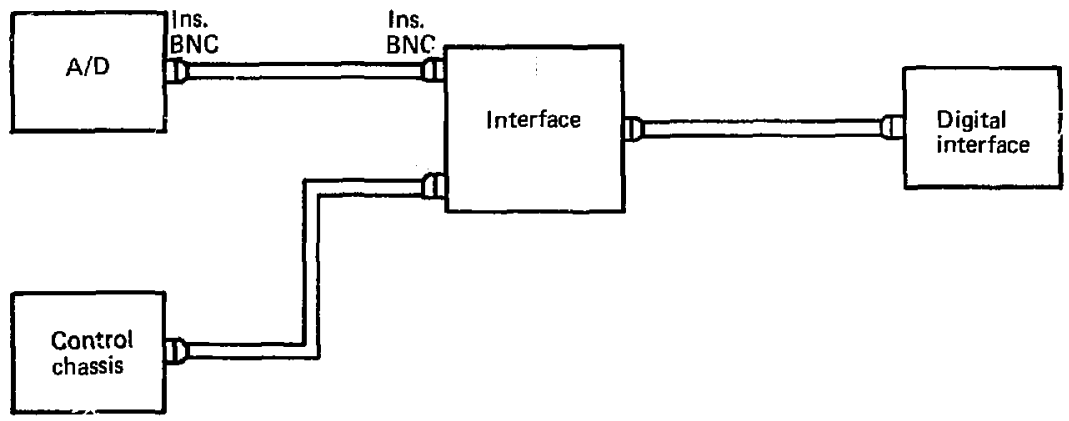

Fig. A-1. Block diagram of the spectrometer interface. 


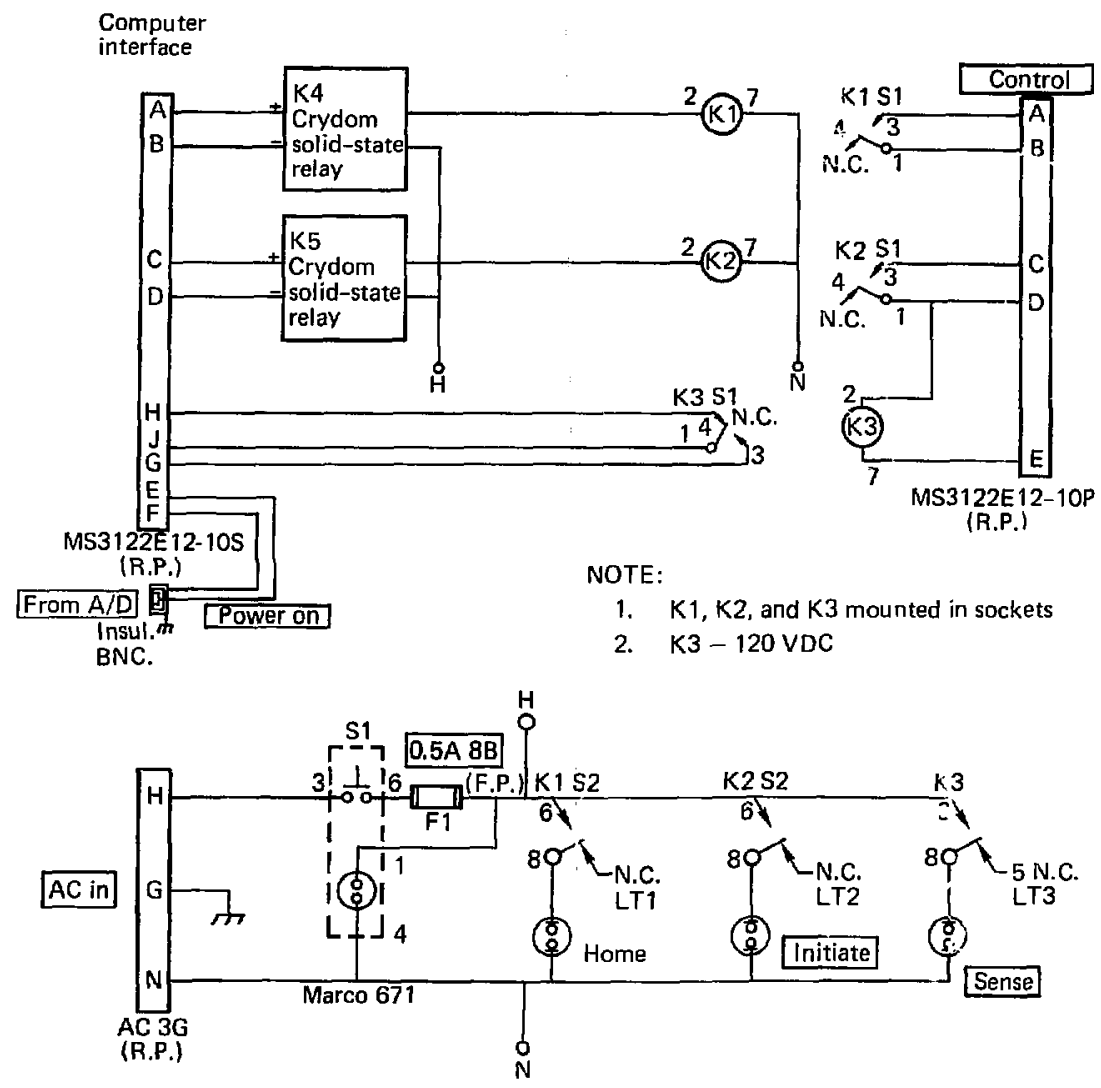

Flg A-2. Diagram of modilications of anglog-to-digltal converter. 


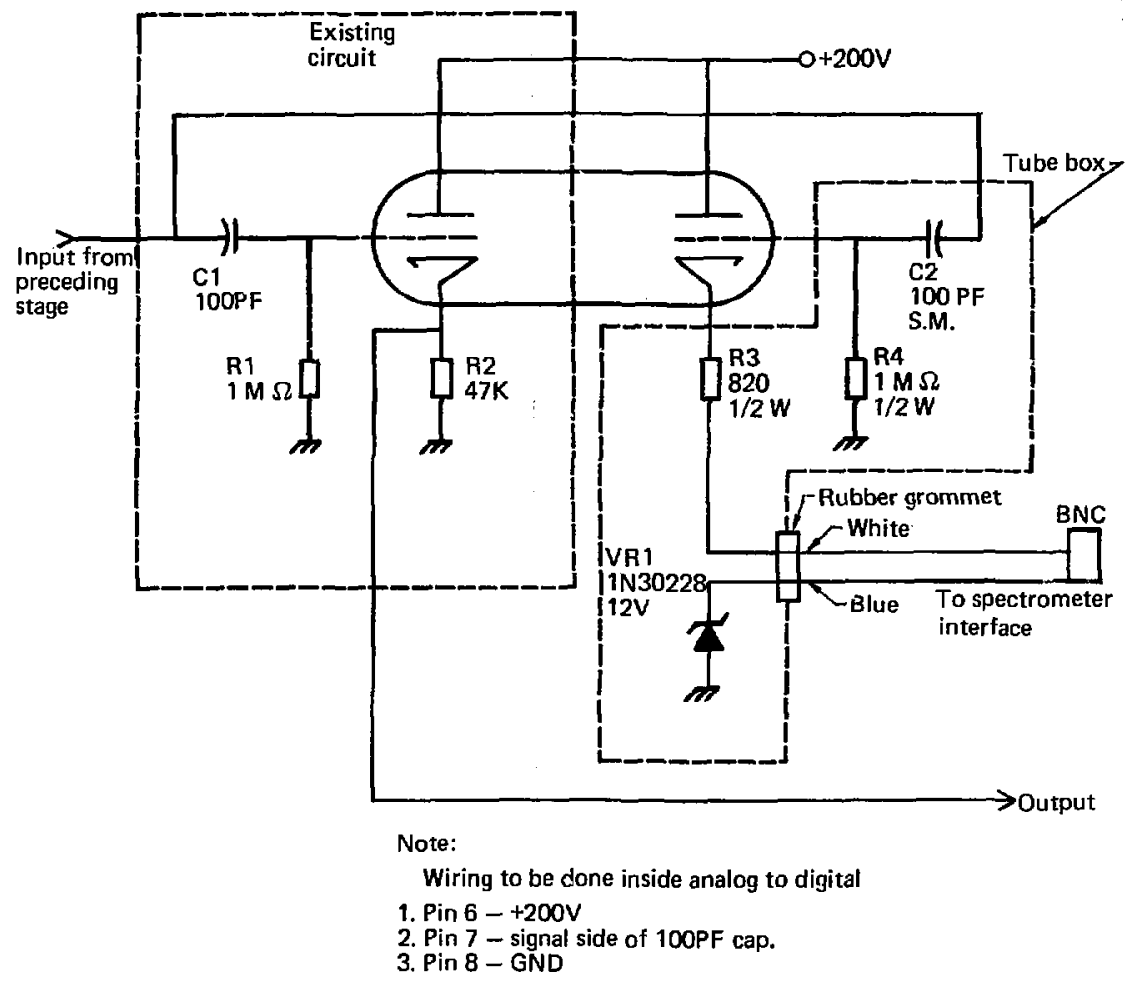

Fig. A-3. Spectrometer interiace. 


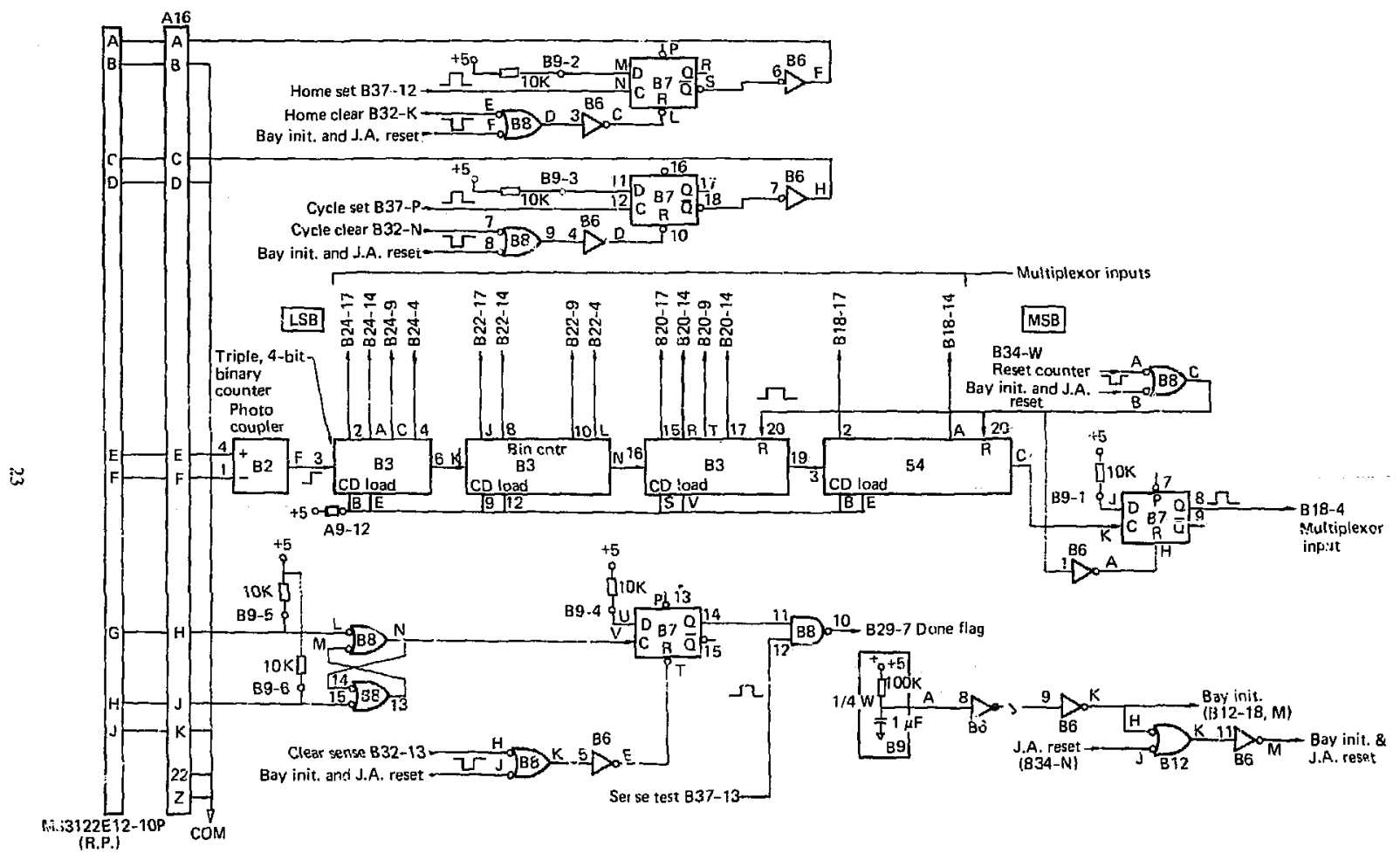

Fig. A-1. Cowputer interface. 


\section{APPENDIX B \\ FLOWCHARTS OF THE BASIC LANGUAGE PROGRAMS \\ FOR THE EMISSION SPECTROMETER}

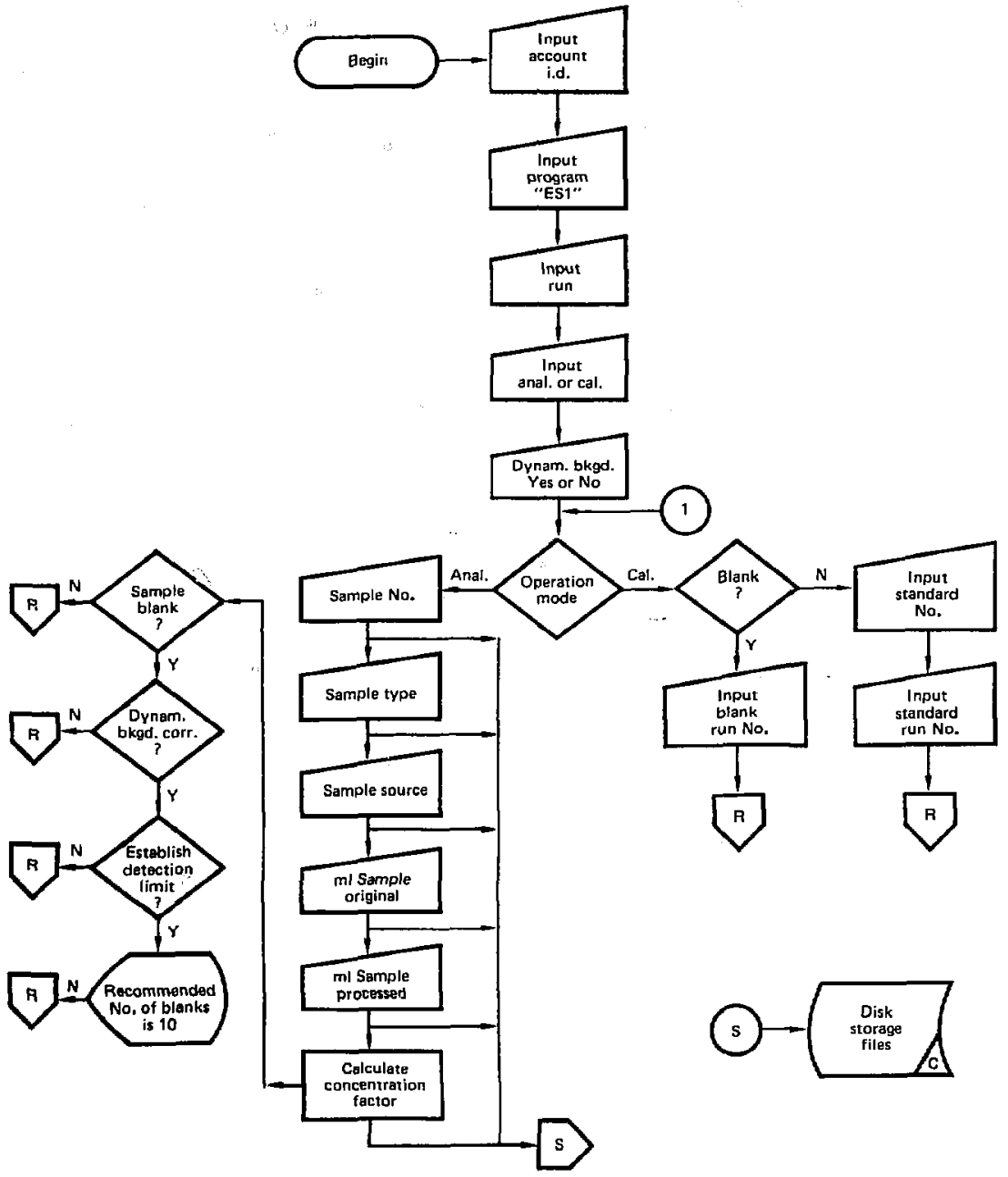

Fig. 13-1. ES-I. 


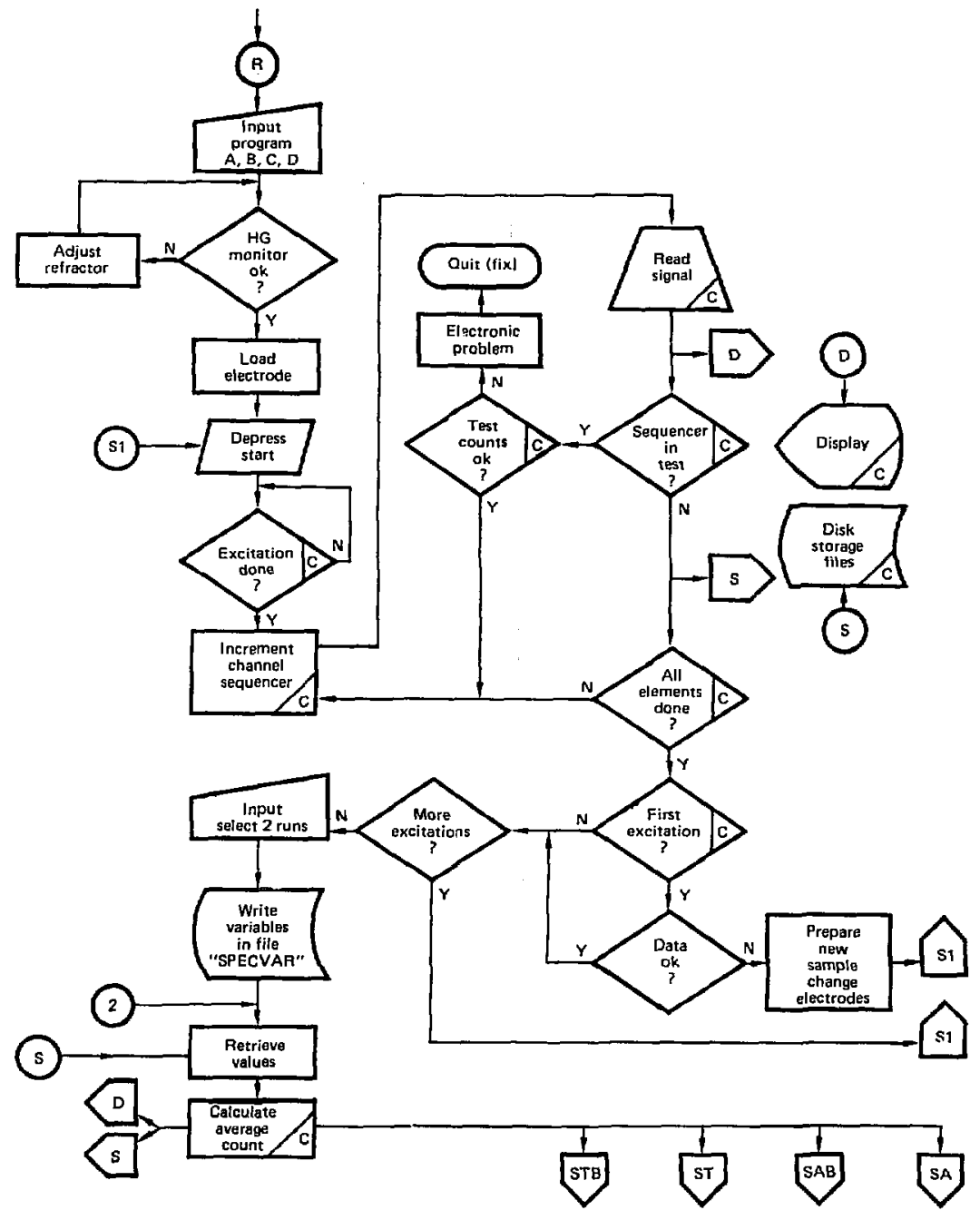

Fig, b.2. ES-2, 


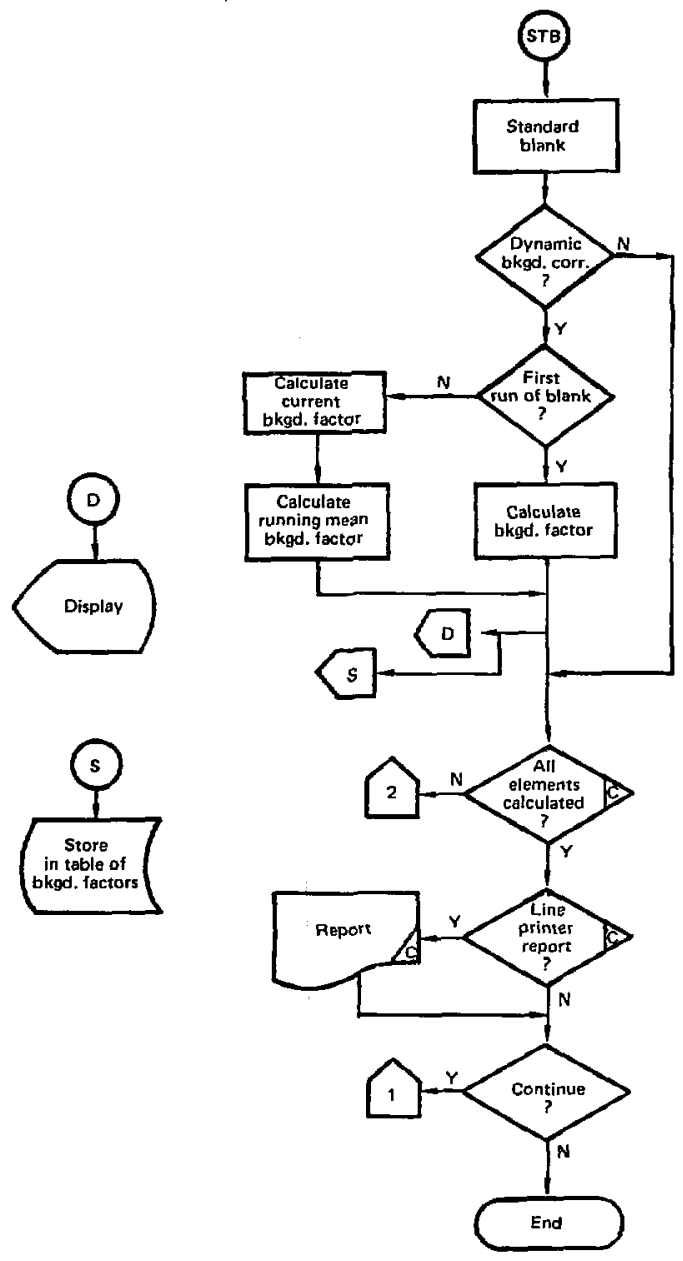

Fig. B-3. ES-3. 


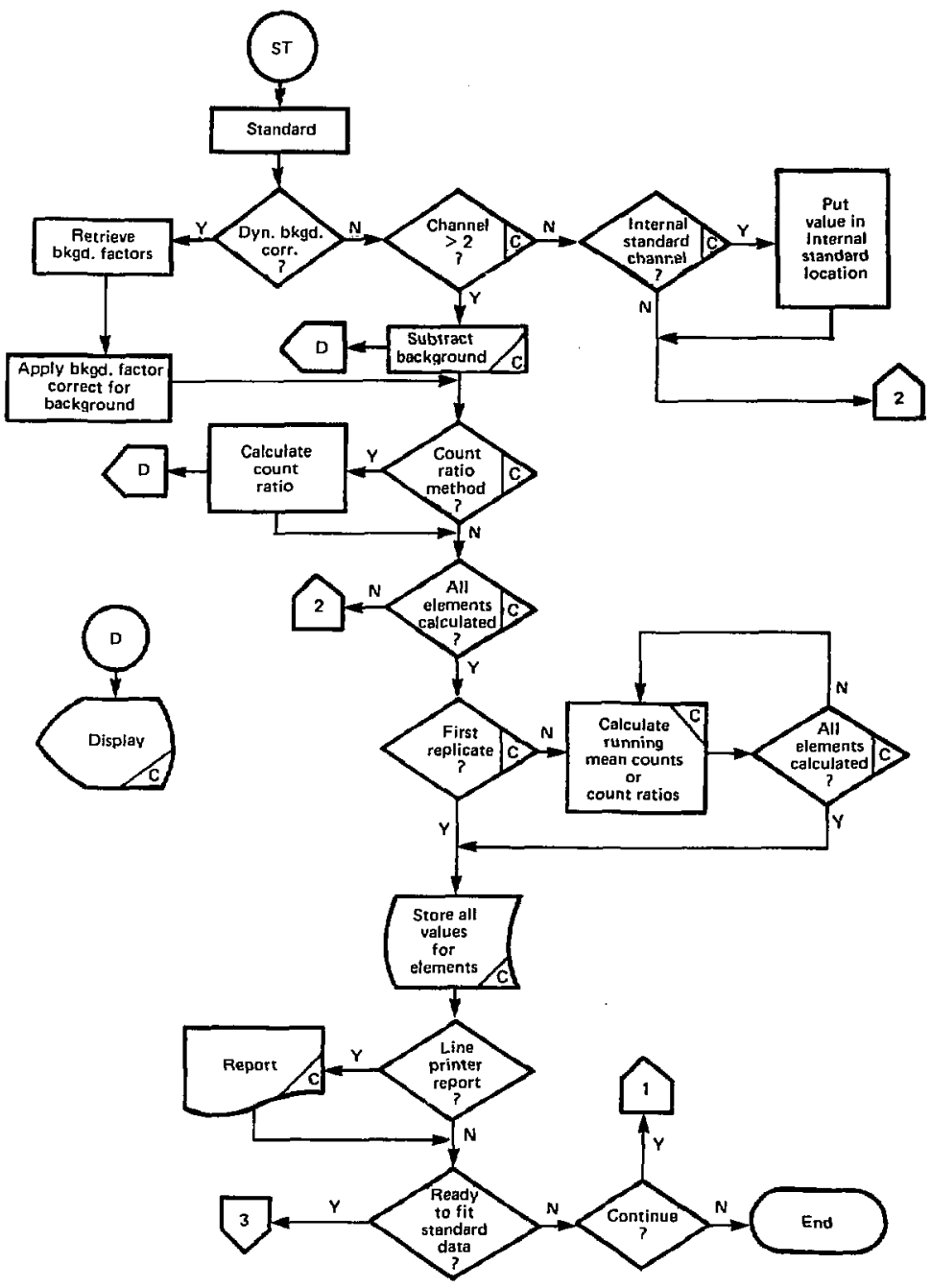

Fï. B-4. 15-4. 


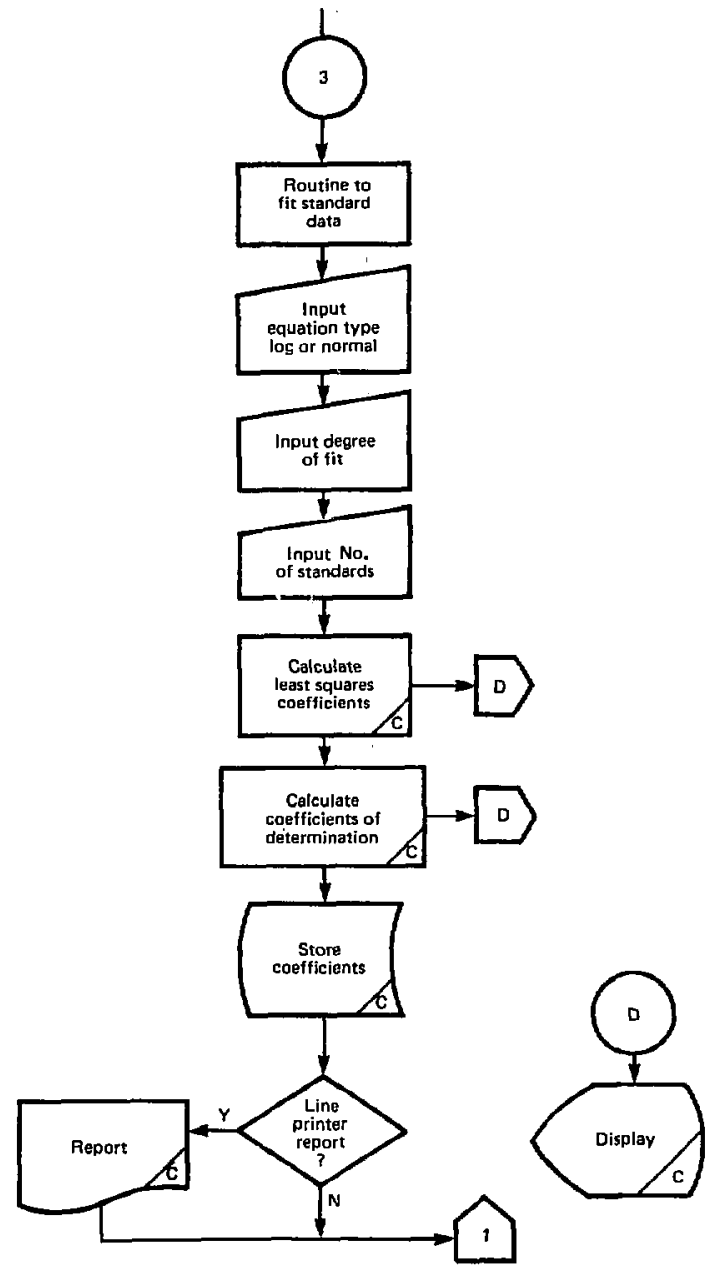

Fig. B-5. HS-5. 


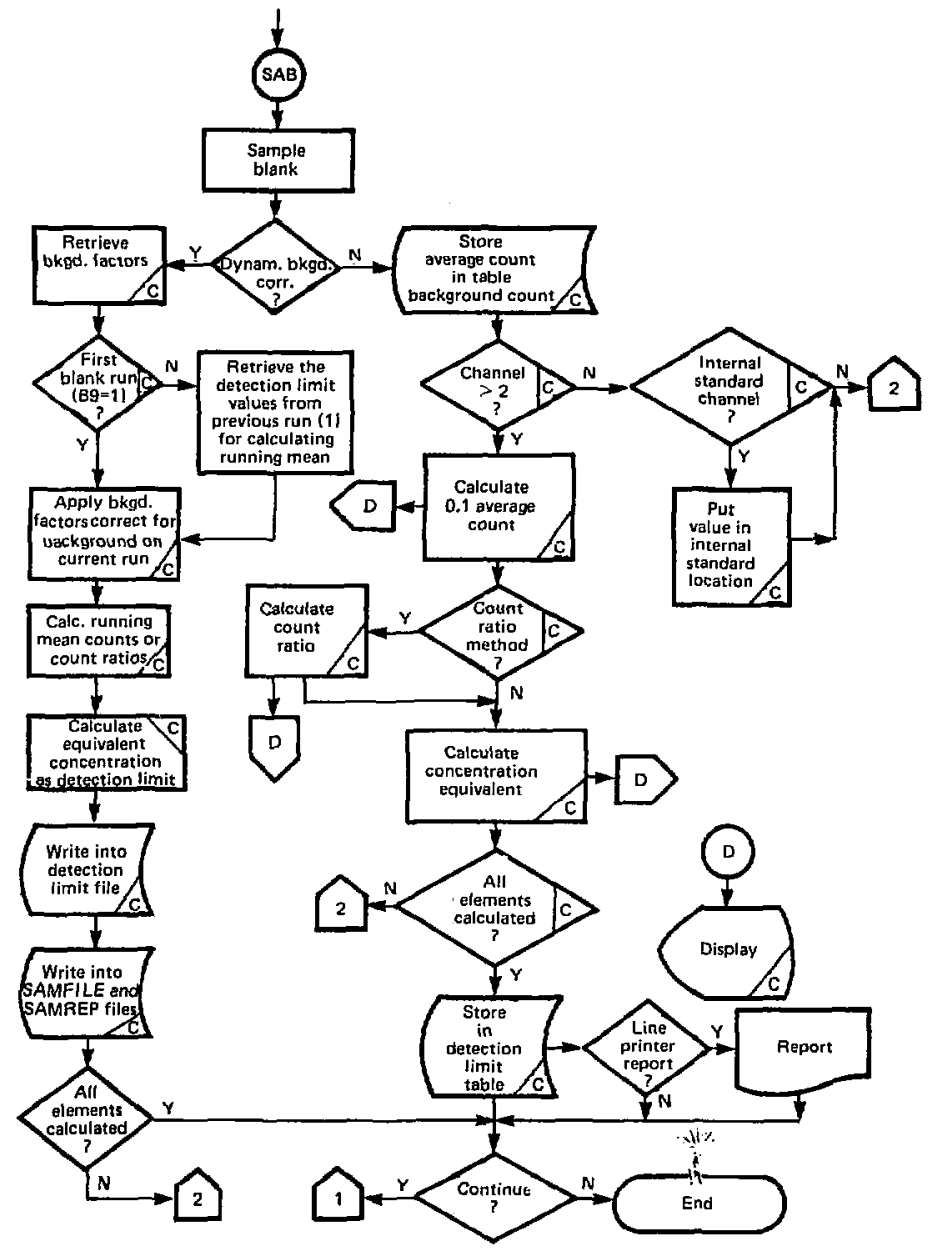

Fig. H-6, ES-6. 


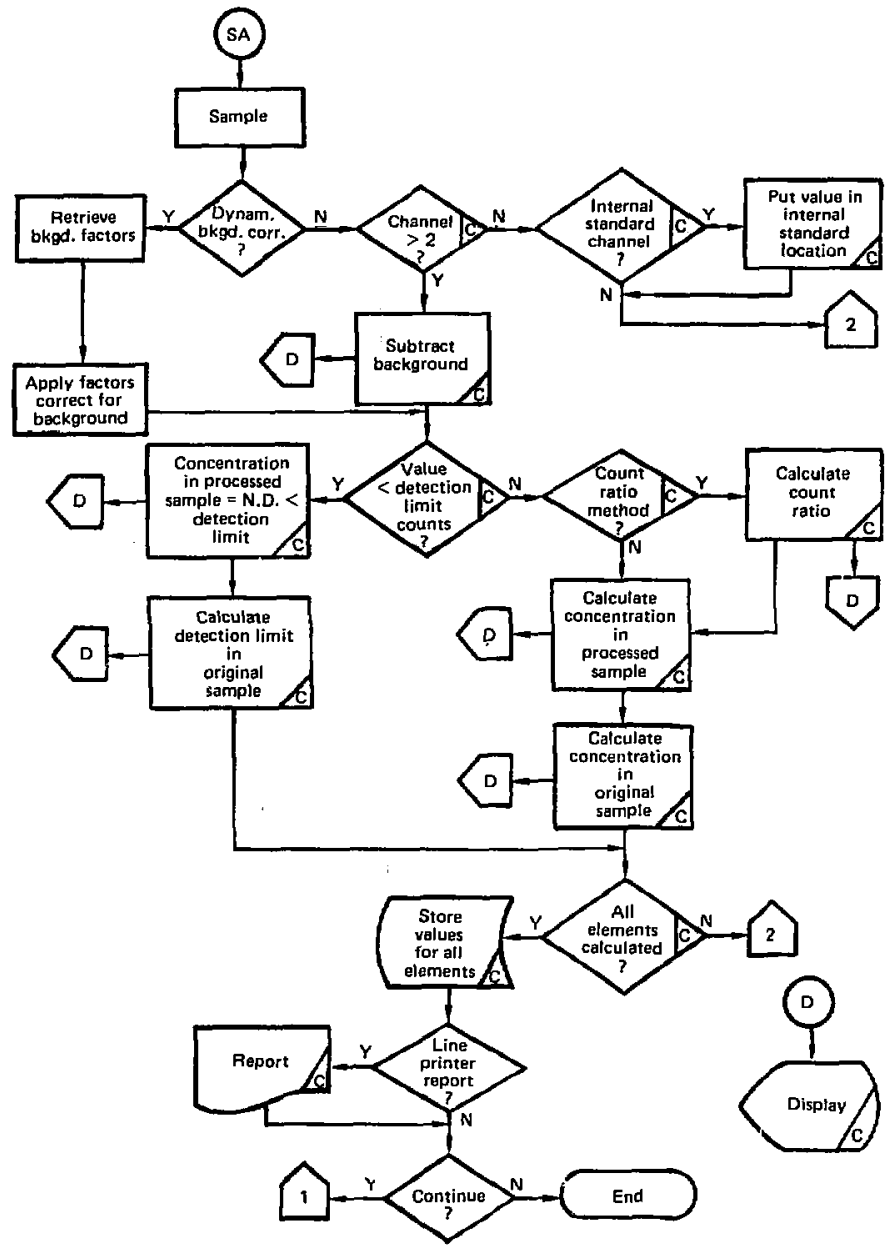

Fig. B-7, ES-7, 


\section{APPENDIX C \\ LISTINGS OH THE BASIC LANGUAGE PROGRAMS}

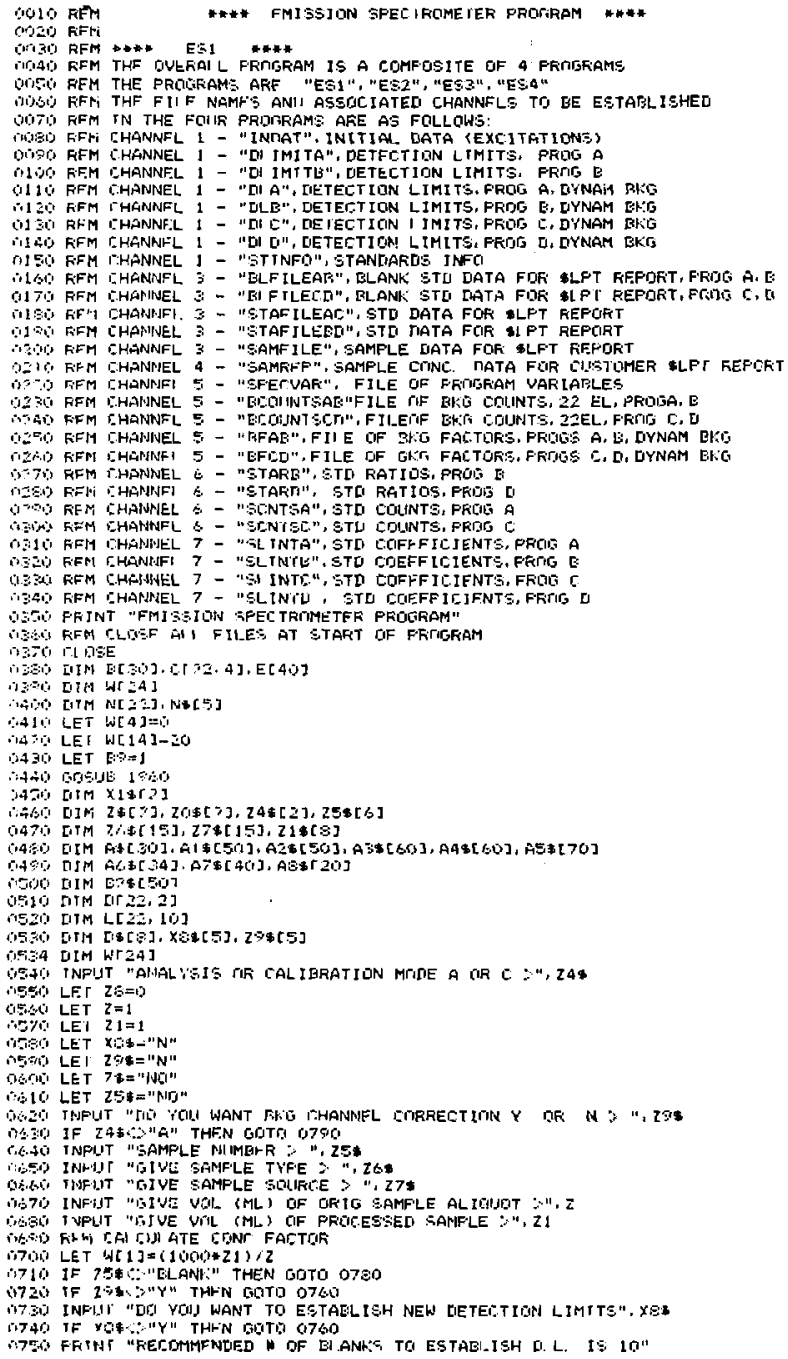




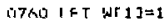

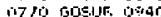

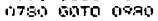

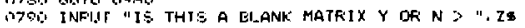

BO, LET $B S=0$,

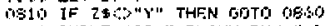

DS20 TPFLIT "BIVE FI ANR: RIN $4 \%$ ", W[ZJ

$\therefore 6.30$ LET $2 S=0$

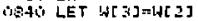

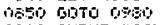

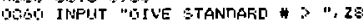

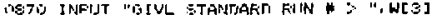

-

19

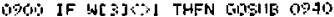

Dris 60 To

DPZO LET W[ 4$]=0$

प)

Q 404 MPEN FIIF[5, 3], "SPECUAR"

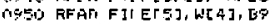

Dogr, I USE FII F [

AGTI: KFTURN

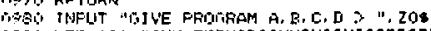

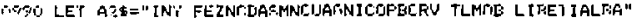

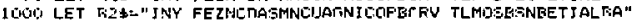

1015 IF $20 \%=" A "$ THFN BOTO 1070

1020 TF $20 \%=" E:$ THEN GOTO 1050

I030 IF 7,5\$" "F" THFN EOTO 1070

1040 TF ZO\$.:"D" IHFN SODTO 10,00

10510 LET $B 2 \$=A 7 \%$

$10 \% 0$ PRINT

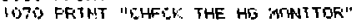

10 ज: LET W[ 5$]=1$

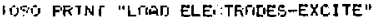

11 GO PRTINT "HIT STAFT"

1110 FFINT "EXI:ITATIDN $"$ "W[S]

1120 T:ALL z

1130 SAI I 12

1140 GOTO 13 iso

1150 INFII "IS DATA DK: $\% " X I \$$

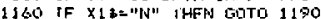

i 170 LET $h \Gamma 5]=\omega[5]+1$

$11 \% 0$ GOTO $113 \%$

19: FFTNT " FEFF" NFW SAMF'LE CHANGF ELET:TFCIDES"

1200 5iDTg 1000

I 210 FFINT

¿220 PRTNT " "ONI HAVE ENHPLEIED EXCITATINNS"

I 230 CI DSE FILET IT

1340 LET W[

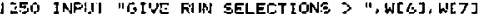

1300 TF $20 \%=" Y "$ THFN GOTO 1200

$1270^{\circ}$ LEI $E \xi=1$

1.78G, TIFEN FIIE[S, 1], "SPECWAR"

I 2 S WFTTE FIIF[5], W[4], B?

1300 WFITE FIIE[5], Z\$, ZC, Z14, 248, 25\$, 26\$, Z7\$

1310 WFITE FIIEYS], W[ $L], W[2], W[32,7 \varepsilon, A Z *$

1 S.․ WRITE FTLE[Sj, W[ $]$, W[ $\Delta], W[7]$

1.390 WFITE FII E[\%], XE\$, 29

1340 LL DEE FILF[S]

1.50 FFINT

1.390 FRTNT

1.970 [HATN "ES:

$13 B C$ TF $W[5]=4$ 1HFN COTO 1740

1.FF IF WTFJ=3 THFN GOTO 1720

1400 IF A:SJ=2 THFN GHTO 1706

1410 LET $J=1$

1420 LET $x=0$

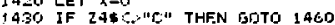

$144 \%$ PFINT "1HI: IS A T.AL JE RLIN, ETR", Z8

1450 FRINI" "

RiJN ", W[ 3$]$

14 AC FAR I $=1$ TQ 2

1470 CAI $3, X$

1430 IF T:I THFN GOTO 1510

$14 \%$ ODOVIJE $1 \% 70$

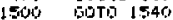

I 10 LET i, $[[-1,1]=x$

1520 GOSUE 1760

IFT: LET E[ $[-1] \div$

$15+0$ NEXT I

IETS CAI I 2

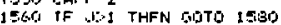

IETG OFEN FILEY \&, 1 ], "INMAT"

1530 FOF $I=1$ TC 22

I596 WFITE FII.EY 1],E[I]

I 600 NEXT 
1610 IF $74 \$: C=1 \%$ THFN GITO 1640

1620 IF Z $Z=" Y "$ THFN GOTD 1640

10.50 LE[ $W[4]=1$

16.40 IF N[S] $=1$ THFN GOTO 1150

135, LET $W[5]=4[5]+1$

1 S\$O INPUT "MRRE EXEITATIONS - Y OR N S", XI*

JE70 IF $X 18=$ "N" THEN GOTO 1210

$13 \% 0$ FRTNT "NEXT"

3 SOD GOTO $10 \% 0$

1700 LET $1=2$

1710 GrTo 1930

1730 LET UI=3

17 Bii) GrJTO 14.30

1740 LET $1=4$

1750 GOJTO 1430

17.50 PFINT TAE(4): A2\$[I+I-3, I+I-2]; TAB(4);

$17 \%$ IF W[S]=1 THFN GOTO 1950

1700 IF W[S] $Z$ THEN EOTO 1840

1790 IF W[5]=5 THFN GDTO 1820

1:300 FRTNT [I-1, J-3]: TAB(11);C[I-1,J-2]; TAQ(18):C[I-1, $1-1]$; TAB(25):

1510 GOTO 135

1820 PFINT $[[I-1, J-2] ;$ TAB(11), C[I-1, J-1]; TABI18);

1830 GDTE 1850

1 : 40 PRINT $[-[I-1, J-1]$, TAB(11)

1350 PETNT $[[1-1, d]$

IERO RETIIRN

YOTO FFM ROIUTINE TO EHFCK TEST COUNTS

IB71 REM ****** 1972 IS A TEMFCRARY CHANIE UNTIL TEST COUNTER IS FIXED *****

IST2 LET $X=300$ Si

1 EAO FRTNT $x$ :

$18: 00$ IF $x=3,300$ THFN GOTO 19,30

1900 IF $X: 3800^{\circ}$ THFN 60701930

1010 PFINT "OK"

1920 GOTO 1850

I 9SO FRINT "TEST CNT OIJTSINE 3000CZOO) LIMTT"

3940 co50 1090

1950, RFTULN

1 SAO NPFW FTI F[5.13, "SPECVAG"

1970 WRITE FILETS], W[4], BO

I9BO CI OSE FILF[S]

JOSO RFTURW

2000 FND

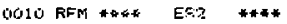

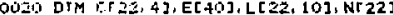

noso [IM Y[?], 4], W[z4]

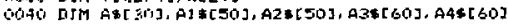

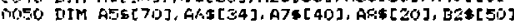

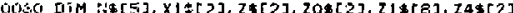

0070 orm 25, [\$1, 26\$[15], 27\$[15]

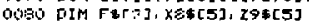

IOGO DFEM FILE[5, 3], "SFECVAR"

(10) FFA FIIF[5], 4[4], ES

0110 FEAT FILETEI, Z\$, 20\$, Z1*, Z4\$, Z5*,Z6*, Z7*

DI 20 FEAD FIIF[5], W[1], wr z], w[3], Z1, A2s

i!z? EEAT FILETS], $h[S], W[\Delta], W[7]$

(i) SO FFA[ FILF[S], XS\$, 2S*

1150 CI CIEF FILE[5]

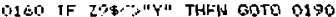

i1 70 [4] $\mathrm{E}[22,4],[\mathrm{L}[2,3,4]$

$01: 0$ GoTQ 0206

i $1 \% 0$ DIM $B[30], D[77,27$

U2010 TF $246="$ ". THFN SOTO O5OQ

IE10 IF 758="ELANK" THEN GOTO 0400

Q2I0 IF $204=" Y "$ HHFN GQTO

DMEO IF ZOSF"E." THFN FOTO 0320

12 240. RPEN FILE[ 1,3$]$, " ПL IMITA"

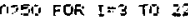

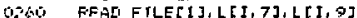

$\therefore=7 \% \quad$ LFI $\mathrm{E}[1,1]=[[1,7]$

6) 7 [A

32F: NFYT I

t)

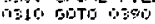

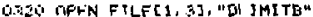

NFEC FOF I 5.5 TI

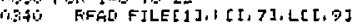

(1) $L E$ G $D[Z, 1]=L[1,7]$

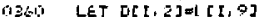

OFTC NFXT I

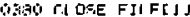

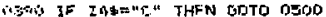

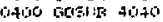




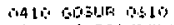

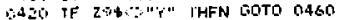

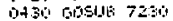

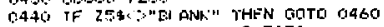

i45ig IF B\%? THFN ECSIJE 7070

0460 FFINT A4[1, 2]; $25 .+$

IATI FFINT AAT

OAGL FFINT AE.4

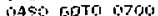

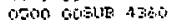

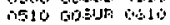

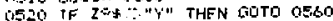

OSTO IF Z\$: "Y" THFN BOTO 0550

$05+0$ TF W[:3J: THFN OMTO OSEO

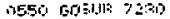

(ESO) FFINT $2 \mathrm{G}$

1757\% F'RTNT GAS:

ngō FFTNT W[3]

DECG FETNT AFI

Q600 gota 0700

isso Fithi An:

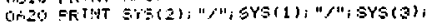

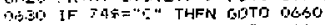

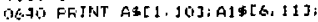

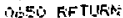

1060 FRTUT A\&[1.1JJi A1\$C6, 14Ji

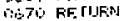

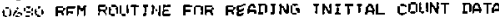

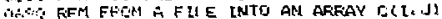

$\because 700$ nFFN FII F[1, 3], "INEIAT"

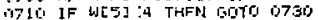

17 $720,50 T 9870$

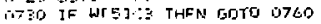

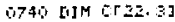

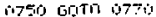

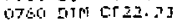

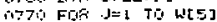

ด7: FIJ $J=1 \quad T=32$

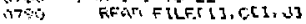

CHED NEXT I

ingti NFT T -1

(j):

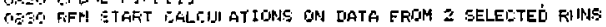

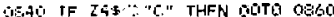

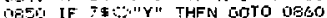

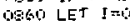

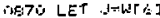

OEETC LET $I=I+1$

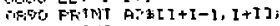

TOOO FFITN TAE $(4)$

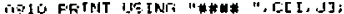

$\therefore$ EO LET $L[I, 1]=[[\mathrm{I}, \mathrm{H}]$

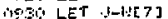

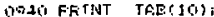

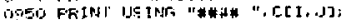

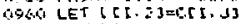

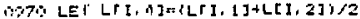

THOS FFINT TAEM 1SI;

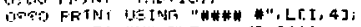

LOOO IF $Z \$=" Y " T H F N$ EIJTO 2460

IDO IF Z5\&="ELfFN" THFN GQTO 2730

jozo iF $2 \%$-" $r "$ THFN gOTO 5930

15\% IF I:I THF GSTO 1130

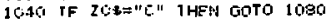

JUE IF 7O\&="C" THEN GDTO 1080

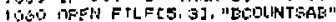

1070 goto $105 \%$

logit GF! FII,F[5, 3], "[COUUNTSLD"

$1000 \quad F Q F+r=1$ TO 20

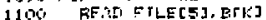

1110 NF.YT $\mathrm{V}$

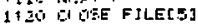

$11 \%$ LEI $r=I$

$124 \%$ TE FO IHFN $50 T 0$ TO 1170

1 15: LEI L[I, ? J*LI $[, 4]$

1 IGO GOTO 11 :

1 IT LET LII: T]-Lr I, 4J-G[K]

ISOS TF ZCE= "E" THFN GDTO 1370

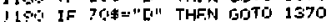

1 [iv: LET N[ I] $=1[I, 7]$

IIIT, IF

1ZZC FRINT TAB(24):

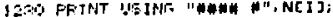

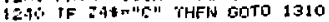

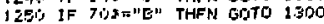




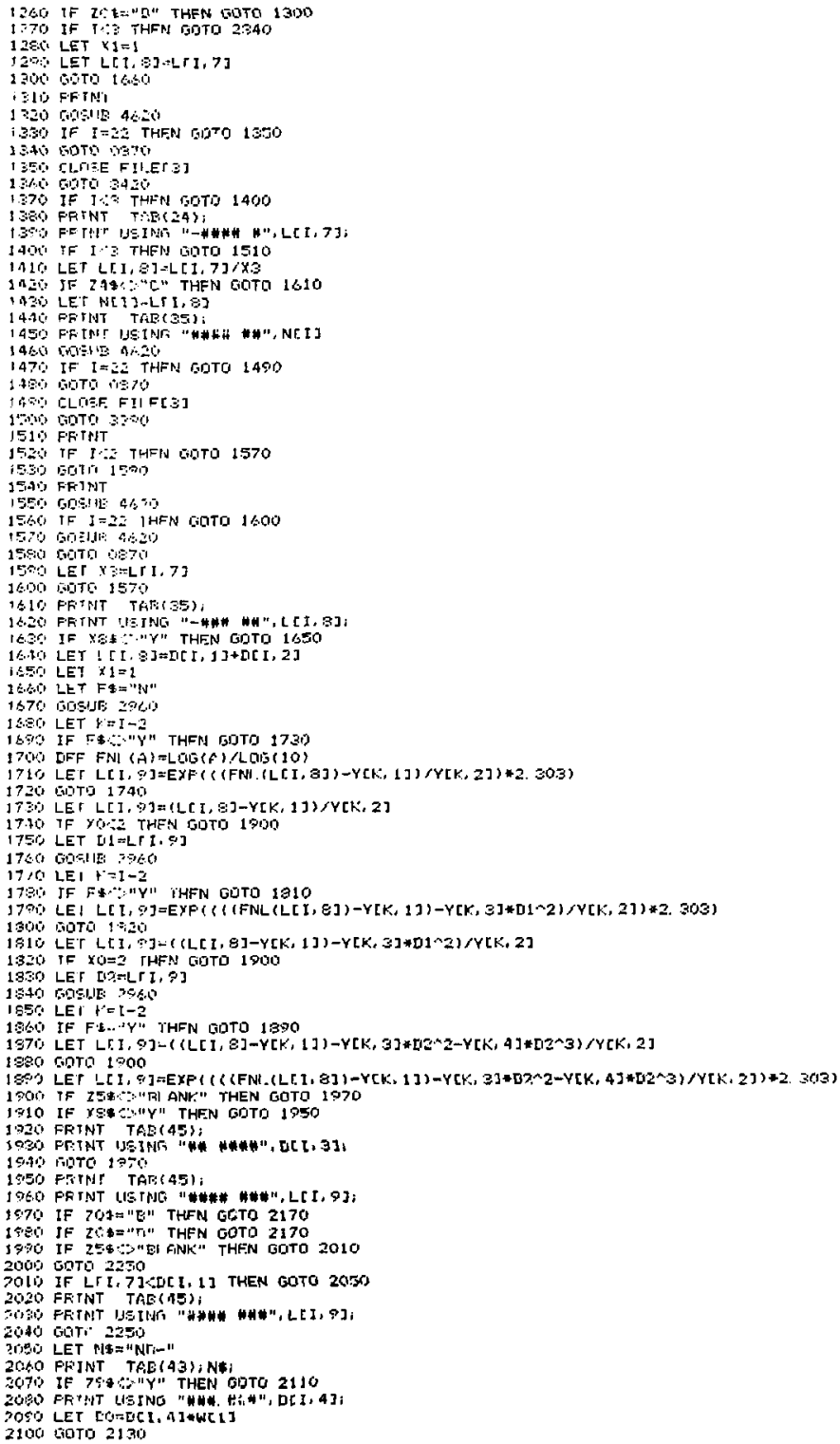




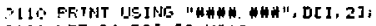

$? 126$ LET [10=n[I, $>] * W[1]$

2130 FFINII TAF(SA); HA

2140 PRTNT UEINR "WHN" ". DO

2150 TiDSUS 4620

1160 GQTO 5350

2170 IF 25\$ "UANK" THFN GOTO 2150

ग180 G0Tा 2550

ZIO" IF $7 \%$ "Y" THFN GDTO 2220

ZZUT IF I C I, E]CD[ [, 1] THEN GQTO 2050

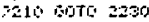

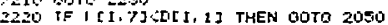

TE FRTAT TAF(45),

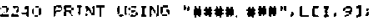

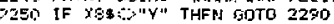

22/OC FFINT TAB(EB);

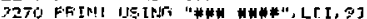

2380 G0T0 2320

2700 LE $[$ LI , 10]=LFI, 9]*W[1]

FSOL FRJPT TAE(SS):

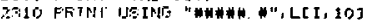

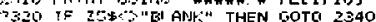

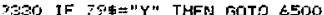

2340 gastus $4 \times 20$

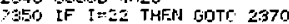

3360 50TO ne70

1375, TI DEE FILEF 3 ]

23:OO TLLDEE F FLE[ 4$]$

I7F" IF 75 क "EI AMK" THEN DOSUE 5440

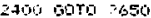

7410 FFTn! TOK(Z4);

2450 FRIJT LI:STNG "\#\#\#甘. W"4, 1, [1,7]

74 FF FII

-440 tilisid 4 H. 20

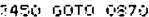

¿4S\% FEM RUITTNE FGR STMRTNG RKG COUNTS IN FILE BCOINTS

$747 \%$ IF $796=" Y "$ THFN G0T0 5\%30

ZABS LET ECIJ=[. [X, 4 J

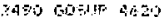

2500 JF I=22 1HFN SOLTO 2530

ZSIO FFTMI

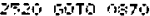

YE.O LLEISE FIIECSB]

2540 ORINT

7550 IF ZIS="E" THFN GOTC 2590

PSO TF $241=" \Pi "$ THFN COTG 2590

7570 CIFEN FILEY5, 1 J, "ECOIJWTSAB"

2TE⿺ G0TO 7400

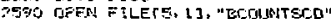

7000 FIR $J=1$ TO 23

741\% IIRITE F[LE[5], E[ I ]

TAO $\mathrm{AE} \times \mathrm{T}$ I

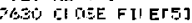

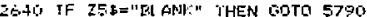

GSE FFIPI

$26 G$ TINUT "IIO VOLI NANT A REFORT ON THE SLFT $; ", \times 1 \$$

iE70 IF $\times 15=" Y "$ THEN GOTO 3760

$26 E 0^{\circ}$ F.F.THIT

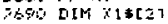

:700 TEFIT "IUL VOU LANT TO CONTINUE Y OR $N>*, X \$ *$

2710 IF $\times 1:=" P ! "$ THFN GOTO $76 B 0$

37E0 PHATU "FS1" THFN GOTO OAJO

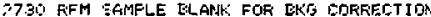

3740 IF Z $81=" Y^{4}$ THFN EOTO 5930

$\Rightarrow 750$ LET E[IJ=L[TI, A]

P7\& IF T:S IHFN GOTO 2790

27.80 LETT L「I, T ] =E[ I ]

フ780

Z7OC LET L[I T]= 1HE[I $]$

GOI FETINT TAE(Z4):

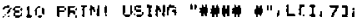

2920 LET N[I]=1 [ [ , T]

TEBO IF T:Z THFN GIJTO 2930

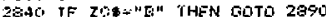

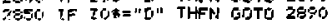

2BSGO LATEUIR 4420

APTS FFTM!T

zage cioto os70

7 Bsit If $T=2$ THEN IDTO Z910

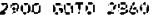

710 LET $\times z=5[$ [ ]

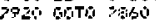

$7 G 30$ IF $709=" E "$ THEN DOTO 1410

TD40 IF ZS: "II" I'HFN GQTD 1410

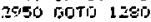




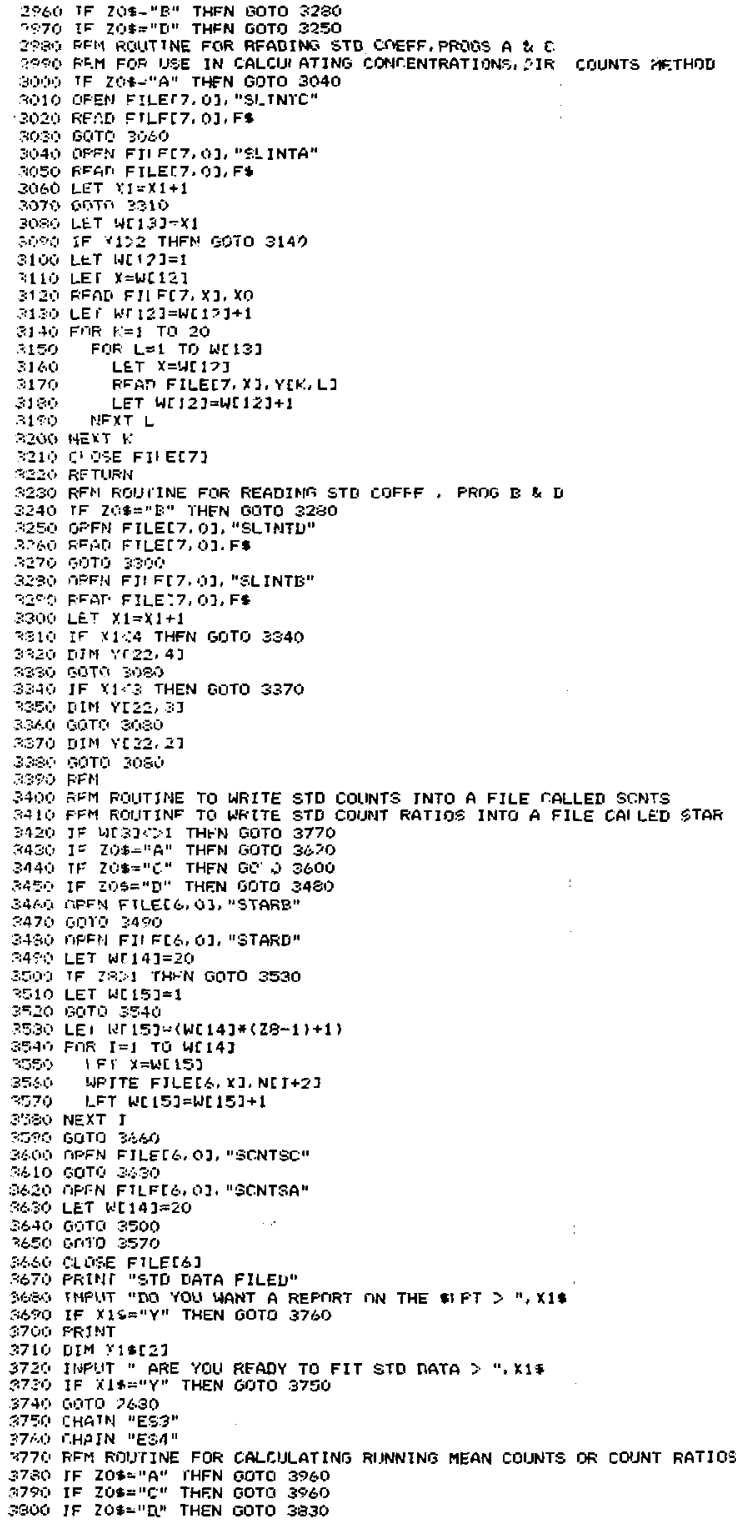


"औ]U் DFEN FILE[G, O], "STARF"

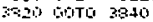

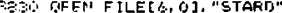

$3: 4 A^{\prime}$ LET $14[143=30$

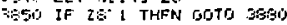

3060 LET $N[15]=1$

F⿻大

$3 B E 0$ LET $1[15] *(4[14] *(28-1)+1)$

s.sen Foh $t=1$ Tis $w[14]$

3900 LET $X-15[15]$

391: FFGR FILET \&, X , E[I]

3020 LET N[ $]+2]=(N[]+2]+(E[1] *(H[3]-1))\}$ S [ 3$]$

1950 LET W[15]=W[15]+

$3440^{\circ}$ NEXT I

\$5\$O GOTO 4020

3260 IF ZOS="A" THFN GOTO 3970

\$क70 OFEN FILF[E, O], "SCNTSC"

Trat GOTO 4000

3990 OFFN! F TLE $[\$, 0], ~ " S C N T S A "$

4000 LET IJ[ 14$]=20$

7010 50TO $\$ 850$

$40 Z$ C DSE FTLE[G]

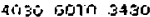

4040 RFM RLUTINE TO STIRRE SPEC ANAL MATA \& HEADER
ATSO LEI AS="

4QGW LET AI\$=" MATE SAMFLE TYFE SDIRCE"

AC76) LET ELENizit)

40 Gं LET A:\$ $A \leqslant[1, A], A \backslash \leqslant[1,4], A \$[1,2]$

4050 LEI $E I=L E N(265)$

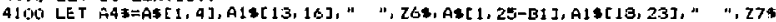

4110 LET AS\$="SFECTRIISRAFHIC ANAI YSIS RFFORT"

4120 LET AT\$=A\$[1, 3]. "FLEMENT

ILZO LET AB\$ "MICRTIGRAMS/LITER"

4140 TF ZOS-"E" THFN GOTO 4250

4150 IF $20 \%=" D "$ THEN GOTS 4250

4160 TF 25:?"ELANK" THEN GOTO 4230

4170 IF 7\%6:" "Y" THEN GOTO 4230

4190 IF XBs'?"Y" THFN GDTO 4210

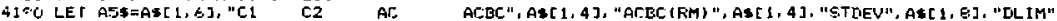

4200 RETIIRN

4710 LFT $A 5 \$=A *[1,5], " C l$ C2 AC 2 ACBC", AE[1, 16], "DLIM"

4230 RETIIFN

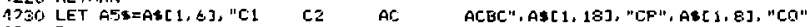

AE40, RETLIFN

4750 IF 75S6"BLANH," THEN SITTO 430R

4360 TF $29 \$$ (\$"Y" IHFN GOTO 4340

4270 IF WGS:"Y" THFN GOTI 4320

4230 LET AES=A\$[1, G], "C1 C2 AC ACBC", A\$[1,6], "CR(RM)", AD[1,6], "SD", AS[1, 7], "DLIH"

4:95 FIF TLLAM

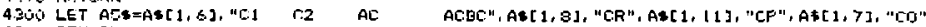

4.516 FIFIURN

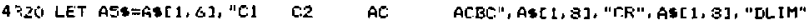

4300 FFTUKN

43.40 LET AS\$ =A\$[1,6],"C. L.2 AC

4350 FF'THEN

4 ZGGO RLM HEATIFF FOF STD REFTRT

4.570 LEI $A \$="$

4.JEO LET AIS="DATE STANIMAREN RIIN* PRGIGRA"

4300 LET $E=L E N(Z 1 \$)$

$4+C, C$ LET A3\$=A\$[1,4], A1\$[1,4], A\$[1, 2]

4410 IF zos C"A" THEN GOTO 4440

4130 LET $A 4 \$=A \leqslant ? ; 4], A 1 \$[21,27], "-A ", A \leqslant[1,23], A 1 \leqslant[1 \leqslant, 1 \$]$

$4 A 30$ STTOE 4520

4440 IF ZU\$="G" THFN GOTO 4470

445 IF IF TOF" "E" THEN CIDTO 4490

$4460^{\circ}$ IF ZOE="G" THEN GOTO 4510

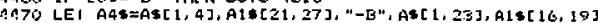

4480 GOTO - 4520

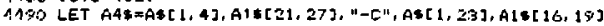

4500 GOTC 4520

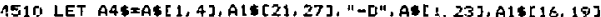

1520 IF $Z S=" Y "$ THFN GQTL 4570

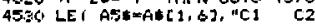

3540 if TOS= "A" THFN GOTU 4560

4500 LET $A F+=A 5 \$, A \leqslant[1, \xi]$, "CF"

4560 CIETC1 4610

4579 IF $Z$ \%\$S"Y" THEN GOTO $4 \$ 00$

45\&O LET AS\$ A\&[1,6],"L:1 C2 AC

4 FSO RFTUFN

4E़ी LET A5\$=A\$ $[1,6]$, "C: 1 C'2 AC."

4 to FF TIJKN

4620 RFM ROLIT TNE TO STORE FILFS FIR MATA TO BE USED IN REFIRTS

46.jO IF Z4\$\$"C" THFN GJTTO DO10

46.40 FIM NATA FIR STU RFPLRTS

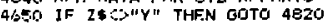




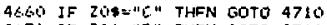

ASTI" IF 2OH="D" THFN GOTO 4710

4680 TF IY] THFN GQTO 4770

A6,5 OEEN FILE[3, 1], "ELFILEAE"

470 SOTL 4730

471\% [F 171 THFM GrJTS $47 / 0$

4720 CFEN FTLE $[3,1]$, "ELFILEND"

47:" WFITE FILE[3], A.3\$, 28, A45, W[ 3$], A 58$

4720 IF $20 \$ \% " Y "$ THFN BOTO 4600

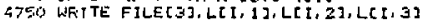

470 SEIIIFN

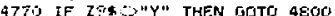

4760 WFI IE FII E[3], I [I, 1], L [I, 2], L[I, 4], B[I, 3], [3] I, 4]

47) FETSW

$4300^{\circ}$ WFI IE FILE[ 3$], 1[5,1], L[I, 7], B[1]$

AE10 FiF ILFIPI

4 40 TF $20 \$-" E . "$ IHEN GOTO 4930

4530 IF $208-\mathrm{N}^{\circ} \mathrm{D} "$ THFN GOTO 4650

$4: 30$ IF I:1 THFN GOTO 4:370

"St: DFEN FILE[3، $1 \mathrm{~g}$. "STAF 1LEar:"

$4: 360$ WFITE FILF[3], A35, Z3, A45, W[3], A5s

$\$ 370^{\circ}$ IF $Z 73 Y^{\prime \prime Y " ~ T H F N ~ G O T D ~} 4910$

+:HST IF I:S1 THEN GOTO $4 \% 10$

4:0 WKITE FILE[\$], L[1, 1 J, L[1,2], LT I, 3]

4000 FEETIIRN

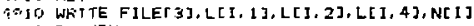

ADA FETIIFN

$4 \$ 0$ IF I I THFN GOTO $4 \% 30$

$4: 40$ DFFN FILE[3, 1$]$, "5TAF ILEP["

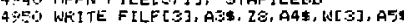

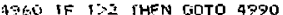

\{S70 WRTTE FILE[3], L[I, I], LE], 2], L[I, 4], L[I, 7]

A

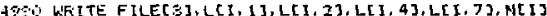

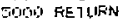

F10 RFM IIATA FGR SAMHLE REPGITE

5020 IF $1: 1$ IHFN GOTQ 5090

$5,10$ C.FEN F ILE[ 3,1$]$, "SAMF II.E"

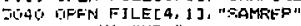

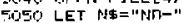

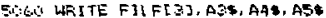

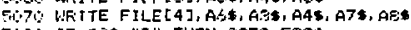

SGi0 TF ZUD="E" THFN GOTO 5330

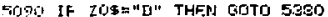

S10 IF J 1 IHFN GOTO 5140

5110 IF $256="$ GLANK" THEN GOTO 5770

$515 \%$ IF $1[[, 7]<[1[I, 1]$ THFN GOTO 5290

5100 GOTO $E x \in 0$

5140 TF ZSTK"Y"Y" THFN GOTO 5190

FI5O LF IOL THFN GOTO $51 \mathrm{EO}$

5160 LARITE FTLF[3], L[I, 1$\}, \downarrow[1,2], 1[1,4]$

:170. RF TURN

51 GO WR I]E F TLE[3], L[I, I], L[I, 2], L [I, 4], N[I]

5190 IF ZES="EI.ANK" THFN GDT 5210

EOW, FRTNT

$5=10$ RFTUFN

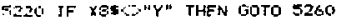

ST3O WFITE FILE[3], L[I, 1$],[[1,2], 2[1,4], 0[1,1], 0[1,3], D[1,4]$

524,0 , NFITE FTLE[4], D[I, 4]

5.55: FiF TURN

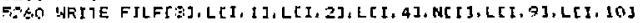

5270 WETTE FILET 4$], L[I, 10]$

ESOB RETURN

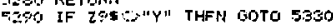

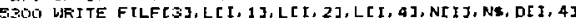

$F 10$ LEI Dij=D[I, 4]*W[1]

5200 GIOTO

630 WET IE FILE[3],L[I, 1], L[I, 2], L[I, 4], Nt I], Ns, D[ I, 2]

$5,346$ LET [IUं $=0[1,2] *$ W[ 1$]$

5.50 WKITE FII F[3], N\$, DO

5.360 WRITE FIIF[4], N\$, DO

5370 RF'TUF'

5380 TF IOI THFN GDTO 5420

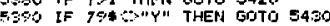

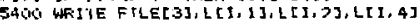

PA10 RF TURM

$54: 0$ JF I:2 THFN COOTO 5450

5430 WFITE FII E[3], L[1, 1], L[ I, 2], L[ I, 4], L[ I, 7]

S440, RETIIFN

5.50 IF $Z 5 \$=$ "ELARH" THEN GOTO 5510

EAEO IF LP\$ 2 "Y" THEN GOTO $\mathbf{5 4 9 0}$

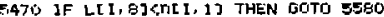

5480 GOTO 550

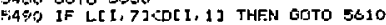

5500 GaTo 3550 


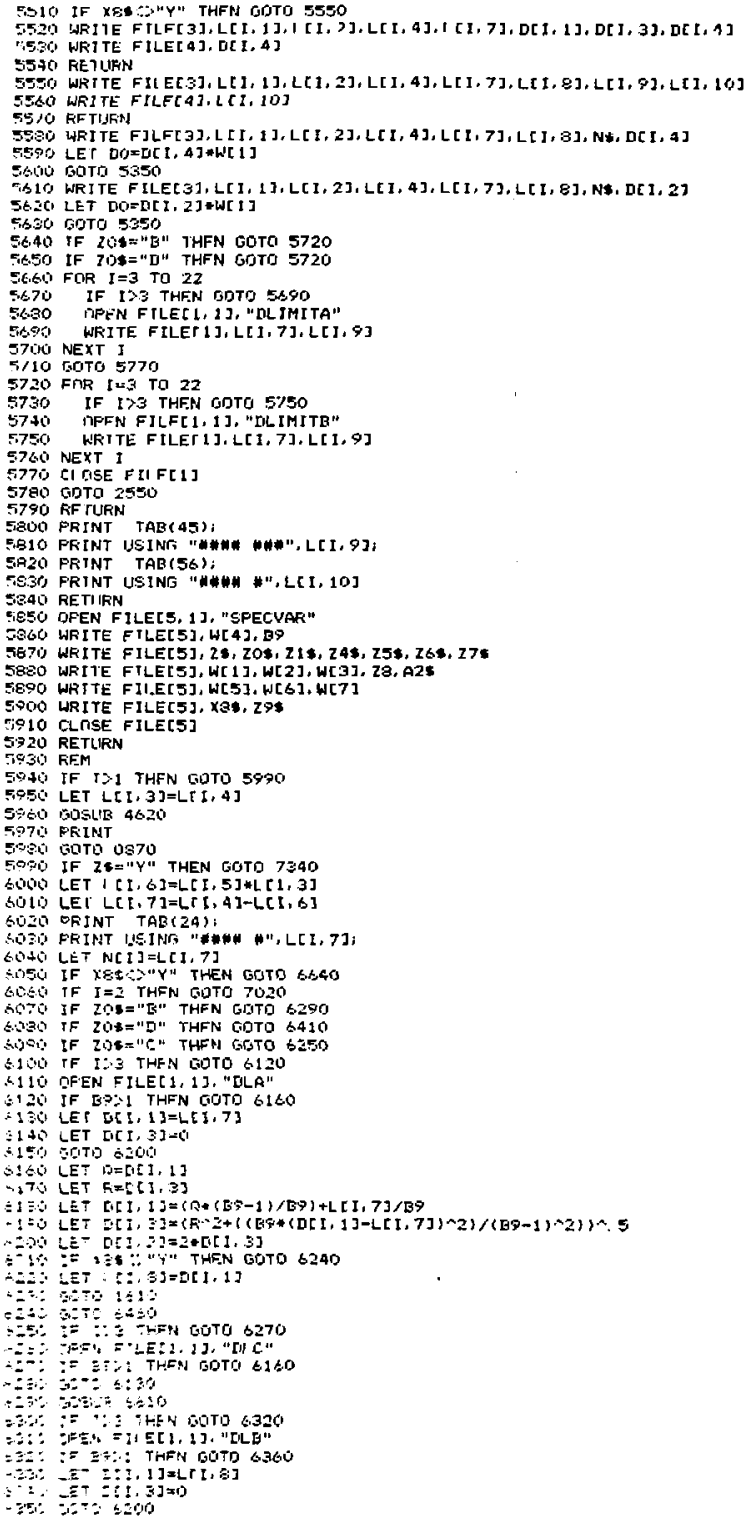




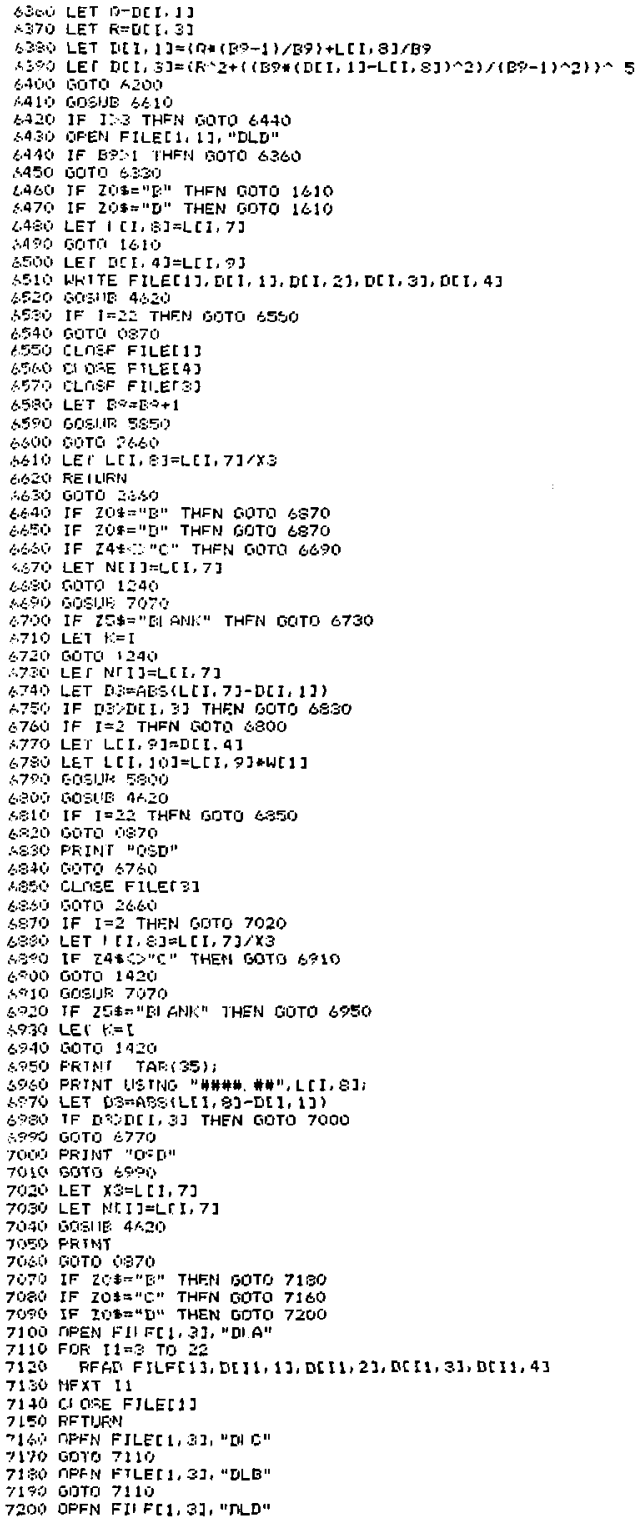


7210 ,

7320 RETURIN

7230 IF ZOS:" THFN GOTO 7320

7240 IF IOL="Q" THFN GOTO 7320

7250 TIFEM FILETS. 33, "EFAR"

7360 FIR $11=2$ TI 22

7270 FFAD FIIEREJ, E[I1, 3$],$ Et [1, 4]

$7>30$ LET L[1 1,5$] \div B[11,3]$

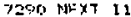

$7: 310$ CI, D:SE F ILE[5]

7\%:10 RFTIJFN

730 IIFEN FILE[5, 3], "EFEE"

$7330 \mathrm{BOTO}-2 \mathrm{sO}$

7340 REM

7350 LET $[[1,1]=L[1,4] / L[1,3]$

7360 LET $\gamma 1=[1][1,1]$

7370 IF INLSI:I THFW SOTO 7470

7390 LET $B[1,2]=0$

7390 G GISIJA 7510

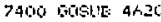

740 IF $\mathrm{I}=22$ THFN GITTO 7440

7420 PRINT

7430 GITT GE70

7440 TILEISE FILE[S]

7450 CLMEE FILEE.

7460 G0ITL 2640

7470 LET E[I, 1$]=(\{E[I, 3] *(W[3]-13) / W[3])+\forall 1 / W[3]$

$7 A B 0$ LET $R[1, Z]=((R[I, 4]) \wedge 2+((W[3] *(B[I, 1]-Y I) \wedge 2) /(W[3]-1) \wedge 2)\} \wedge, 5$

7490 progle 7510

750,000017000

$7 \rightarrow 10$ LET E[I, 3]-E[I, 1$]$

7520 LET E[I, 4]=E[I, 2]

7G:AO FRTNT TAR:24);

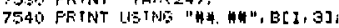

7 LESO FRINT TAF(E,5),

$75 \& 0$ FRINT ISINB "W *H\#", E[1,4];

$75 \%$ IF 706 "C" THFN GCTQ 7630

7530 IF 204:"G" THFN GOTO 7630

7050 IF ISZ THFN OSDTO 7610

7SOG DFFN FILE[E, 1], "[BFAB"

$7 \leqslant 10$ WFITE FILE[S], E[1, 3$],$ B[], 43

7 SIO REIIJWN

$7 \$ 30$ IF IS2 THFN SOTO 7610

7640 TFF'N FILF[5, 1], "EFCD"

7650 G[TIO 7610

7400 END

ODIO RFM *t* ECF ***

0020 DIM E[30], n[22, 2], F[40], L[22, 101, N[22]

J030 DIM AT\$[50]

OOA0 DIM O[22,7], Y[22,7], W[24]

bSo DIH $C[72,43 ; H[2,2,3], F \leq[2]$

OOGO DJM Es[55], B 1 te 25], B2E[50], B3:[30]

jo70 [IM E44[30]. BSt [45], BSt[30], 97\%[30]

UCABO DTM BSE[ 45], BPE[40]

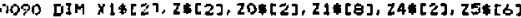

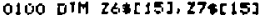

j10 DIN Xet[5], zकs:[5]

0120 OPEN FILF[5, 3], "SPEEVAR"

1130 RFAT FILET5]; W[4], BQ

0140 RFAD FILE[S1, 2s, 20t, Z2t, 24s, 25t, 26s, 27*

WIJU RFAN FILE[SJ, W[1], W[2], W[3J, Z8, A2

OIGU RFAD FILE[5], H[5], W[6], W[7]

i) REA FILE[5], XEs, $29 \%$

DIB CI GRE FILFIS]

AIEO INFIJT "WHICH FROGRAM A, B, E. D ?", ZOs

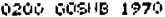

DZ10 RFM LEAGT SRIJARF\& FIT RDUTINF

QZZ: MAT $F=2 F F[4,4]$

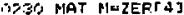

Q2415 MAT A=2FR[4]

DESO MAT $\mathrm{G}=2 \mathrm{ER}[4,4]$

DIGO MAT $I T=Z F R[4]$

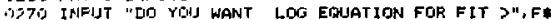

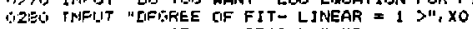

DEGO IAIFITT "NIMBER OF STUS $2 ", \times 2$

(1):30, LET $x \mathrm{I}=1$

DE (i) LET $x 1=x_{1+1}$

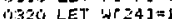

iJES F[JR $T=1$ TO W[14]

OEA1; MAT B=ZFF[X $X \geq 1$

VIFI MAT $R=Z E R[X Z]$

QEST MAT $F=Z F R[X 1, \times 1]$ 


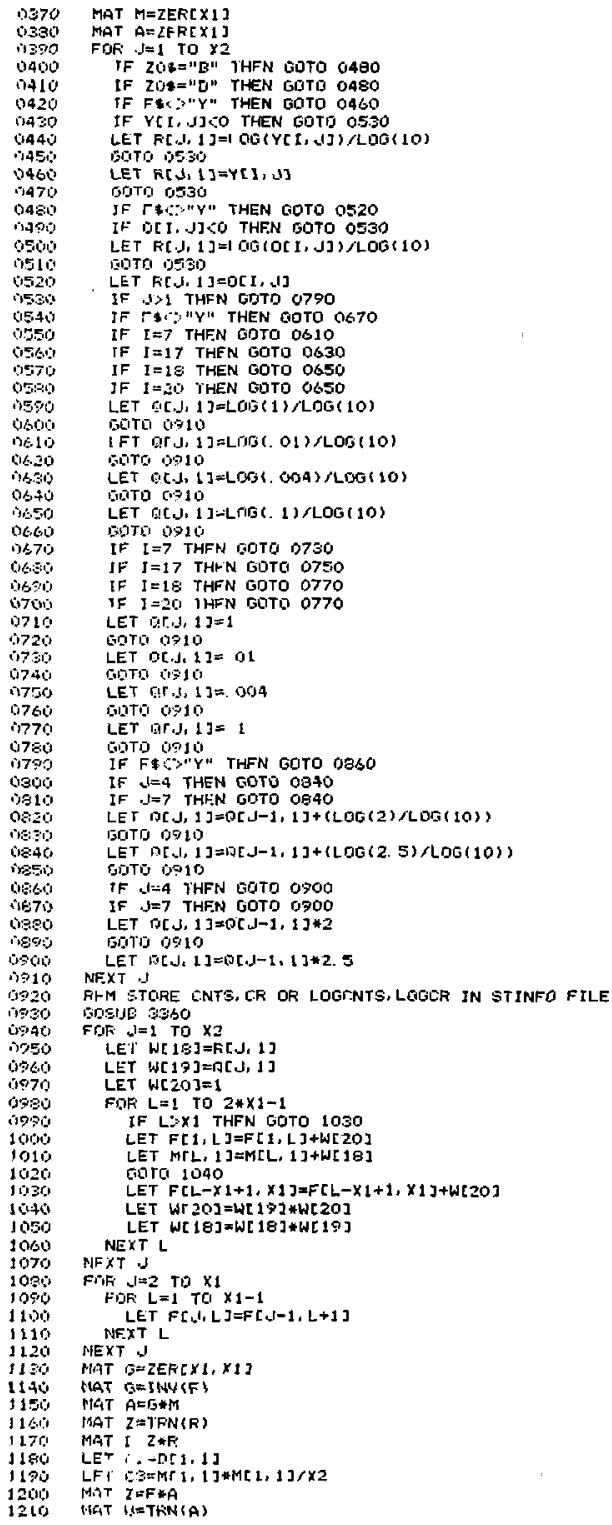




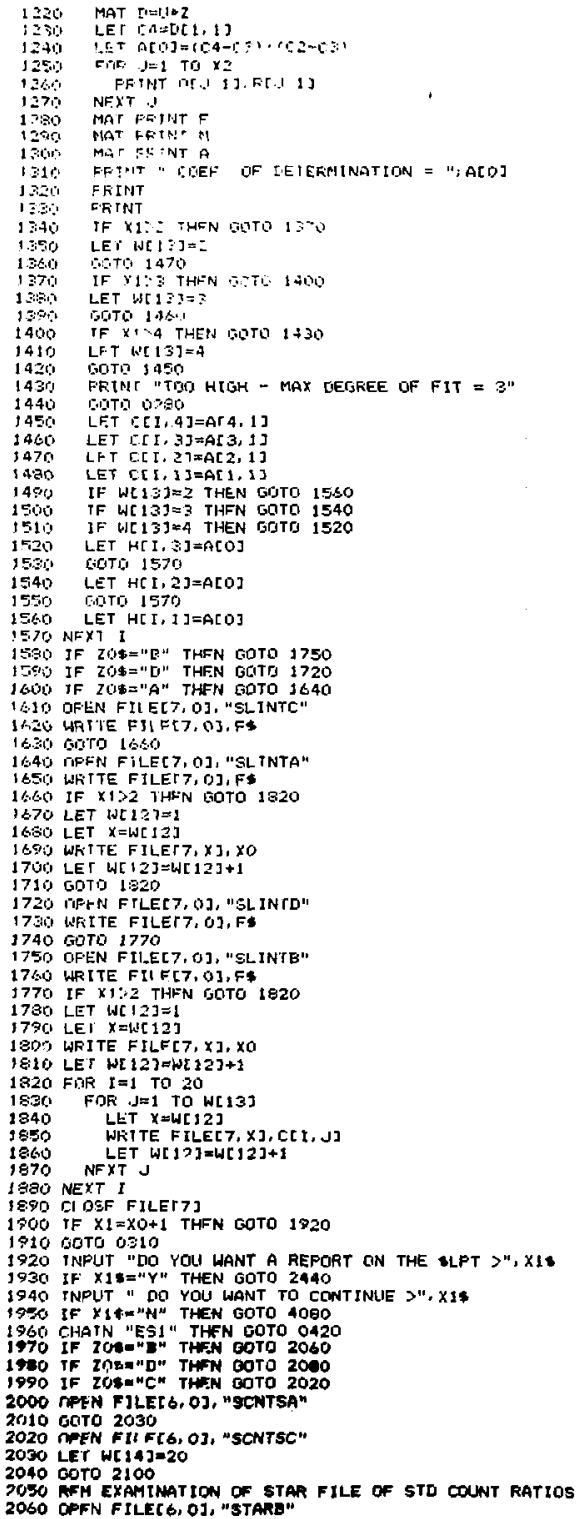


2070 GOTO 2090

2000 MPFN FTLE[G, U], "GTARD"

7090 LE'I $W[14]=20$

2100 DIM C[20,4], H[20, 3]

2110 F.FM 7 STDS

2120 FOA $H=1$ TO $T$

3130 LFT ZEx.J

2140 TF $29 \times 1$ THEN GOTO 2170

3150 LET $W[15]=1$

$\geqslant 160$ EOTO $>190$

7170 LET $W[15]=(W[14]=(28-1)+1)$

2130 RFM 20 CHANWELS FE TO RA

2190 FDF 1 1 1 TO WT:4J

2200 IF $205=$ "B" THFN GOTO 2250

2010 IF ZOS="D" THEN GOTO 2250

2220 LET $X=W[15]$

22.20 FFAD FILE[6, $X], Y[1, \mathrm{~J}]$

2240 GOTO 2270

3050 LET $x=W[15]$

2260 FFAD FILF[6, $x], 0[1, J]$

2270 LFT W[ 15] $=W[15]+1$

2200 NEXT J

2290 NEXT

3300 IF 20:" "S" THEN GOTO 2340

710 IF 2U\$="n" THFN GOTO 2340

320 INPUT "חO YGU WANT TO DUTPUT COUNTS FRCH SCNTS $2 ", K 1 *$

3300 15070 3350

2340 INPJIT "DO VIU WANT TO DUTFUT RATIOS FROM STAR $>", \times 1 *$

7550 IF $\times 1 \$=" Y "$ THFN GOTO 2370

3260 nOTO 2420

$\$ 370$ IF 70\$="E" THFN 10OTO 2410

3300 JF 208="D" THEN GOTO 2410

7390 MAT FRINT' $Y$

2400 tOTO 2420

2410 MAT FRINI 0

2420 CI GSE FILE[G]

7430 REYURN

2490 FFM RFFLIRT IF LEAST SIDUARES FIT DATA AND CCEFFICIFNTS

7450 LET EE:="STANIIARD DATA ANI CAI IBRATION COEFFICIENTS"

2460 LES E.1\%="ELEMFNT= NECREE OF FIT $\approx$ "

7479 LET BO\$="ERIJATION FOR DEGREE DF FIT -"

2480 LE'T $E 4 s=" Y=A 1+A 2 X+A 3 X^{\wedge} Z+A 4 X^{\wedge} 3 "$

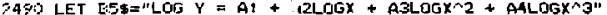

2500 LET D: $\$=$ "CNEFF ICIFNT OF DETERMINATION $="$

"SIO LET B7\$ "STD CIJNI $(X)$ STD COINTS (Y)"

za20 LET BAS="l OG STD CONC (LOOK) LEIE STD COLINTS (LOGY)"

3530 LET RSE="STD RATIGS (Y) LOG STU RATIOS (LDGY)"

2540 LET $\times 1=1$

2550 ords, 350

2560 GOGIIE 3470

2570 IJFFN FILE[ 7, 1], "LLPT"

TEGO PEINT FILF[7], "<11>"

250 FRINI FIIETJJ, TAB(10); B*

2GOL PRTNT FILE[7], TAB $(6) ! \operatorname{BQ}[1,13]$

3610 FFINT FIIE[7], TAB (s): $B 2 \$[9,23]$, XO

2620 LET $X=1$

YQSO IF $F \$=" Y "$ THFN GOTO 2750

Z\&4O PRINT FJLE[7], TAB( $b$ ); [3s; $x_{i}$ TAB(3);

ZCSO IF $x=3$ THFN GOTO 2710

2860 IF $X=2$ THFN GOTO $26 \% 0$

36.70 FRTMII FILE[7], [14:[1, 12]

28,80 GOTO 2720

7\&OQ PRTMTT FILET 7], BA\&[1, 20]

2700 G0TO 3720

2710 FRINT FILET7], B4\%

2720 LET $x=x+1$

7730 IF $X=4$ THEN GOTO $2 B 60$

2740 GOTS 2640

3750 FRINT FILE[7], TAE(d), BS* $X$, TAE(3),

2760 IF $x=3$ THEN GOTO 2820

$37 \%$ IF $X=2$ THEN GDTO 2000

2780 FRINT FII,F(7), BS\$[1,19]

27\%, GDTO 2830

?300 FRINT FILECY 1, 854 1, 303

ZE10 ODTD 2650

2820 FRINT FILE[7], BS*

Yer, LE'T $x=x+1$

2340 IF $X=4$ THFN GOTO 2860

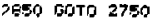

2BSO FRINT FILECT]

2870 FOR $K=1$ TO 20

Zago LET $\mathrm{K}=\mathrm{K}+2$

TEDO FRINT FILE[7J, TAE(6), BJ\$[1, $\theta] ; A Z \$[K+K-1, K+K]$

2900 IF F\$O "Y" THFN GOTO 2850

$\% \% 10$ IF $20 \%="$ E" THEN GOTO 2060 
2920 IF ZO\$="D" THFN GOTO 2970

IOS: FFINT FI!E[7], TAB(b); BEA[1, 12], TAE (24), BES[21,34]

$2 \cdot 740$ FRINT FILE[7], TAB(6), BaE[14, 19]; TAB (24); BE\$(36,41]

3t5i: DQTO $\$ 040$

2960 FEINT F[I E[7], TAB(6); B3⿻[1, 12]; TAB(24); E9E[ 16, 203

$297 \%$ PRINT FILE[7], TAB (6); BgE[14, 19]; TAB (24); B9:[31,36]

$3 \rightarrow 30$ GOTO 3040

7986 IF ZO\$ "B" THEN GDTO 3030

3000 IF TO\$="R" THEN GOTO $\$ 030$

BClo PRINT FII,FI7], TAE(S): BT:[1,12], TAE(24):B7\$[14, 27]

ROSO GLTO 30,40

7930 FRINI FILE[7], TA[3(6);E7E(1, 12]; TAB(24); B9\$[1,14]

$30 .+0$ LET $K=K-2$

Rijo FOR $J=1$ TO $\times 2$

31) 60$)$ PRINT FILE[7], TAB(b); D[K,J]; TAQ (24); Y[K, J]

3070 NFXT IJ

30:30 FRTNT FILE[7], TAE (6); "AI=";C[K, 1]; TABIZ1;; "AZ=",C[K, Z];

30190 IF $\times 1: 2$ THEN GOTO 3190

3100 FRTNT FTLE[7]

3110 FRINT FILE[T], TAE(S):BSE; H[K, 1]

3120 FRINT FILE[7]

$\because 130$ NEXT

3140 TF $x(0=1$ THEN GOTO 3340

3150. [I ISSE FILET 7 ]

3160 5051IE 3630

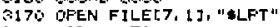

3i:AO GOTO 7370

3150 FRTNT FILE[7], TAD (15); "A.3="; C[K, 3]

3200 IF $X 1: 3$ THFN EOTO 3300

\$Z10 FRINT FILET7]

$22: 20$ PRINT FILF[7], BL\$ H[K, 2$]$

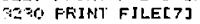

$3 Z 40$ NEXT K

2350 IF $X 0=2$ THFN GOTO 3340

3260 CI OSE FILE[7]

i27i GDSIJ 36.30

3290 OPFN F TLE[7, 1], "\$LPT"

320,300 GDTO 2470

3300 FRINT F[IF[7], TAB(15); "A4="; C[K, 4]

7310, PRINI F[LE[7], BS\$, H[K, 3]

3730 PRINT FTLE[7]

3330 NFXT $K$

3340 CLLISE FILE[7]

3550 DIJTO 1940

3360 DPFN FTLE[1, 0], "STINFO"

3370 LET $Y=W[24]$

3300 FOR $J=1$ TO 7

२390 WRTTE FILEC \&, X J, Rr L, 1 J

3400 LET $x=x+1$

3410 WFITE FILE[ $1, x], G[, S, 1]$

3420 LET $Y=X+1$

34:0 NFXT J

3440 LET WT $243 \times X$

3450 FLINSF FILE[ 1$]$

2460 FEIUIRN

$\$ 470$ LET $W[24]=1$

3430 PIFEN FiLE[1, 0], "ST INFO"

$349 \%$ FOR $1=1$ TO 20

3500 LET $x=W[2 A]$

3510 FOF, $j=1$ TO 7

3520 FIFAD FILE[ $\{, X], R[J, 1]$

$.7530 \quad$ LET $X=X+1$

3540 FFAD FILE[ $1, x], 0[3,1]$

3.5ए LET $x=x+1$

3560 LET Y $[1, J]=R[J, 1]$

\% 510 LEC DS1,J]AR J, 1]

3SBD NEXT

3590 LET W[24] $=\mathrm{X}$

3600 NEXT I

3S10 [LNSF FILE[1]

3620 RE'HINT

St30 IF 20SE"E" THFN GOTO 3970

3640 IF ZOS="D" THEN GOTO 3940

$\therefore 650$ REH

SWO REH

3670 IF 208="A" THFN GDTD 3710

3S80 OPFN FILEET, OJ, "SL INTC"

$\$ \$ 90$ REAH FILEI 7,0J, Fe

3700 GDTO 3730

3710 OPEN FILE[7,0], "SLINTA"

3720 READ FJLE[ 7,0$], F$

7730 LET $X 1=X_{1+1}$

3740 DOTO 4000

7750 LEI $W[1,3]=X 1$ 
3760 TF X132 THEN [OOTO 3930

7770 LEV W[12]=1

3790 GDTo 3900

3790 LET W[ 12$\} \times W[12]+1$

7800 IET $X=W[12]$

3810 RFAN FILE[7, $x], \times 0$

$3: 20$ LET $W[12]=W[12]+1$

TE 30 FOR $K=1$ TO 20

3840 FOR $L=1$ TO $W[13]$

TEक 0 LET $X=W[12]$

3S60 RFAD FILE[7, X], EPK,L]

NE\%O LET $N[12]=N[12]+1$

$3 B 80$ NEXT L

3E9O NFXT $K$

3700 CLOGE FILE[7]

3910 RF TURN

3920 REM

3730 RFH

3940 GIPFN FII F[7, 0], "GL INTD"

S\%5O RFAN FILE[7, 0],FE

3960 GOTO 3730

F⿻7 OF OFEN FILE[7, 02, "SL INTE"

3980 RFAD FILET 7,03,F*

¿790 G0TC 3730

4000 IF X1<4 THEN GOTO 4030

4010 DIM C[22, 4]

4020 G0T0 3750

4030 IF $X 12.7$ THFN GOTO AOST

4040 DTM C [22, 3]

4050 GOTO 3750

4060 Dim C $[22,2]$

4070 GOTO 3750

4090 FND

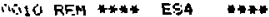

0026 EIH Cr22, 4], E[40], L[22, 10], N[22]

noji $\mathrm{CIM}$ a[ 20,7$], Y[22,7]$, W[ 24$]$

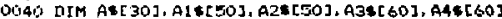

1050 [IM ASE[BO], ASE[34], A7\$[40], ABs[20], B2:[50]

poso [IM N*[5], X1\$[2], Zs[?], Zos[2], Z1*[a], Z4s[2]

is7o DIM Z5\$[6], ZE\$[15], Z7\$[15]

ULBO nTM Xas[5], ZOS[5]

IOOD DFEN FJLE[F, 3j, "GFER.VAR"

0100 RFAD FILE[S], W[4], BS

i1 10 REAT, FILECSI, 24, 20\%, 21\%, 24, 25*, 264, 275

(120 F[FAD FILE[5], W[ 1], W[Z],W[3], Za, A28

DI.30 RFATI FIIE[S], W[5], W[G], W[7]

OS 40 RFAL FILF[5], XBS, Z95

MIST ELFIEE FILE[5]

ज

i17: $[I I M E[22,4], D[2 Z, 4]$

0180 G0T5 0200

$\because 190$ DIM E[30], D[22, 4]

Q20, LET A

"1210 IF Z4t="C:" THFN GITTO 0400

1220 IF 25\%="RLANK:" THFN GOTO 0400

iิन30 IF Z9:="Y" THF.N GDTO 0400

"240 IF ZOQ ="B" THFN GOTO 0330

$\therefore$ OFEN FILET, 1, \$], "DLIMITA"

D. $\$ 0$ FRR I=3 TD 22 .

i) FIFAD FILE[ 1], L[I, 7], L[I,9]

Q3BC LET D[I, I] [ [I,7]

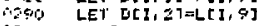

Q3r,U NEXT I

ISID CLREE F ILER 11

$0=20$ GITTO 0400

DETO OFEN FILEC , E】, "DLIHITE"

0340 FחR I=3 TO 22

C5:G FFAT FII EI 1], L[I, 7], L[I, 9$]$

G:

i70 LET D[I, 2 1=LEI, G]

OSOS NEXT I

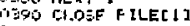

04\%) KFM

IS10 RFM FTN TS FFTRIEVE MEADERE (SAWPLES) FOA FRINTING GN LPT

UA20 REM RTN TO RETRIEUE HEADER (STDS) FOA LPT

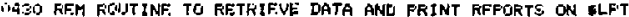

0440 IF $74 \$$ "S"C." THFN GGTO 1640

IASO FIFM DATA FUR STL FIFPCATS

O4GU LET AI "TIATE STANDARD" RUNM PROTRAM"

11470 IF $766 " Y "$ THFN IDTD 0930

O4BO TF 20\%" "G" THEN GOTO DS30

i490 IF 2DE"U" THEN FOTO OS30 
WOOO RFM EI ANK STD REPORT

"15L Q GPEN FILEF 3,3$]$, "BLF ILEAB"

0.20 60TO 0.540

ITSO OPEN FILET 3,3$]$, "ELFILECD"

S540 FIR $I=1$ TO 23

135ti IF I'>I THEN GDTO O570

U5,0 FEA[ FILF[3],A35, 2B, A4s, W[3], AEs

DEPG IF ZS\$="Y" THEN OSTO DSOO

05:50 FFAD F[IE[3], I [ [, 1], L[I, 2], BC I ]

10,90 DOTD OS4O

TE.OO IF I\%1 THFN GDTO 0630

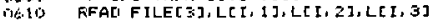

0630 GOTO OS.40

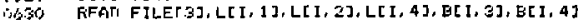

(1E) NEXT I

iEST ELTSE FILE[3]

DE 60 APF'N F]LE[3, 1], "\$LFT"

nETO PRTNT FILE[3], "<11>"

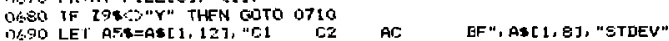

0700 ETTO 0720

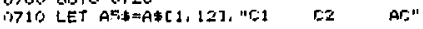

U 30 FOR $I=1$ TB 22

IT:3 IF $1: 1$ THEN BUTO 0800

0740 b0:DIE 2310

$\therefore \rightarrow 50$ FRTNI FILE[:3], Z8

QTEO PFINT FILE[:3], A4\$, W[3]

IT70 FRTNT FILET3J

OTSO PRINT FILE[3], ASE

179\% FRTNT FIIE[\%]

0300 IF Z\$\$"Y" THEN GOTO 0890

INS10 IF I $>1$ THFN GOTO 0840

UE:0 PFINT FJLE[3], TAB (b);A2*[I+I-1,I+I]; TAB (10);LI[,1]; TAB(I6);L[I, 2]; TAB(2Z);L[I,3]

(1)

(2:

is:50 GOTOD 0900

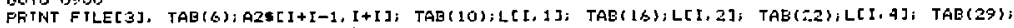

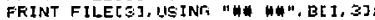

PRINT FILE[3], TAB(B);

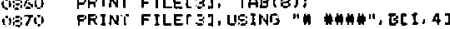

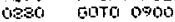

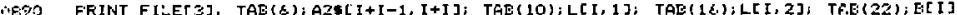

NOOO NEXT I

JOIO CLOEF FILE[.Z]

WZO FHAJN "ES.2" THFN GIJTO 2630

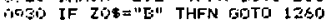

0940 IF 7\%, "L" THEN GOTO 1260

1950 FEM GTD REFDKT PRTISRAMS A \& $\mathrm{C}$

U9GQ APFN FILE[ 2,3$]$, "STAF ILEAC"

ISTO FOR $I=1$ TI 22

GQSO IF TSI THFN SOTO 1030

DESO FFATI FILE[3], A:\$\$, 28, A4\$, W[3], A5\$

1000 TF 2950 "Y" THFN GOTO 1030

1010 EFATI FILET $\$], L[I, 1], L[I, 2], L[I, 4]$

1020 GOTO 1040

1030 FFATI FILE[3], L[I, I], L[I, 2], LEI, 4], NT I I

1040 NEXT I

TOSO CI DEF FILET 3 .

1060 UPFN FILE[3,1], "ELPT"

1070 PRTN' FILET 3 ." "6112"

$10 \exists O$ LET AEt=At[1,12], "C1 C2 AC ACEC"

1090 FGR $I=1$ TO 22

1100 TF I $>1$ THFN GOTO 1190

1110 GDSIJL 2310

1120 FRTNT FTLE[3], 29

1130 FRTNT FILET3],A4*, W[3]

1140 FEINT FILF[3]

1150 PRTNT FILE[3], ASE

1160 PRINT FJLE[3]

1170 PFINT FILE[3], TAB(b), A2S[1+1-1,1+1J; TAB(10);L[I,1]; TAE(16);L[I, 2]; TAE(ZZI;L[1,4]

$1130 \quad$ GOTO 1730

1190 IF $790=" Y "$ THEN GOTO 1210

I 200 IF $I=2$ THEN GOTO 1170

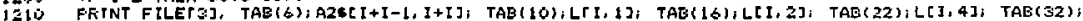
IZZO FRINT FILE[3], USTNG "-NHWH. HWH", NEI]

$12,30^{\circ}$ NEXT 1

1240 GOTO 1500

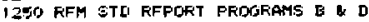

1260 rifFN FILE[3, ;], "STAF ILEBL"

770 FOR IEI TO 32

1290 IF $I: 1$ THEN GOTO 1300

IIST FFAII FILE[3], A.A , Z3, A4 B, w[3], A5:

1300 TF T:3 THEN GOTO 1330

131, FFAn FILET;], L[1, L],L[1, 2], L[1,4],L[I,7]

1.720 GOSO 1300

1330 RFARI FILE[3], LE $[, 1], L[I, 2], L[1,4], L[I, 7], N[$ I ]

1340 NEXT 1 


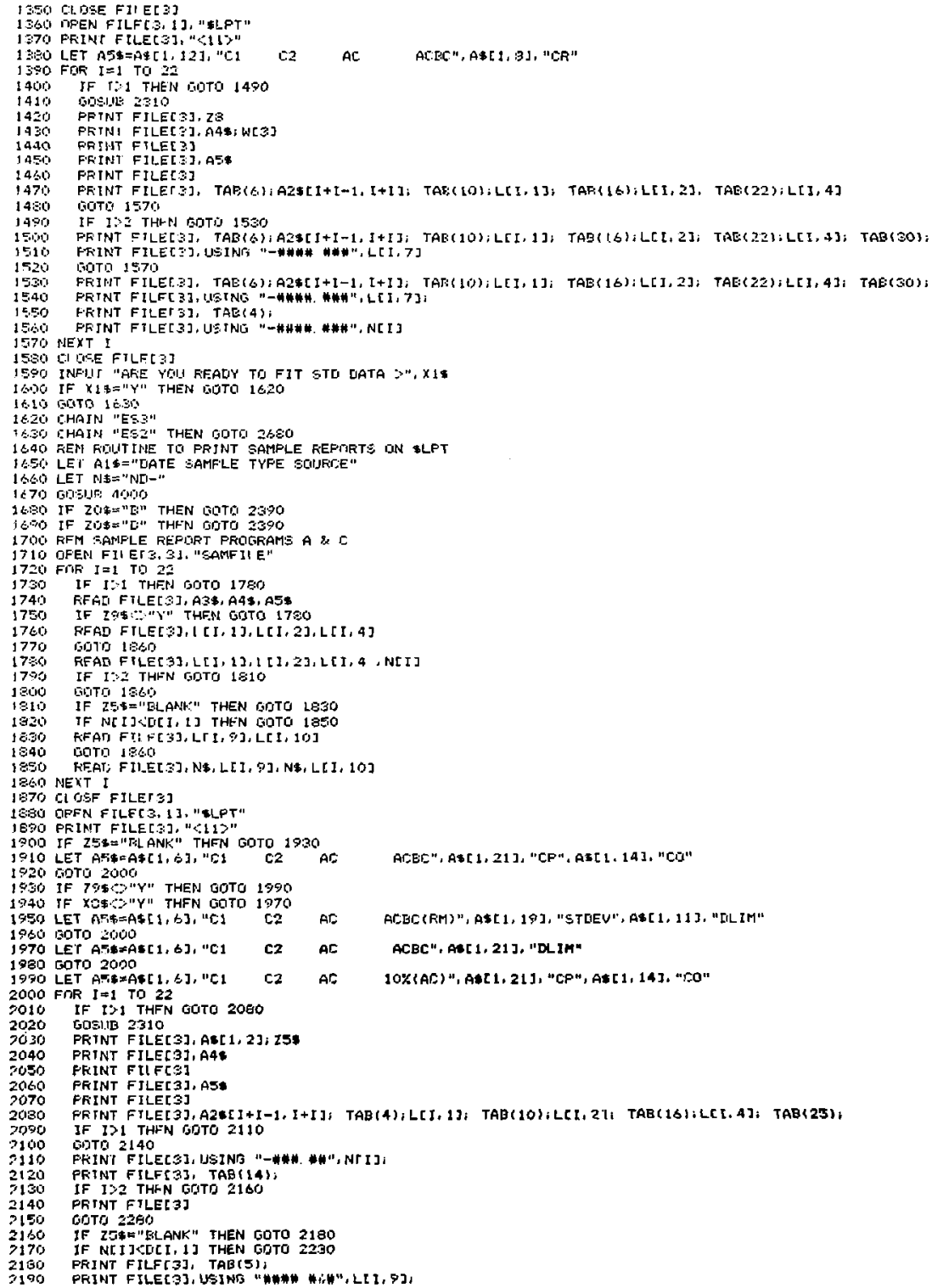




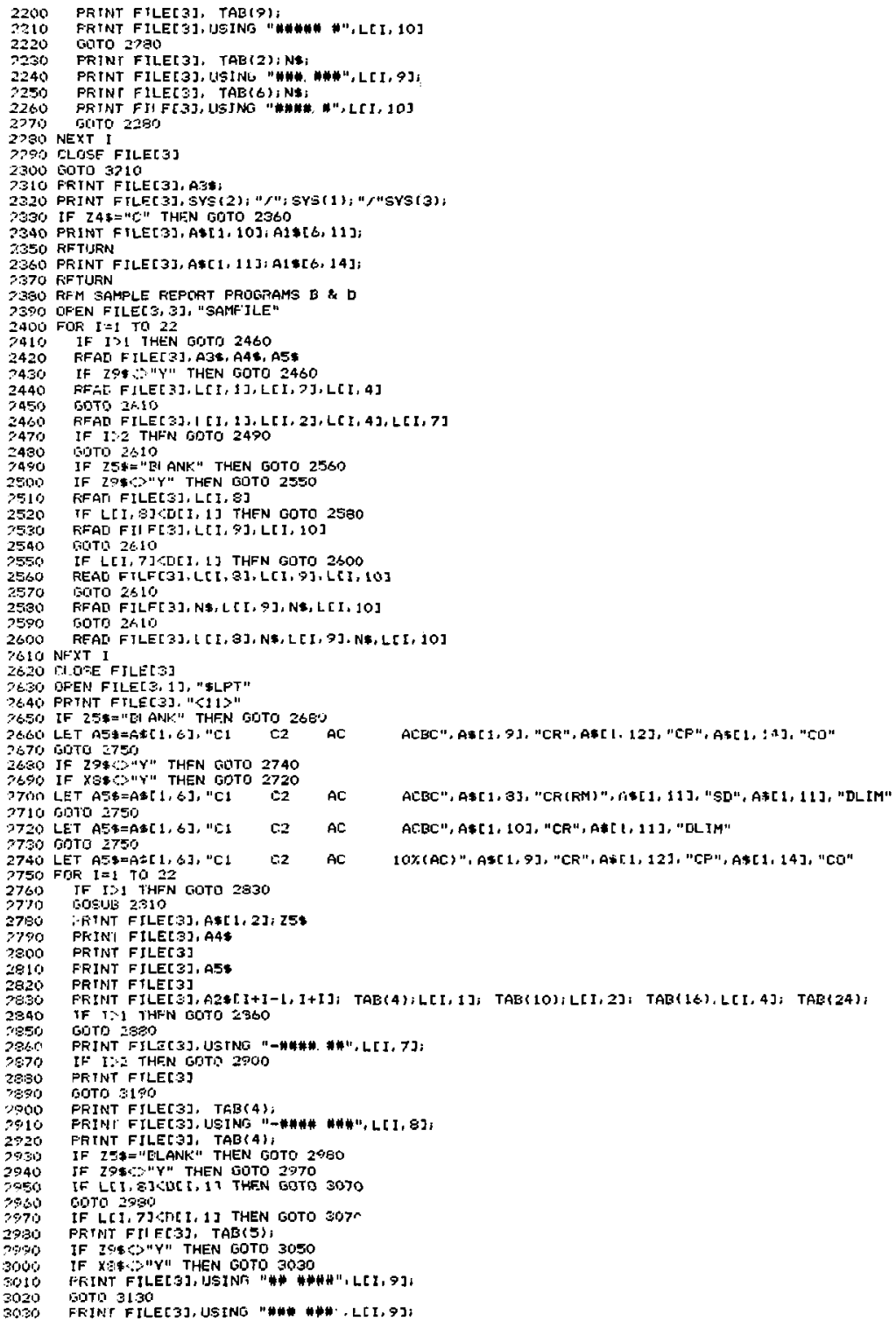




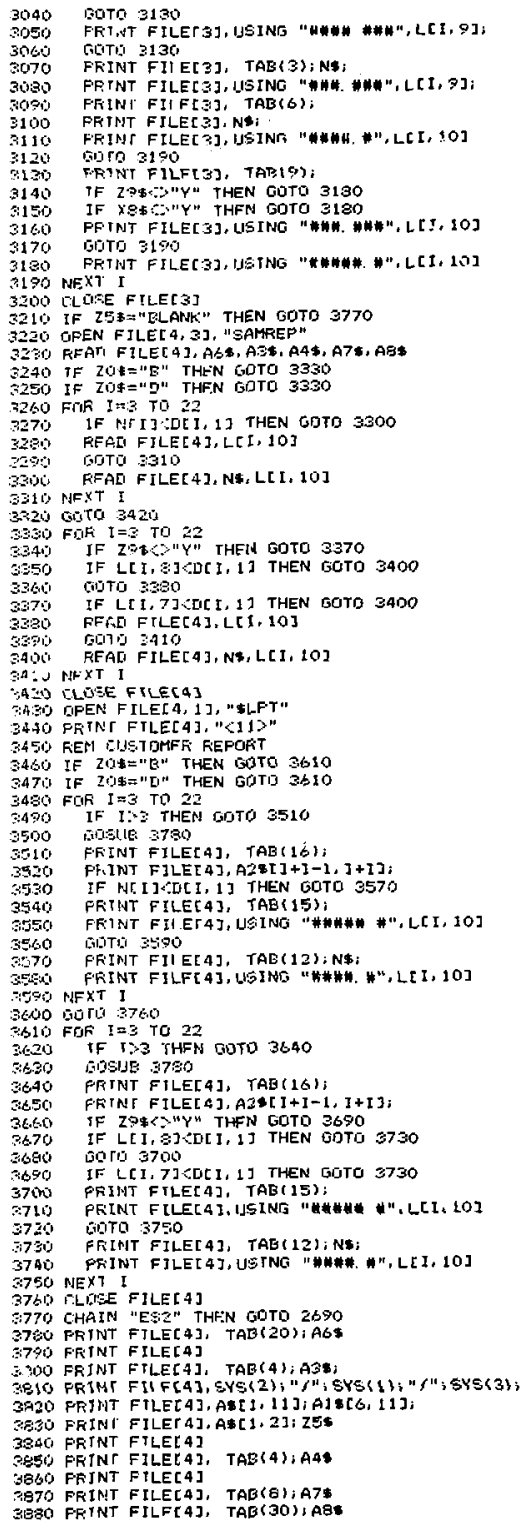


A\$90 PRINT FILER 4$]$

3900 RETLIRN

10 FDF $[4=1$ TO क

3920 FRINT FTLE[3]

$\$ 930$ NFXT IA

3940 RETLIFN

FFO FGR $14=1$ TO

GWSC FRTNT FTLE[4]

$\$ 970$ NEXT I4

3980 RETLIRN

3900 ENII

4000 IF $20 \%=" F "$ THEN GOTO 4110

4010 IF $70 \$=$ "C" THEN GOTO 4090

4020 IF ZO\$z"n" THFN GOTO 4130

$40 \Xi 9$ DFEN FILE[ 1,3$]$, "DLA"

4040 FaR I $1=3$ TO 22

4050 FFAN FILE[1], D[I 1, 1], D[ 11,2$], D[11,3], 0[11,4]$

4060 NEXT II

4ח7D CL DSE F ILET 1 I

40SO REYIIFN

$45 \% 0$ DPEN F ILE [ I, 3], "DLC"

4100 GOTO 4040

4110 OFFN F[LET 1,3$],$ "DLB"

4120 GOTO 4040

4130 DPEN FILE[ 1, 3], "DLD"

4140 DOTO 4040

4150 FFTUFN

4160 FND 


\title{
APPENDIX D \\ EMISSION SPECTROMETER PROGRAMS: \\ DESCRIPTIONS OF VARIABLES, ARRAYS, AND FILES
}

\section{Variables (ES1)}

Variablc
I
J
X
Z
Z1
Z8
B9

\author{
Description \\ Control variable in a FOR loop \\ Control variable in a FOR loop \\ Location for data currently being acquired by CALL $3, X$ \\ Milliliters of original sample \\ Milliliters of processed sample \\ Standard number \\ Counter
}

\section{String Variables (ES1)}

String Variable
A2S
B2\$
X1\$
Z\$
Z0\$
$24 \$$
$25 \$$
$26 \$$
$27 \$$
$28 \$$
Z9\$

Description

Element symbols, list 1

Element symbols, list 2

$\mathrm{Y}$ or $\mathrm{N}$; "Is data $\mathrm{OK}$ "

Y or N; "Is this a blank standard"

A. B, C

$A$ or $C$, analysis or calibration mode

Sample number

Sample type

Sample source

$\mathrm{Y}$ or $\mathrm{N}$; "Do you want to establish new detection limits"

$\mathrm{Y}$ or $\mathrm{N}$; "Do you want BKG correction $\mathrm{Y}$ or $\mathrm{N}$ "

\section{Arrays (ES1)}

$\begin{array}{cc}\text { Array } & \text { Dimension } \\ \text { C } & 22 \times 4 \\ \text { E } & 40 \times 1 \\ \text { W } & 24 \times 1\end{array}$

Description

Data array, initial excitation data

Data array, initial excitation data

Various information, e.g. $W(2)=$ blank run No.,

$W(3)=$ standard run No., $W(4)=$ control variable,

$W(5)=$ excitation No., $W(6)=$ run selection,

$W(7)=$ run selection. 
Variables (ES2)

Variable
A
B
B1
D1
D2
I
J
K
L
X
X0
X1
X3
Z8

\author{
Description \\ Dummy arithmetic variable in expression: LOG(A)/LOG(10) \\ Vuriable contuining length of string variable \\ Variable containing length of string variable \\ First approxination of coneentration \\ Second approximation of concentration \\ Control variable in a FOR loop \\ Control variable in a FOR loop \\ Control variable in a FOR loop \\ Contral variable in a FOR loop \\ File record number \\ Degree of fit \\ Control variable in a FOR loop \\ Internai standard location \\ Standard number
}

\title{
String Variables (ES2)
}

\begin{tabular}{|c|c|}
\hline String Variable & Description \\
\hline AS & 30 space characters \\
\hline A $1 \$$ & "DATE SAMPLE TYPE SOURCE" \\
\hline A2S & Elenent symbols, list 1 \\
\hline A3S & Report header information. combination of strings and variables \\
\hline A4\$ & Report header information combination of strings and variables \\
\hline A5s & Report header information, combination of strings and variables \\
\hline A65 & Report header information, conbination of strings and variables \\
\hline A7s & Report header information, combination of strings and variables \\
\hline A8\$ & Report header information, combination of strings and variables \\
\hline B2\$ & Element symbols. list 2 \\
\hline F\$ & Y or $N, "$ Log or normal equation" \\
\hline F\$ & Y or N, "Log or normal equation" \\
\hline N\$ & "ND-" \\
\hline $\mathrm{X} 1 \mathrm{~s}$ & Y or $\mathrm{N}$ \\
\hline ZS & Y or $N$, blank standard \\
\hline $\mathrm{zo} \$$ & A, B, C, or D, spectrometer progrum A, B, C, or D. \\
\hline ZIS & Date \\
\hline $\mathrm{Z} 4 \$$ & A or $C$, analysis or caljbration mode \\
\hline Z5\$ & Sample No. \\
\hline Z6\$ & Sample type \\
\hline Z7\$ & Sample source \\
\hline
\end{tabular}

\section{Arrays (ES2)}

$\begin{array}{cc}\text { Array } & \text { Dimension } \\ \text { B } & 30 \times 1 \\ \text { C } & 22 \times 4 \\ \text { D } & 22 \times 2 \\ \text { E } & 40 \times 1 \\ \text { L } & 22 \times 10 \\ \text { N } & 22 \times 1 \\ \text { W } & 24 \times 1 \\ \text { Y } & 22 \times 4\end{array}$

\section{Description}

Background counts from BLANK

Data array, data retrieved from INDAT file

Detection linits, equivalent counts or count ratios

Dati array

Contains intermediate and final caleulated data

Amay for background corrected counts, programs A and C

Various information (sec listing of ESI arrays)

Standard calibration coefficients 


\section{Variables (ES3)}

Variable
C2
C3
C4
I
$\mathrm{J}$
$\mathrm{K}$
$\mathrm{X}$
$\mathrm{X} 0$
$\mathrm{X} 1$
$\mathrm{X} 2$

\section{Description}

Variable used to calculate coefficient of deternination (see Appendix D, least squares) Variable used to sulculate coefficient of determination (see Appendix D, least squares) Variable used to calculate coefficient of determination (sec Appendix D, least squares) Control variable in a FOR loop

Control variable in a FOR leop

Control variable in a FOR Ioop

File record number

Degree of fit

Contcol variable in a FOR loop

Number of standards

\section{String Variables (ES3)}

String Variable

BS

B1s

B38

B4\$

B5S

B6S

B7\$

B8S

B9\$
Description

"STANDARD DATA AND CALIBRATION COEFFICIENTS"

"ELEMENT $=$ DEGREE OF FIT $=$ "

"EQUATION FOR DEGREE OF FIT - -

$" Y=A 1+A 2 X+A 3 X 2+A 4 X 3 "$

"LOGY $=A 1+A 2 L O G X+A 3 L O G X 2+A 4 L O G X 3 "$

"COEFFICIENT OF DETERMINATION"

"STD CONC $(X)$ STD COUNTS (Y)"

"LOG STD CONC (LOGX) LOG STD COUNTS (LOG Y)"

"STD RATIOS (Y) LOG STD RATIOS (LOG Y)"

\section{Arrays (ES3)}

$\begin{array}{cc}\text { Array } & \text { Dimension } \\ \text { C } & 22 \times 4 \\ \text { H } & 22 \times 3 \\ \text { O } & 20 \times 7 \\ \text { W } & 24 \times 1 \\ \text { Y } & 20 \times 7\end{array}$

Description

Data array, data retrieved from standard coefficients file

Coeffjcients of determination

Stundard count ratios, seven standards

Various information, refer to ESI arrilys

Standard counts, seven standards

\section{Variables (ES4)}

$\begin{array}{cl}\text { Variable } & \text { Description } \\ 1 & \text { Control variable in a FOR loop } \\ \mathbf{Z 8} & \text { Standard number }\end{array}$


String Variables (ES4)

Siring Variable
A\$
A1\$
A2S
A35
A4\$
A4\$
A5\$
A6\$
A7\$
A8\$
B2\$
F\$
NS
X1\$
2\$
Z0\$

Description

Same as ES2

Same as ES2

Same as ES?

Sante as ES2

Same as ES2

Same as ES2

Same as ES2

Same as ES2

Sume as ES2

Salne as ES2

Same as ES2

Sume as ES?

Same as ES2

Same as ES2

Same as ES2

Sume as ES2
Arrays (ES4)

$\begin{array}{cc}\text { Array } & \text { Dimension } \\ \text { B } & 30 \times 1 \\ \text { C } & 22 \times 4 \\ \text { D } & 22 \times 2 \\ \text { E } & 40 \times 1 \\ \text { L } & 22 \times 10 \\ \text { N } & 22 \times 1 \\ \text { W } & 24 \times 1 \\ \text { Y } & 22 \times 4\end{array}$

Description

Same as ES2

Same as ES2

Same as ES2

Same as ES2

Same as ES2

Same as ES2

Sanie us ES2

Same as ES2

Files

Name of file

Description

Created

Used

(write file) (read file)

INDAT Contains initial excitation data for 22 elements for up to four replicate excitations.

ES1

ES2

SPECV::R Contains spectrometer program variables that must be carried through-

ES1

ES1

DLIMITA out the four programs.

DLIMITB

Contuins detection limits, (A) for direct counts method, (B) for count

$\mathrm{ES} 2$

ES2

BCOUNTSAB ratio method.

BCOUNTSCD

Contain background counts, (AB) for element list 1 , (CD) for elenent

ES2

ES2

BLFILEAB Contain data for standard blanks. (AB) for element list 1, (CD) for or samples.

ES2

ES4

STAFILEAC element list 2. The data stored in these files arc later retrieved for generation of a report of the standard blank.

STAFILEBD

SCNTSA

SCNTSA

STAR B

STAR D

SAMFILE

SAMREP

STINFO
Contain data relative to stundard runs. (AC) direct counts method, (BD) count ratio method. The data stored in these files are later retrieved to generate reports of standard runs.

Contain standard counts data. (A) for element list 1, (C) for element list 2. These are random access files with the data filed in records corresponding to the standard No. The data stcred in these files are later retrieved when the least squares fit of standard data is carried out.

Contain standard ratio dat, (B) for element list l, (D) for element list 2. These are random access files, etc., see above.

Contains sample datu. These data are later retrieved to generate a laboratory sample data report.

Contains sample results. These data are later retrieved to generate a customer analysis report.

Contains standards information, concentration, and corresponding count or count ratio for each element in each of seven standards. The data are retrieved to generate a report of the least squares fit parameters. 
SLINTA

SLINTB

SLINTC

SLINTD

BFAB

BFCD

DLA

DLB

DLL.
Contain the least squares fit cocfficients, the degree of the fit, and whether a log or normal equation was used. The data are retrieved for use in calculating concentrations in unknown samples.

Contains background factors for use in dynamic background correc-

ES2

ES2 tion. BFAB - factors for list 1, programs A and B, BFCD - factors for element list 2, progranss $C$ and $D$.

Contains detection limits for elements determined by method using

ES2

ES2 dynamic background correction. 


\section{APPENDIX E \\ EMISSION SPECTROMETER SAMPLE DATA REPORTS}

Detailed Analytical Data Report

$\begin{array}{ll}\text { DATE } & 3 / 12 / 1976 \\ \text { TYPE } & \text { WATER }\end{array}$

C1 $\mathrm{C} 2 \quad \mathrm{AC} \quad \mathrm{ACBC}$

\begin{tabular}{lrrlr} 
& Cl & C2 & \multicolumn{1}{c}{ AC } & ACBC \\
In & 62 & 66 & 64 & \\
Y & 573 & 598 & 585.5 & 585.50 \\
$\mathrm{Fe}$ & 912 & 944 & 928 & 713.00 \\
$\mathrm{Zn}$ & 247 & 257 & 252 & 93.50 \\
$\mathrm{Cd}$ & 322 & 329 & 325.5 & 173.50 \\
$\mathrm{As}$ & 539 & 566 & 552.5 & 96.50 \\
$\mathrm{Mn}$ & 835 & 877 & 856 & 690.50 \\
$\mathrm{Cu}$ & 744 & 777 & 760.5 & 611.50 \\
$\mathrm{Ag}$ & 592 & 591 & 591.5 & 19.00
\end{tabular}

SAMPLE 1200

SOURCE RIVER
CP

11.319

20.240

14.768

5.455

7.599

10.484

ND-0.046
CO

11318.6 20239.9

14768.2 5454.8 7598.7 10483.9 ND-45.5

\section{Spectrographic Analysis Report}

\begin{tabular}{lr} 
DATE 3/12/76 & \multicolumn{1}{c}{ SAMPLE 1200 } \\
TYPE WATER & $\begin{array}{c}\text { SOURCE RIVER } \\
\text { Concentration, } \\
\mu g / l i t e r\end{array}$ \\
Element & 11318.6 \\
\hline Fe & 20239.9 \\
Zn & 14768.2 \\
Cd & 5454.8 \\
As & 7598.7 \\
Mn & 10483.9 \\
$\mathrm{Cu}$ & ND- 45.5 \\
Ag & \\
\hline
\end{tabular}




\section{APPENDIX F \\ FLOWCHARTS OF THE ASSEMBLY LANGUAGE CALLS AND DESCRIPTIONS OF MISCELLANEOUS SUBROUTINES AND CONVENTIONS}

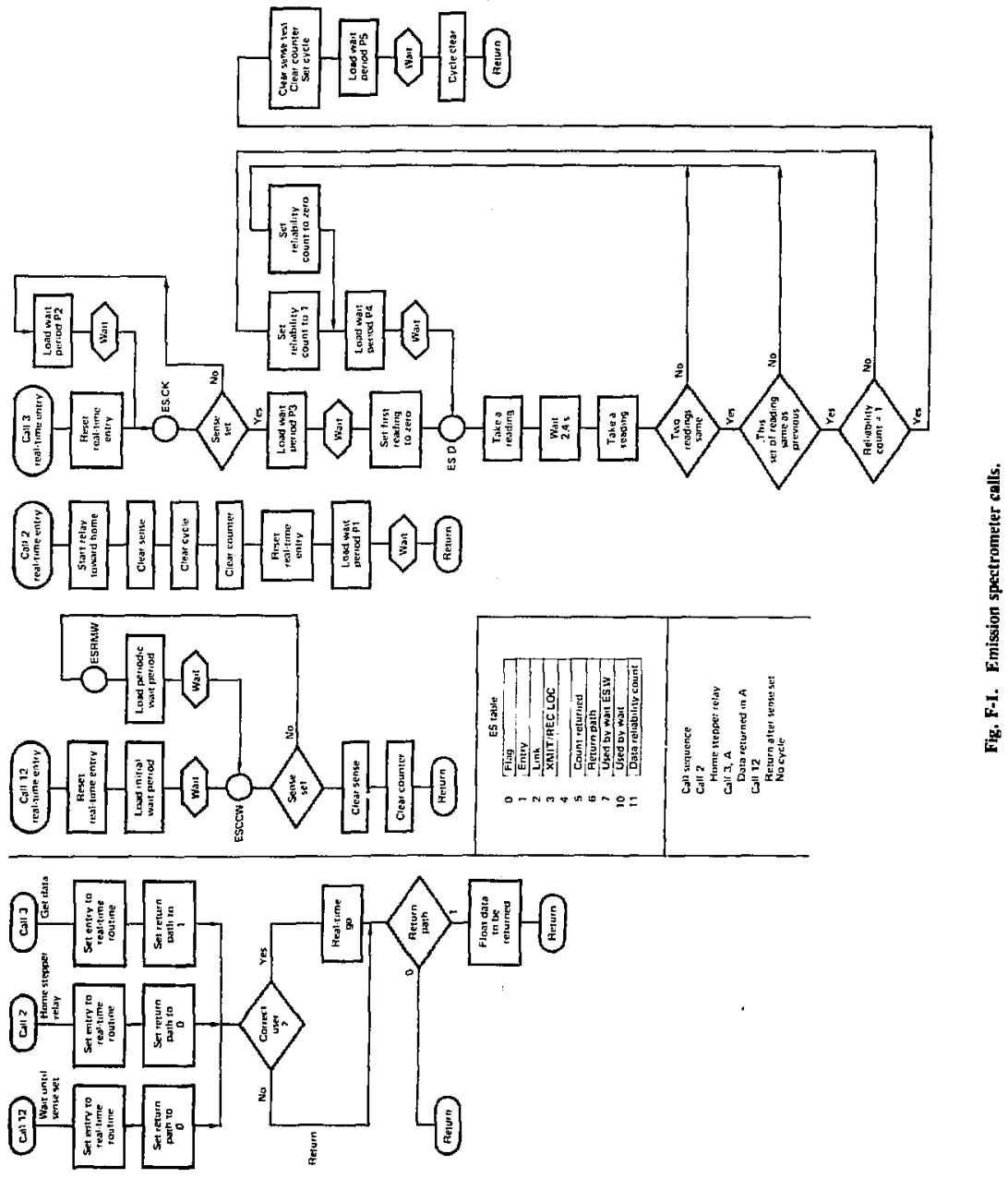


The following are descriptions of miscellaneous subroutines and conventions used by the emission spectrometer assembly language programs.

\section{Subroutines}

- ES.W - This is a subroutine used throughout the emission spectrometer real-time code (E.S. RTC) for waiting a given period of time.

- FRRT - This is a subroutine used by the E.S. RTC. It is the final exit point from the real-time data acquisition routine.

- RECS - This is a subroutine used in the emission spectrometer call routine. It suspends the BASIC user while data are being acquired.

\section{Conventions}

- C3 - This is a constant used wo address in the emission spectrometer call routtne.

- TR3 - This is a page-zero locaticn (temporary register) that is saved and restored by BASIC. It is a linkage table address of the BASIC subroutine. 


\section{APPENDIX G. \\ EMISSION SPECTROMETER ASSEMBLY LANGUAGE PROGRAMS.}

\begin{tabular}{|c|c|c|c|c|}
\hline \multirow{3}{*}{$\begin{array}{l}\text { ES.R: } \\
\text { PI: }\end{array}$} & \multicolumn{4}{|c|}{ E.S. RTC ROUTINE } \\
\hline & JMP@ & 4.2 & ; & VECTOR TO ENTRY POINT \\
\hline & 500 & & ; & RELAY HOME TIME PERIOD \\
\hline P2: & 100 & & : & SENSE DONE WAIT LOOP \\
\hline P3: & 200 & & ; & AFTER SENSE DONE BEFORE FIRST POINT \\
\hline P4: & 40 & & ; & BETWEEN POINTS \\
\hline P5: & 20 & & : & CYCLE SET PERIOD \\
\hline P6: & 100 & & & \\
\hline .ESRW: & ES. MR & & & \\
\hline ESIW: & ES. W & & & \\
\hline .ESRH: & ES. $\mathbf{H}$ & & & \\
\hline .ESRS: & ES. S & & & \\
\hline .ESRT: & ES. $V$ & & & \\
\hline \multirow[t]{5}{*}{ ES. MR: } & LDA & $1,$. ESRT & ; & WAIT ADDRESS \\
\hline & STA & $1,4.2$ & ; & NEXT \\
\hline & LDA & $1, \mathrm{P6}$ & ; & 5 SEC WAIT \\
\hline & JSR@ & ESIW & ; & WAIT \\
\hline & JMP & ESCCW & & \\
\hline \multirow[t]{2}{*}{ ESRMW: } & LDA & $1, \mathbf{P} 2$ & ; & WAIT \\
\hline & JSR@ & ESIW & & \\
\hline \multirow[t]{5}{*}{ ESCCW: } & SKPDN & DC. F & ; & GET SENSE DONE \\
\hline & JMP & ESRMW & & \\
\hline & ESCCO+DC & A & ; & COUNTER CLEAR \\
\hline & ESCSS+DC. & $\mathbf{F}$ & ; & CLEAR SENSE SET \\
\hline & JMP@ & PFRRT & & \\
\hline \multirow[t]{10}{*}{ ES. H: } & ESHMS +DC. & $\mathbf{F}$ & & : HOMESET \\
\hline & ESCSS+DC. & F & & ; CLEAR SENSE SET \\
\hline & ESCYC+DC. & F & & ; CYCLE CLEAR \\
\hline & ESCCO+DC. & A & & ; COUNTER CLEAR \\
\hline & LDA & 1., ESRT & ; & LOAD WAIT ADDRESS \\
\hline & STA & $1,4,2$ & ; & NEXT ENTRY \\
\hline & LDA & $1, \mathrm{P} 1$ & ; & 5SECONDS \\
\hline & JSR@ & ESIW & ; & WAIT \\
\hline & ESHMC+DC. & F & & ; HOME CLEAR \\
\hline & $\begin{array}{l}\text { JMP@ } \\
\text { FRRT }\end{array}$ & +1 & & \\
\hline \multirow[t]{3}{*}{ ES.S: } & & $1,$. ESRT & ; & LOAD WAIT ADDRESS \\
\hline & STA & $1,4,2$ & ; & NEXT ENTRY \\
\hline & JMP & ES, CK & ; & IS SENSE DONE \\
\hline \multirow[t]{2}{*}{ ES. SW: } & LDA & $1, \mathbf{P 2}$ & ; & SENSE WAIT LOOP \\
\hline & JSR@ & ESIW & ; & WAIT \\
\hline \multirow[t]{7}{*}{ ES. CK: } & SKPDN & DC. $F$ & : & SKIP SENSE DONE \\
\hline & JMP & ES. SW & ; & WAIT MORE \\
\hline & LDA & 1,P3 & ; & WAIT BEFORE THE FIRST POINT IS TAKEN \\
\hline & JSR@ & ESIW & ; & WAIT \\
\hline & SUB & $0,-$ & ; & ZERO \\
\hline & STA & $0,5,2$ & : & READING \\
\hline & JMP & ES. D & ; & SKIP WAIT LOOP FIRST TIME \\
\hline \multirow[t]{2}{*}{ ES. I: } & SUBZL & 0,0 & ; & ONE \\
\hline & JMP & ES. $M+1$ & & \\
\hline
\end{tabular}


ES. $M$

$\begin{array}{ll}\text { SUB } & 0.0 \\ \text { STA } & 0,11,2 \\ \text { LDA } & 1, P 4 \\ \text { JSR@ } & \text { ESIW }\end{array}$

; ZERO

ES. D: DIA

$\begin{array}{ll}\text { DIA } & 0, D C . \text { G } \\ \text { JMP } & .+1 \\ \text { JMP } & .+1 \\ \text { JMP } & .+1 \\ \text { DIA } & 1, \text { DC. G } \\ \text { SUB } & 0,1, \text { SZR } \\ \text { JMP } & \text { ES. M } \\ \text { LDA } & 1,5,2 \\ \text { STA } & 0,5,2 \\ \text { SUBZ } & 1,0, S Z R \\ \text { JMP } & \text { ES. M } \\ \text { DSZ } & 11,2 \\ \text { JMP } & \text { ES. I } \\ \text { ESCSS+DC. } & \text { F } \\ \text { ESCCO+DC. } & \text { A } \\ \text { ESCYS+DC. } & \text { F } \\ \text { LDA } & 1, \text { P5 } \\ \text { JSR@ } & \text { ESIW } \\ \text { ESCYC+DC. } & \text { F } \\ \text { JMP@ } & \text { PFRRT }\end{array}$

: WAIT BETWEEN READINGS

: WAIT

: GET DATA

; COUNTER CHANGING NOW!

; LAST

; THIS

; SKIP SAME

; STILL CHANGING, WAIT

PFRRT: FRRT

;E. S.

CALL ROUTINE

ES. TP: ES. T

ESPSW: LDA

SUB

JMP

1.,ESRW

0,0

ES. CR

ES. $\mathrm{CH}$ LDA

SUB

1, ESRS

0,0

ES. CR

ES. CS: LDA

SUBZL

I...ESRS

ES. CR: STA

0,0

2,TR3

LDA

STA

2,ES. TP

STA

$0,6,2$

SUB

STA

$1,4,2$

STA

0,0

$0,3,2$

LDA

$0,0,2$

ADD

$0, \mathrm{C} 3$

RECS

DSZ

JMP@

2,0

SUB

LDA

JSR@

IMP

LDA

6,2

TR3

0,0

$1,5,2$

.FLOT

$+1$

3,TR3

LDA

$2,0,3$

DOBS

2,FPUI

CYCLE SET WAIT

; CLEAR SENSE TEST

; COUNTER CLEAR

CYCLE SET

; WAIT

; RETURN TO CALL ROUTINE 


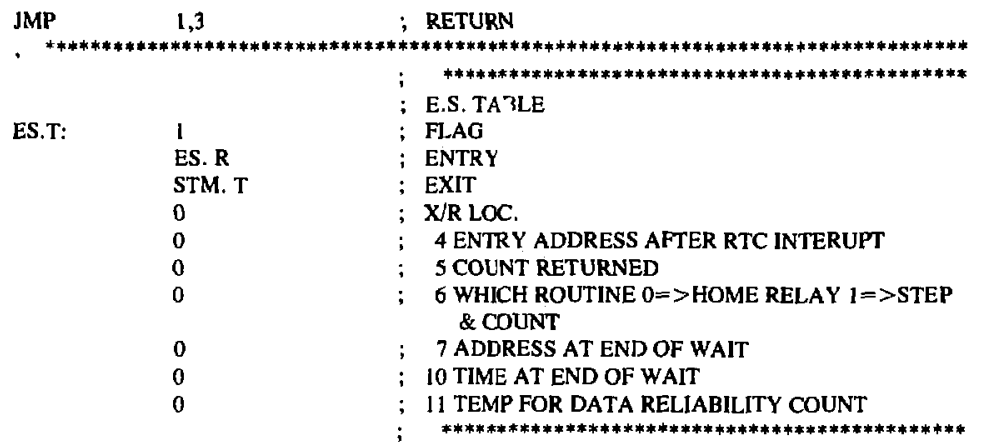




\section{APPENDIX H \\ LINE PRINTER REPORT OF LEAST SQUARES DATA-EMISSION SPECTROMETER PROGRAM*}

\begin{tabular}{|c|c|c|}
\hline Standard Data and Calibration Coefficients & 20 & 0.58740583 \\
\hline & 40 & 0.90606364 \\
\hline Standard data & 100 & 1.6023334 \\
\hline Degree of fit $=1$ & $A 1=0.15531757$ & $\mathrm{~A} 2=1.52782[8 \mathrm{E}-02$ \\
\hline $\begin{array}{l}\text { Equation for degree of fit }-1 Y=A 1+A 2 X \\
\text { Equation for degiee of fit }-2 Y=A 1+A 2 X \\
+A_{2} X \wedge 2\end{array}$ & \multicolumn{2}{|c|}{ Coefficient of determination $=0.96623691$} \\
\hline \multicolumn{3}{|l|}{ Equation for degree of fit $-3 \mathrm{Y}=\mathrm{A} 1+\mathrm{A} 2 \mathrm{X}$} \\
\hline$+\mathrm{A} 3 \mathrm{X} \wedge \mathbf{2}$ & Std Conc $(\mathrm{X})$ & Std ratios $(Y)$ \\
\hline$+A 4 X \wedge 3$ & 1 & $5.5455359 \mathrm{E}-02$ \\
\hline & 2 & $4.8521984 \mathrm{E}-02$ \\
\hline Element $=\mathrm{Fe}$ & 4 & $9.6239271 \mathrm{E}-02$ \\
\hline Std conc $(X)$ & 10 & 0.13961266 \\
\hline 9.28498 I $9 \mathrm{E}-02$ & 20 & 0.32850595 \\
\hline 0.27119507 & 40 & 0.64487926 \\
\hline 0.56953228 & 100 & 1.6804573 \\
\hline 1.4584252 & $\mathrm{Al}=8.8064215 \mathrm{H}-03$ & $A 2=1.6565124 \mathrm{E}-02$ \\
\hline $2.0 n 89453$ & \multicolumn{2}{|c|}{ Coefficient of determination $=0.99824962$} \\
\hline 5.9007182 & & \\
\hline 14.057809 & & \\
\hline $\mathrm{Al}=5.6675245 \mathrm{E}-02 \quad \mathrm{~A} 2=0.14103247$ & Element $=\mathbf{M n}$ & \\
\hline \multirow[t]{4}{*}{ Coeffieient of determination $=0.99942745$} & Std conc $(X)$ & Std ratios $(Y)$ \\
\hline & 1 & 0.22266139 \\
\hline & 2 & 0.39935128 \\
\hline & 4 & 0.77194863 \\
\hline Element $=\mathrm{Zn}$ & 10 & 2,0077288 \\
\hline Std ratios (Y) & 20 & 3.9405964 \\
\hline $8.54320(4 \mathrm{E}-03$ & 40 & 8.0979974 \\
\hline $3.9207078 \mathrm{E}-02$ & 100 & 19.369823 \\
\hline $9.4328814 \mathrm{E}-02$ & $\mathrm{Al}=6.5826562 \mathrm{E}-02$ & $A 2=0.19406396$ \\
\hline 0.11770476 & \multirow{2}{*}{\multicolumn{2}{|c|}{ Cocfficien! of determination $=0.99967882$}} \\
\hline 0,25957838 & & \\
\hline 0.32489145 & & \\
\hline 0.66815895 & & \\
\hline $\mathrm{A} 1=5.5979063 \mathrm{E}-02$ & Element $=\mathbf{C u}$ & \\
\hline \multirow[t]{4}{*}{ Coefficient of determination $=0.96675173$} & Std conc $(X)$ & Std ratios $(Y)$ \\
\hline & 1 & 0.11256518 \\
\hline & 2 & 0.27081529 \\
\hline & 4 & 0.56008902 \\
\hline Element $=\mathbf{C d}$ & 10 & 1.4402457 \\
\hline Std Conc $(\mathrm{X})$ & 20 & 2.706313 \\
\hline $6.7105675 E-02$ & 40 & 5.2279295 \\
\hline 0.10755033 & 100 & 10.988112 \\
\hline 0.17296798 & $\mathrm{Al}=0.26356799$ & $\mathrm{~A} 2=0.10994968$ \\
\hline 0,34804067 & \multicolumn{2}{|c|}{ Coefficient of detemination $=0.99362354$} \\
\hline
\end{tabular}

"The exemple shows the least squares data for the first six of twenty elements printed. 